\title{
NBSIR 73-335
}

\section{CALIBRATION OF RADIO RECEIVERS \\ TO MEASURE BROADBAND INTERFERENCE}

Ezra B. Larsen

Electromagnetics Division

Institute for Basic Standards

National Bureau of Standards

Boulder, Colorado 80302

September 1973

Final Report, Phase I

Prepared for

Calibration Coordination Group Army / Navy /Air Force 



\section{NBSIR 73-335}

\section{CALBRATION OF RADIO RECEVERS \\ TO MEASURE BROADBAND INTERFERENCE}

Ezra B. Larsen

Electromagnetics Division

Institute for Basic Standards

National Bureau of Standards

Boulder, Colorado 80302

September 1973

Final Report, Phase I

Prepared for

Calibration Coordination Group

Army/Navy/Air Force

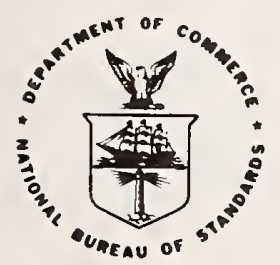

U.S. DEPARTMENT OF COMMERCE, Frederick B. Dent, Secretary 

CONTENTS

$\underline{\text { Page }}$

1. BACKGROUND - . $\ldots \ldots \ldots \ldots$

2. INTRODUCTION $\ldots \ldots \ldots$

3. DEFINITIONS OF RECEIVER BANDWIDTH AND IMPULSE

STRENGTH (Or Spectral Intensity)-................. 5

3.1 Random noise bandwidth.................. 5

3.2 Impulse bandwidth in terms of receiver response transient-.................... 7

3.3 Voltage-response bandwidth of receiver-...-. 8

3.4 Receiver bandwidths related to voltageresponse bandwidth-..................... 9

3.5 Impulse strength in terms of random-noise

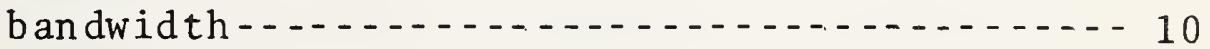

3.6 Sum-and-difference correlation radiometer

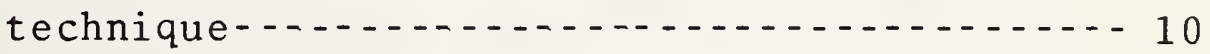

3.7 Impulse strength in terms of Fourier trans-

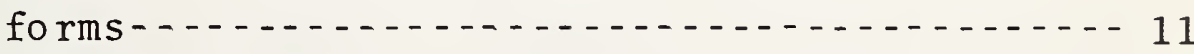

3.8 Impulse strength in terms of rectangular

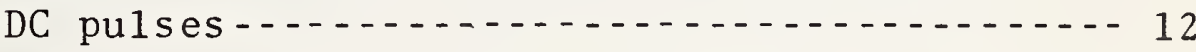

3.9 Impulse strength and impulse bandwidth in



4. EXPERIMENTAL PROCEDURE AND DATA-................ 16

4.1 Measurement of receiver input impedance and

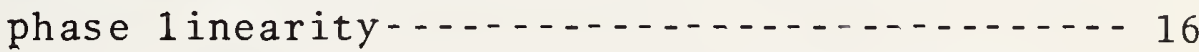

4.2 Calibration of receiver as a tuned RF volt-



4.3 Stepped-frequency measurements of receiver

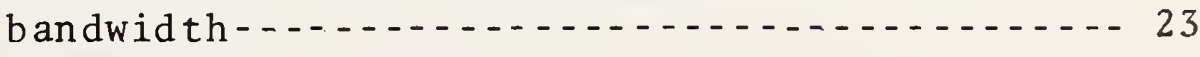

4.4 Calibration of receiver impulse bandwidth with a baseband pulse generator-........ 37 


\section{CONTENTS (Continued)}

4.5 Calibration of receiver impulse bandwidth

Page with a pulsed-RF source-........................ 38

5. DISCUSSION OF IMPULSE INTERFERENCE AND FOURIER

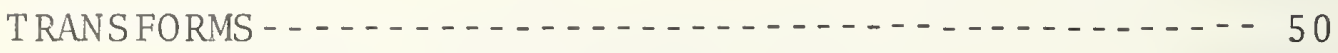

6. SUMMARY AND CONCLUSIONS - .................. 58

7. ACKNOWLEDGMENTS - . $\ldots \ldots \ldots 7 \ldots$

8. REFERENCES - . $\ldots \ldots$. $\ldots \ldots \ldots$ 
Fig. 1. Measured Input VSWR of FIM-1 Receiver Tuned to $400 \mathrm{MHz}$, Signal Frequency $=100$ to $1200 \mathrm{MHz}-\cdots$

Fig. 2. Measured Input VSWR of FIM-1 Receiver Tuned to $400 \mathrm{MHz}$, Signal Frequency $=395$ to $407 \mathrm{MHz}-\ldots 18$

Fig. 3. Variation of Receiver Input Impedance and Phase Angle Across the Receiver Passband-.........

Fig. 4. Block Diagram of Instrumentation for Calibrating a Receiver to Measure CW Voltage and SteppedFrequency Bandwidth-.....................

Fig. 5. Measured Insertion Loss vs Frequency of the $27 \mathrm{~dB}$ and $47 \mathrm{~dB} \mathrm{~L}-\mathrm{Pads} \ldots \ldots$

Fig. 6. Stepped-Frequency Measurement of Receiver Bandwidth at $300 \mathrm{MHz}$, dB Response vs Signal Fre-

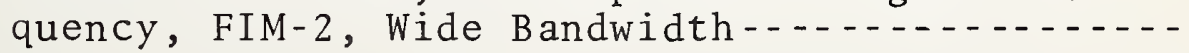

Fig. 7. Stepped-Frequency Measurement of Receiver Bandwidth at $300 \mathrm{MHz}$, Response Voltage vs Signal Frequency, FIM-2, Wide Bandwidth-.........

Fig. 8. Stepped-Frequency Measurement of Receiver Bandwidth at $300 \mathrm{MHz}$, Squared Response Voltage vs Signal Frequency, FIM-2, Wide Bandwidth-.....-

Fig. 9. Stepped-Frequency Measurement of Receiver Bandwidth at $500 \mathrm{MHz}$, FIM-2, Wide Bandwidth-...-.

Fig. 10. Stepped-Frequency Measurement of Receiver Bandwidth at $700 \mathrm{MHz}$, FIM-2, Wide Bandwidth-....

Fig. 11. Stepped-Frequency Measurement of Receiver Bandwidth at $900 \mathrm{MHz}$, FIM-2, Wide Bandwidth-....-

Fig. 12. Stepped-Frequency Measurement of Receiver Bandwidth at $300 \mathrm{MHz}, \mathrm{dB}$ Response vs Signal Frequency, FIM-2, Narrow Bandwidth-.........

Fig. 13. Stepped-Frequency Measurement of Receiver Bandwidth at $300 \mathrm{MHz}$, FIM-2, Narrow Bandwidth-...- 
LIST OF FIGURES, continued

$\underline{\text { Page }}$

Fig. 14. Stepped-Frequency Measurement of Receiver Bandwidth at $500 \mathrm{MHz}$, FIM-2, Narrow Bandwidth-..--

Fig. 15. Stepped-Frequency Measurement of Receiver Bandwidth at $700 \mathrm{MHz}$, FIM-2, Narrow Bandwidth-....

Fig. 16. Stepped-Frequency Measurement of Receiver Bandwidth at $900 \mathrm{MHz}$, FIM-2, Narrow Bandwidth-...-

Fig. 17. Impulse Strength vs Frequency of NBS Baseband Impulse Generator.......................

Fig. 18. Block Diagram of Instrumentation for Calibrating Receiver Impulse Bandwidth with a Standard Base-

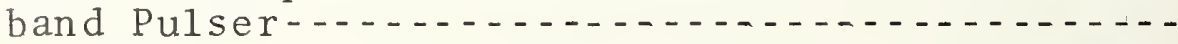

Fig. 19. Check of Receiver Linearity for Impulse Interference at a Tuned Frequency of $400 \mathrm{MHz}$

Fig. 20. Graph of Receiver Linearity for Impulse Inter-

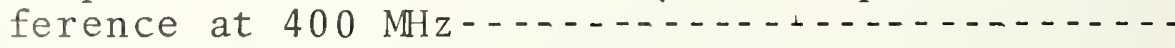

Fig. 21. List of Measured Impulse Bandwidths of FIM-2 Receiver, Using a Standard Baseband Impulse

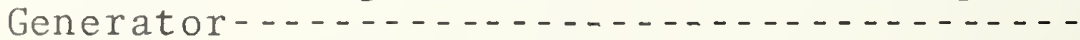

Fig. 22. Block Diagram of Instrumentation for Calibrating Receiver Impulse Bandwidth with a Pulsed-RF Source - . . . . . . . . . . . . . . . . .

Fig. 23. Waveform of the Pulsed-RF Burst as Measured



Fig. 24. List of Measured Impulse Bandwidths of FIM-2 Receiver, Using a Pulsed-RF Source with Effective Time Duration of $0.1 \mu$ Seconds-........-

Fig. 25. Summary of Measured Bandwidths of the FIM-2

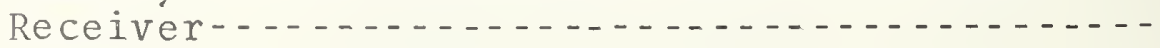

Fig. 26. Graphs of Measured Bandwidths of the FIM-2 Receiver-

Fig. 27. Table of Ratios of Measured Bandwidths of the FIM-2 Receiver..... 


\section{CALIBRATION OF RADIO RECEIVERS}

TO MEASURE BROADBAND INTERFERENCE

\section{ABSTRACT}

This report covers one phase of a project to improve the accuracy for calibrating field-strength meters to measure broadband signals, especially impulse interference. The amplitude of a narrowband signal is commonly expressed in $\mu \mathrm{V}$, and a broadband signal is expressed in $\mu \mathrm{V} / \mathrm{MHz}$ bandwidth. A future report (2nd phase) will deal with standards and techniques for producing a known impulse field to calibrate an antenna-receiver system in $\mu \mathrm{V} /(\mathrm{m} \cdot \mathrm{MH} z)$. The technique used for initial calibration of a receiver as an RF voltmeter is new, employing a special L-pad with $48 \Omega$ input resistor and $2 \Omega$ output resistor across the receiver. The input power across $50 \Omega$ is leveled, producing a low-impedance, constant-voltage source at the receiver input terminal.

Broadband interference is generally divided into two types: (a) random noise is best characterized by its power spectral density, and (b) impulse interference (uniform periodic pulses) is best quantified by its impulse strength. Several possible approaches were evaluated for defining and measuring various bandwidths of a receiver. The response of a receiver to impulses, as measured with a peak-reading detector, is proportional to the product of receiver impulse bandwidth and signal impulse strength. Of the two types of impulse sources evaluated here (pulsed DC and pulsed RF), the latter appears to be the most accurate and repeatable. We were able to produce a clean RF pulse, choosing an effective duration of 0.1 us in our experiments, which covered a frequency range of 100 to $1000 \mathrm{MHz}$. The worst-case uncertainty of this standard source for calibrating receiver impulse bandwidth is $\pm 0.7 \mathrm{~dB}$.

Key words: Broadband interference; field strength meter; impulse standards; receiver bandwidth calibration; spectral intensity. 


\section{BACKGROUND}

This report covers one phase of a project at the National Bureau of Standards (NBS) to improve the overall accuracy for calibrating field strength meters, concentrating on accurate measurement of broadband interference. The present report deals with measuring conducted radio-frequency (RF) signals, that is, signals at the antenna input terminal of a measuring receiver. The amplitude of a narrowband signal is commonly expressed in units of microvolts $(\mu V)$, whereas a broadband signal is expressed in microvolts per megahertz bandwidth $(\mu \mathrm{V} / \mathrm{MHz})$. A subsequent report (2nd phase) will deal with development of standards and accurate techniques for calibrating a radio interference meter or field intensity meter (RI/FI meter or FIM) as a system; that is, calibration of the antenna, receiver and associated hardware while connected in a normal-use configuration. The impulse response of a measurement system is affected by impedance mismatches, such as between the antenna and receiver, or between a calibrating impulse generator and receiver. Previous workers in the area of broadband interference have generally ignored these system effects on FIM calibration.

The second phase of this NBS project (future report) involves the design of a pulsed RF source and broadband antenna for radiating a standard impulse field of known amplitude and spectral characteristics. The amplitude of an electric field is commonly expressed in units of microvolts per meter for a narrowband signal and microvolts per meter per $\mathrm{MHz}$ bandwidth $(\mu \mathrm{V} /(\mathrm{m} \cdot \mathrm{MHz})$ for a broadband signal. The objective of this second phase is to make meaningful calibrations of field strength meters for measuring radiated impulse-interference fields. This is analogous to calibrating the "antenna coefficient" or field strength "antenna factor" for measuring sinusoidal field strength. That is, a calibration factor is determined experimentally at a field site for each frequency at which the field strength meter will be used. For frequencies up to $1000 \mathrm{MHz}$ this can be done by comparing the measured antenna/receiver system response to that of a standard open-circuit dipole placed at the same position as the FIM dipole. The field strength factor thus applies to the measuring system as connected in its normal-use configuration. It would be desirable to also use this system approach for calibrating a receiver to measure impulse-interference fields. It would then not be necessary to consider separately the errors of measured receiver impulse bandwidth, errors caused by receiver and antenna phase shift across the passband, or errors due to impedance mismatches at various points in the system. 
When measuring broadband interference it is not possible to use the same "antenna factor" used for sinusoidal fields, which has a value that is independent of receiver bandwidth. Receiver response to impulse interference, however, is proportional to the receiver bandwidth. Proper calibration of the effective impulse bandwidth of a receiver thus makes possible an absolute measurement of conducted impulse interference. This receiver with calibrated bandwidth can also be used, in turn, to measure the impulse strength or spectral intensity of a working impulse generator, such as the internal impulse-generator source of an FIM. However, the terms "impulse strength" and "spectral intensity" are variously defined, and the measured value often depends on the instrument used to measure it. Further, the "impulse bandwidth" of a receiver depends in important ways on factors other than the usual voltage-response-vs.-frequency type of bandwidth. These topics have been investigated at NBS and are the subject of this report.

\section{INTRODUCTION}

In this report the term "receiver" is used to designate a frequency-selective voltmeter used to measure RF signals. Generally the receiver is basically a superheterodyne communications-type receiver with one or two additional values of time constant in the detector. Three types of detectors are commonly, found on an interference meter, namely average, peak and quasi-peak detectors. The average-of-envelope detector indicates a time-average voltage of the detected output from the IF amplifier. The peak detector indicates the maximum voltage value (long time constant) of the IF amplifier output. At present no commercially-available FIM employs a power or RMS detector. No discussion is given in this report of amplitude probability distribution (APD) or other schemes used to quantify mixtures of the various types of interference. The receiver is one part of the overall measurement system (designated field strength meter, interference meter, FIM or RI/FI meter) which also contains antennas, step attenuators, calibrating generators, various metering circuits and output indicators.

An RF signal is considered to be narrowband or broadband depending on whether its frequency spectrum is less than or greater than the bandwidth of the receiver. The overall bandwidth of an FIM is determined essentially by the selectivity of the IF amplifier strip and is typically of the order of $0.1 \%$ of the receiver tuned frequency. The term "CW" stands 
for a single-frequency sinusoid of constant amplitude. The term "impulse" is used for a baseband (DC) pulse or an RF burst (pulsed RF) whose time duration is short compared with the period of the receiver circuit which responds to the impulse. This period is generally approximately the reciprocal of the IF bandwidth.

A common practice is to divide broadband interference into two categories, which may be defined as follows: (1) Random noise consists of a large number of overlapping signals with random amplitude, frequency and relative phases. Examples are thermal noise and shot noise. (2) Impulse noise is due to a single short pulse of voltage, or repetitive pulses, causing a signal with systematic relative phase and amplitude vs. frequency. Examples are switching transients, automobile ignition noise and interference from radar transmitters. The response of a receiver to either type of broadband signal is determined (partially) by the receiver bandwidth. This is because all frequency components of the input signal which fall outside the receiver bandwidth are rejected, or at least amplified less than the frequency components at the center of the passband.

Differences between the possible types of RF signals can be illustrated by comparing receiver response (indicated leve1) as a function of receiver bandwidth. For $\mathrm{CW}$ the response amplitudes for a peak-voltage, average-voltage, or RMS-voltage detector is independent of the receiver bandwidth. For random noise the average-voltage and RMS response values of an FIM are proportional to the square root of bandwidth. For impulse noise of low repetition rate, the average voltage is typically independent of bandwidth but the peak value is proportional to bandwidth (among other things). This proportionality factor makes it convenient to define an impulse bandwidth for the receiver. Actually, the response of a tuned receiver to an impulse, as measured with a peak-reading detector, depends not only on bandwidth but also on the shape of the bandpass curve and phase characteristics of the receiver. The response of ideal interference meters to various inputs, as a function of bandwidth, is summarized in the following table. 


\begin{tabular}{|c|c|c|c|c|}
\hline $\begin{array}{l}\text { Type of } \\
\text { Detector }\end{array}$ & \multirow[b]{3}{*}{$\begin{array}{l}\text { Receiver indi- } \\
\text { cation is: }\end{array}$} & \multicolumn{3}{|c|}{ Type of RF Signal } \\
\hline \multirow[b]{2}{*}{$\begin{array}{l}\text { Average } \\
\text { (voltage) }\end{array}$} & & Sine wave & Random noise & $\begin{array}{l}\text { Periodic } \\
\text { impulses }\end{array}$ \\
\hline & & $\begin{array}{l}\text { Independent of } \\
\text { bandwidth }(\mathrm{BW})\end{array}$ & $\begin{array}{l}\text { Proportional } \\
\text { to } \sqrt{\mathrm{BW}}\end{array}$ & $\begin{array}{l}\text { Independent } \\
\text { of } \mathrm{BW}\end{array}$ \\
\hline $\begin{array}{l}\text { Peak } \\
\text { (voltage) }\end{array}$ & $\begin{array}{l}\text { Receiver indi- } \\
\text { cation is: }\end{array}$ & $\begin{array}{l}\text { Independent of } \\
\text { bandwidth }(B W)\end{array}$ & - & $\begin{array}{l}\text { Proportional } \\
\text { to } \mathrm{BW}\end{array}$ \\
\hline Power & $\begin{array}{l}\text { Receiver indi- } \\
\text { cation is: }\end{array}$ & $\begin{array}{l}\text { Independent of } \\
\text { bandwidth (BW) }\end{array}$ & $\begin{array}{l}\text { Proportional } \\
\text { to } \mathrm{BW}\end{array}$ & $\begin{array}{l}\text { Proportional } \\
\text { to } \mathrm{BW}\end{array}$ \\
\hline $\begin{array}{l}\text { RMS } \\
\text { (vo1tage) }\end{array}$ & $\begin{array}{l}\text { Receiver indi- } \\
\text { cation is: }\end{array}$ & $\begin{array}{l}\text { Independent of } \\
\text { bandwidth (BW) }\end{array}$ & $\begin{array}{l}\text { Proportional } \\
\text { to } \sqrt{\mathrm{BW}}\end{array}$ & $\begin{array}{l}\text { Proportional } \\
\text { to } \sqrt{\mathrm{BW}}\end{array}$ \\
\hline
\end{tabular}

In most common approaches to impulse measurement, the impulse bandwidth of the receiver is a calibration factor determined by adjusting the output of a CW generator to give the same indication on the receiver output meter as the peak response to an impulse generator of known characteristics. The impulse bandwidth in $\mathrm{MHz}$ is then the output of the $\mathrm{CW}$ generator in $\mu \mathrm{V}$, divided by the output of the impulse generator in $\mu \mathrm{V} / \mathrm{MHz}$. Some commonly-used definitions relating to broadband interference are discussed in the next section.

3. DEFINITIONS OF RECEIVER BANDWIDTH AND IMPULSE STRENGTH (OR SPECTRAL INTENSITY)

The "effective" or "equivalent rectangular" passband of a given receiver is different for random and impulse noise. Also, the numerical value of impulse bandwidth depends on the definition chosen for this quantity. A summary of various definitions for bandwidth and the corresponding equations for impulse strength are given in this section. We do not necessarily endorse all of these definitions; in fact we consider the use of some of them to be ill-advised. The receiver gain is assumed to have been calibrated in terms of the root-meansquare (RMS) voltage value of an applied sine wave.

3.1 Random noise bandwidth or squared-voltage-response bandwidth or "power" bandwidth of receiver [1] and [2]. 


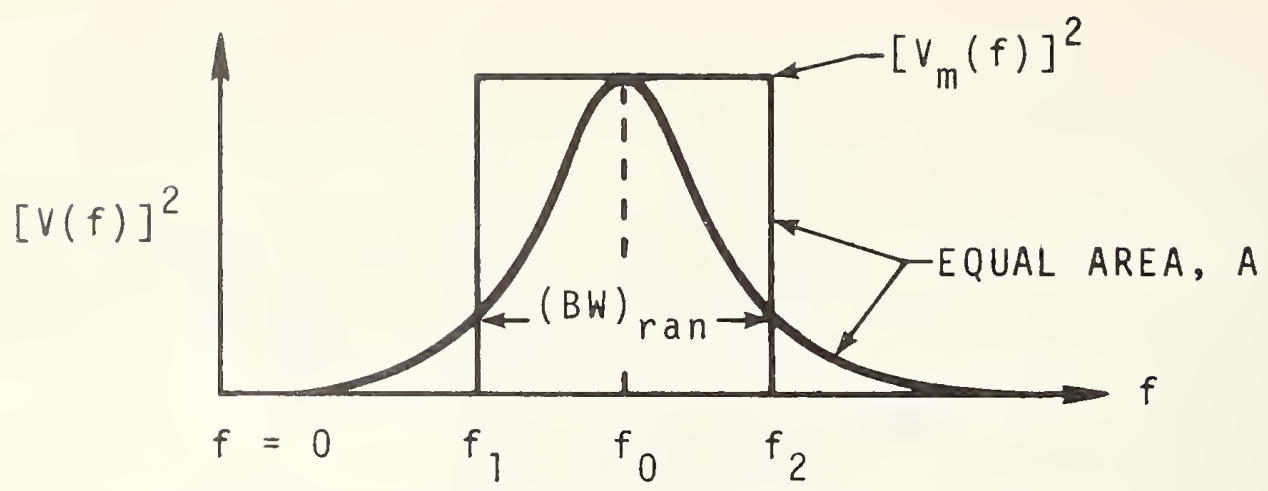

(a) Equivalent rectangular bandwidth of receiver, as determined from a point-by-point measurement and analys is.

$$
\begin{aligned}
& \text { (BW) }{ }_{\text {ran }}=\frac{\int_{0}^{\infty}[V(f)]^{2} d f}{\left[V_{m}(f)\right]^{2}} \\
& =\frac{\text { Area under squared-voltage-response curve }}{\text { Square of maximum voltage response }} .
\end{aligned}
$$

(b) Power spectra1 density or random-noise spectral intensity, as measured by a receiver whose bandwidth has been calibrated by eq. (1) above.

$$
(S)_{\operatorname{ran}}=\frac{\left[V_{m}(f)\right]^{2}}{\left(G_{0}{ }^{2}\right)(B W)_{\operatorname{ran}}\left(R_{0}\right)} \frac{\text { watts }}{\text { hertz }}
$$

where: $\quad G_{0}=\underset{f_{0}}{C W}$ gain of receiver (maximum) at tuned frequency

$$
\mathrm{R}_{\mathrm{O}}=\text { Receiver input resistance }\left(\begin{array}{ll}
50 & \Omega
\end{array}\right) \text {. }
$$

A discussion of these expressions is given in section 4.3 of this report. The random-noise bandwidth of a receiver should technically be defined in terms of the power response for a Gaussian signal which is flat with frequency across the receiver passband. The power delivered to a receiver within its passband is given by

$$
P=(S)_{\text {ran }}{ }^{(B W)} \operatorname{ran}^{*}
$$

The definition generally used for receiver random-noise bandwidth is given in terms of a fictitious, rectangular 
passband which has the same area as the actual receiver passband. As indicated by the sketch on page 6, this bandwidth is given by the expression

$$
(B W)_{\text {ran }} \equiv\left(f_{2}-f_{1}\right)=\text { Area } A /\left[V_{m}(f)\right]^{2} \text {. }
$$

As described in section 4 of this report, the area $A$ is determined at NBS with high precision by using a steppedfrequency approach and an automatic network analyzer.

3.2 Impulse bandwidth in terms of receiver response transient [1], [2], [3], [4], [5] and MIL-STD-463.

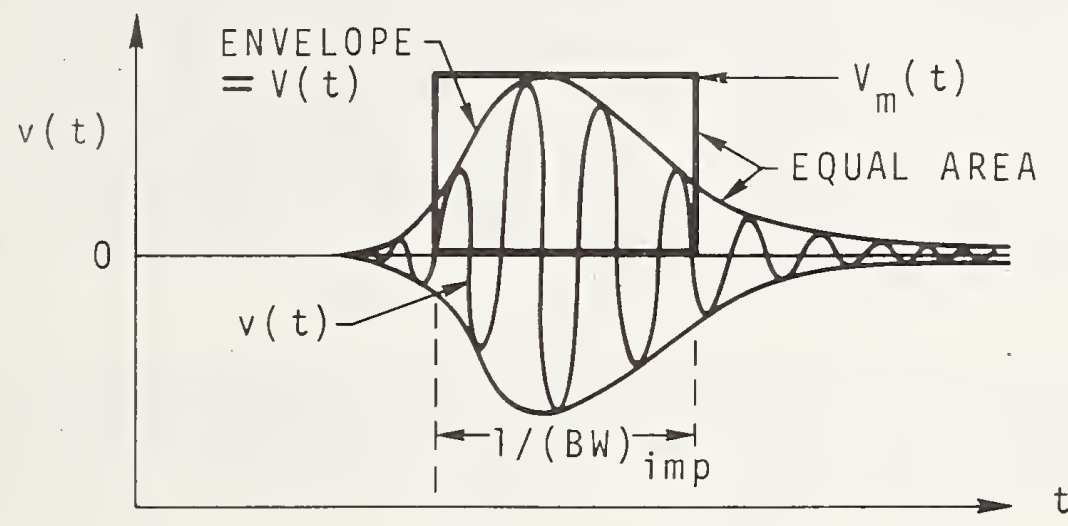

(a) Equivalent rectangular bandwidth of receiver, as determined from the envelope of the receiver impulse response transient.

$$
(B W)_{i m p}=\frac{V_{m}(t)}{\int_{0}^{\infty} V(t) d t}
$$

= Maximum voltage of receiver response envelope Area under response envelope curve

(b) Strength of impulse signal applied to the antenna input terminal, as measured by a receiver whose impulse bandwidth has been calibrated by eq. (4).

$$
(S)_{i m p}=\frac{V_{m}(t)}{\left(G_{0}\right) \cdot(B W)_{i m p}} \frac{\text { volts }}{\text { hertz }} \text { or volt. seconds. }
$$

That is, impulse strength of an ideal impulse is defined as the peak response of an ideal amplifier to this pulse divided by the bandwidth. Also, 


$$
\text { (S) } \operatorname{imp}=\frac{1}{G_{0}} \int_{-\infty}^{\infty} V(t) d t \equiv \frac{\text { Area A }}{G_{0}} .
$$

This approach for measuring impulse bandwidth is usually done by photographing an oscilloscope display of the receiver IF response to identical repetitive pulses. The positive area under the envelope curve of the receiver response transient can be measured by counting squares or with a planimeter or it can be integrated electronically. In any case, the measurement precision is somewhat limited. There are also fundamental errors with this definition as explained in [6] and the discussion of section 5. According to Palladino [7] "The preceding method is used simply because no other accurate economic convenient method is currently available." It can be shown mathematically that the impulse strength of an instantaneous DC pulse (delta function) in volts per hertz is numerically equal to twice the area of the pulse in volts seconds. This means that the area $A$ under the receiver response curve (for the ideal case and after normalizing for receiver gain) would be double the area of the original applied pulse, in volt. seconds.

3.3 Voltage-response bandwidth or swept-CW bandwidth of receiver [1], [2] and [5]. This is sometimes given (incorrectly) as an alternative definition of impulse bandwidth.



(a) Equivalent rectangular bandwidth of receiver, as determined from the CW voltage-response curve (swept signal frequency or swept bandpass filter).

$$
\begin{aligned}
& (B W)_{\text {voltage }}=\frac{\int_{0}^{\infty} V(f) d f}{V_{m}(f)} \neq(B W) \text { imp } \\
& =\frac{\text { Area under voltage-response curve, volts } \cdot \text { hertz }}{\text { Maximum detected voltage at frequency } f_{0}} .
\end{aligned}
$$


(b) Strength of impulse signal applied to the antenna input terminal, as measured by a receiver whose impulse bandwidth was calibrated by eq. (6).

$$
\text { (S) } \text { imp }=\frac{V_{m}(t)}{\left(G_{0}\right)(B W)_{i m p}} \text {. }
$$

The value of bandwidth when using this definition can readily be measured with a stepped-frequency $\mathrm{CW}$ approach, similar to that of random noise bandwidth. The numerical integration is more accurate for the random noise or power (voltage squared) case of section 3.1 than for the voltage case of section 3.3. This is due to the inherent error in integrating the area under long tails. In either case the numerical integration can be programmed on an automatic network analyzer. The peak value of receiver response transient $V_{m}(t)$ can be measured with a peak reading voltmeter, such as those found on military and commercial interference meters.

There is a fundamental error if eq. (6) is used to define impulse bandwidth, as explained on page 7 of [1]. This definition would be correct only if the phase is linear across the receiver passband. Since phase shift is present in a practical amplifier (see section 4.1 of this report for graphs of data taken for a typical FIM receiver) the impulse bandwidth should be defined differently. According to Geselowitz, page 7 of [1], "since $\phi$ is, in general, not linear over the passband, the integrated bandwidth cannot be used as the effective impulse bandwidth. For example, in the case of a single-tuned resonant circuit, the integrated bandwidth becomes infinite! ... The integrated bandwidth (of eq. (6)) is an upper limit which may be approached in some cases, e.g., as the number of tuned stages increases." A similar comment can also be found on page 72 of [8].

3.4 Receiver bandwidths related to the voltage-response bandwidth described in section 3.3 .

$3 \mathrm{~dB} B$ andwidth = Frequency width of the receiver selectivity curve at the points where the response voltage is $3 \mathrm{~dB}$ below the maximum response.

The $6 \mathrm{~dB}, 10 \mathrm{~dB}$, and $20 \mathrm{~dB}$ bandwidths are defined in a similar manner. 
3.5 Definition of impulse strength in terms of random-noise bandwidth and stepped CW measurements.

This approach was proposed by Andrews [9] and has been used for a prototype measurement system. The basic equation for the so-called "root-mean-square spectral intensity" is

$$
\text { (S) } \text { imp }=\frac{1}{G_{0}} \sqrt{\frac{\left(P_{0}\right)\left(R_{O}\right)}{(P R F)(B W)_{\text {ran }}}} \text {, }
$$

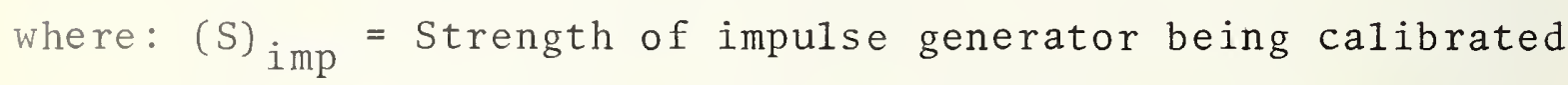

$\mathrm{P}_{0}=\underset{\text { Average power output of calibrating system }}{\text { into } \mathrm{R}_{0}}$

$\mathrm{R}_{0}=$ System load resistance $(50 \Omega$ power meter $)$

$\mathrm{G}_{\mathrm{O}}=$ System tuned-frequency $\mathrm{CW}$ gain

$\mathrm{PRF}=$ Pulse repetition frequency of impulse generator

$(B W)_{\text {ran }}=$ Random noise bandwidth, as defined by eq. ( 1 ), page 6 .

It can be seen that this approach defines impulse strength in terms of random noise bandwidth (obtained from CW measurements) and measurements of CW power and CW voltage. The system described by Andrews measures the bandwidth on a steppedfrequency basis, establishing the RF voltage at each frequency by means of a low-resistance RF micropot. An impulse generator calibrated with eq. (8) can then be used to calibrate the impulse bandwidth of an unknown receiver by the usual expression of eqs. (5) and (7):

$$
(B W)_{i m p}=\frac{V_{m}(t)}{\left(G_{0}\right)(S)_{i m p}} .
$$

3.6 Sum-and-difference correlation radiometer technique

This technique was developed at NBS to calibrate the power spectral density of random noise in watts/Hz, by radiometric means. The approach can be used to measure a random noise generator and, in turn, calibrate the random noise bandwidth of a receiver. Also, the strength of an unknown repetitive impulse generator can be compared against a thermal white-noise 
source whose power spectral density is known, making use of the pulse repetition rate and impedance of the impulse source being calibrated. It can be seen from the table on page 5 that the RMS response of a receiver is proportional to $\sqrt{B W}$ for either random or impulse noise.

However, this approach suffers from the required complexity of instrumentation and the difficulty of measuring the weak power output of an impulse generator. It should be mentioned that most of the "internal" impulse generators of FIM's have low repetition rates, typically about $60 \mathrm{~Hz}$. The average power output of an impulse generator is thus extremely low since the duty cycle may be less than $0.00001 \%$. According to Reeve, page 28 of [11], "it would appear that radiometric techniques, while having potentially high accuracy, are not desirable for general measurements of impulses. Radiometers measure total power and respond to artifacts between the major impulses. which means they will be measuring something different than the typical impulse receiver which responds only to the peak amplitude of the largest signal appearing at its detector.... A radiometric technique would be of great value in cross-checking the accuracy of another type of impulse calibration system providing the impulse signal source used as a transfer standard is known to be free of artifacts and the repetition rate is kept high to maintain an adequate signal to noise ratio."

\subsection{Definition of impulse strength in terms of Fourier transforms [6], [12] and [13].}

Another practice is to define impulse strength in terms of the absolute value of the Fourier transform of a single time-domain pulse. See discussion in section 5 of this report. In this method, repetitive pulses from a baseband impulse generator are measured (digitized) in the time domain, for example with a sampling oscilloscope, and the Fast

Fourier Transform is calculated with a digital computer. The impulse generator. with "known" impulse strength (S) imp is then applied to a receiver to calibrate its impulse bandwidth. The mathematical expression used is the basic definition of eq. (9), as follows:

$$
(B W)_{i m p}=\frac{V_{m}(t)}{\left(G_{0}\right)(S)_{i m p}} .
$$


A known $50 \Omega$ impulse generator using a step-recovery diode source was fabricated and tested at NBS [12]. Experimental measurements made with this standard impulse generator are described in section 4.4 of this report.

3.8 Definition of impulse strength in terms of rectangular

The time and frequency domain properties of repetitive baseband pulses are indicated in the following sketch. The vertical lines in the frequency-domain sketch represent the spectrum $V(f)$ of the time-domain pulses $v(t)$. That is, the Fourier components of the impulse signal shown consist of essentially discrete frequencies. For DC pulses these lines occur at $\mathrm{f}=0,1 / \mathrm{T}, 2 / \mathrm{T}$, etc.

TIME DOMAIN

FREQUENCY DOMAIN
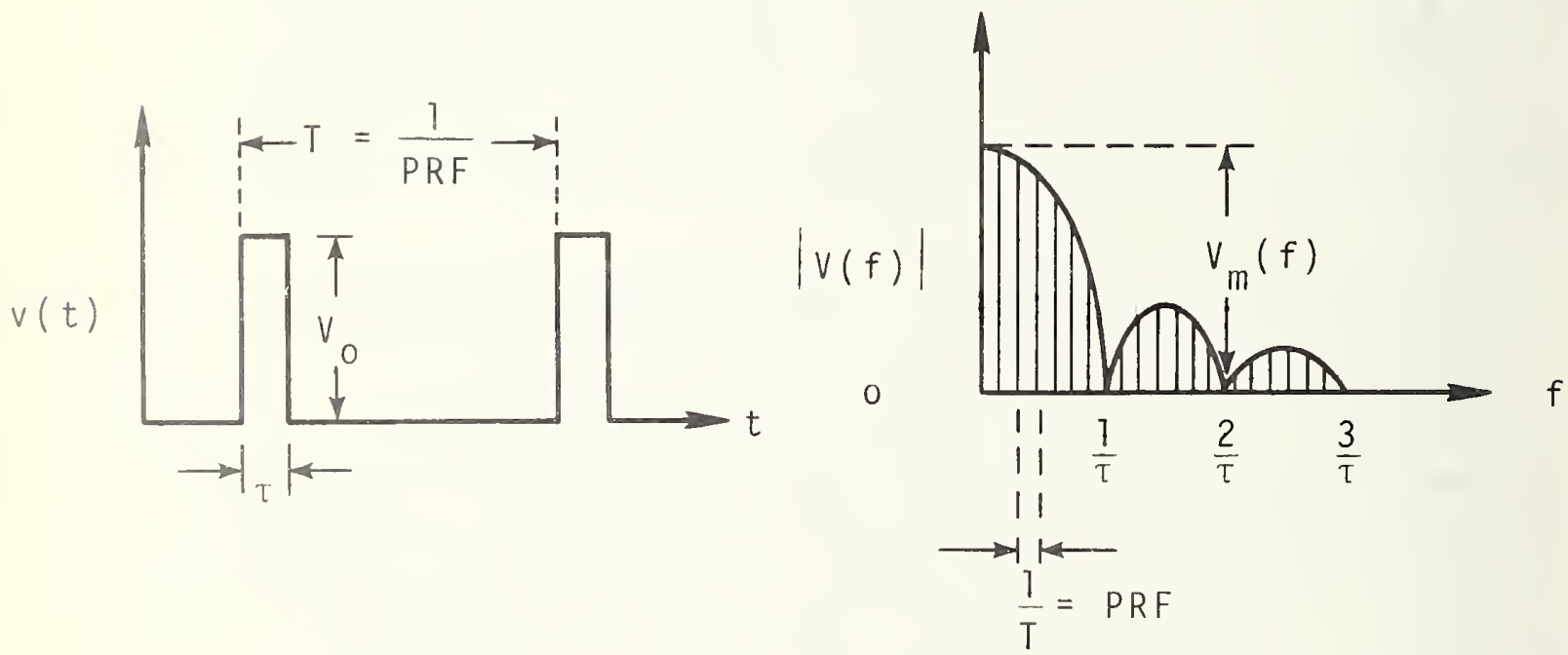

An often-made statement is that impulse strength is equal to double the area under the time domain curve of a baseband pulse. This is strictly true only for an idealized deltafunction impulse, in which the pulse duration is zero and the pulse height is infinite. In this case the frequency spectrum $V(f)$ has constant amplitude, independent of frequency. For pulses of finite duration the impulse strength is also often defined as twice the pulse area, in volt.seconds or volts/hertz. Actually, the frequency spectrum of a single rectangular pulse is given by

$$
V(f)=\left(V_{0} \tau\right)\left(\frac{\sin \pi f \tau}{\pi f \tau}\right) \equiv V_{0} \tau \operatorname{sinc}(\pi f \tau),
$$


where: $\quad V_{0}=$ Pulse amplitude in volts

$\tau=$ Pulse duration in seconds

$f=$ Frequency in hertz

sinc $\pi f \tau=(\sin \pi f \tau) /(\pi f \tau)$.

For short pulses and low frequencies the sinc function approaches 1 , and the impulse strength is approximately $2 \mathrm{~V}_{0} \tau$, or twice the pulse area. That is, for low frequencies where $f<1 / \tau$,

$$
\text { (S) } \text { imp }_{2} \simeq 2 \mathrm{~V}_{\mathrm{o}} \tau \text {, volts/hertz. }
$$

Some impulse-generator calibrators are based on this approximation. It is then essential that the receiver bandwidth be narrow compared with $1 / \tau$. However, for determining the strength $S$ of a standard impulse generator it is also necessary to use pulses which are long enough so that $V_{0} \tau$ or pulse area can be measured accurately. As far as the response of a filter circuit to a pulse is concerned, the actual pulse is often considered as instantaneous if the time duration of the pulse is much less than (e.g., < 0.2 ) the reciprocal of the frequency of the filter circuit. For an interference meter this filter circuit is essentially the IF strip of the receiver.

The impulse bandwidth of a receiver to be used for measuring impulse interference can then be calibrated with this standard impulse generator in terms of the basic equation

$$
(B W)_{i m p}=\frac{V_{m}(t)}{\left(G_{0}\right)(S)_{i m p}} \cong \frac{V_{m}(t)}{2 G_{0} V_{o} \tau}
$$

3.9 Definitions of impulse strength and impulse bandwidth in terms of RF pulses [14], [15] and [16].

(a) Impulse bandwidth of receiver, as determined by applying a pulsed RF with known effective time duration $\tau$.

$$
(B W)_{i m p}=\frac{V_{m}(t)}{\left(G_{0}\right)(S)_{i m p}}=\frac{V_{m}(t)}{G_{0} V_{1} \tau}=\frac{V_{m}(t)}{V_{c} \tau},
$$


where: $V_{m}(t)=$ Maximum value of receiver response transient, as a function of time $G_{0}=\begin{aligned} & C W \\ & \text { quency } f_{0}\end{aligned}$

(S) imp $=$ Calculated impulse strength of calibrating signal $=V_{1} \tau$ in this case

$V_{1}=$ RMS voltage of CW signal (during the RF pulse) applied to the receiver antenna-input terminal

$V_{C}=$ RMS voltage of CW signal (during the RF pulse) at the receiver detector, after amplification in the receiver

$\tau=$ Time duration of rectangular RF burst; if the pulse is not rectangular, $\tau$ is the "equivalent rectangular" time width.

(b) Strength of impulse signal applied to the antenna input terminal, as measured by a receiver whose impulse bandwidth has been calibrated by eq. (14).

$$
\text { (S) })_{i m p}=\frac{V_{m}(t)}{G_{o}(B W)_{i m p}} \text {. }
$$

The time and frequency domain properties of repetitive RF pulses are indicated in the following sketch. Note that the measuring receiver must be tuned at or near the CW calibration frequency $f_{0}$. Also, the above equations assume that there is no impedance mismatch between the impulse generator output and the receiver input. These definitions are used for two different commercial impulse calibration systems, and apply to MIL-STD 826A. In all these cases the calculable broadband signal used for calibrating the impulse bandwidth of an FIM is produced by pulse-modulating a CW source. That is, near the carrier frequency $f_{0}$,

$$
\text { (S) } \text { imp }_{1} \simeq \mathrm{V}_{1} \tau \text {, volts/hertz. }
$$



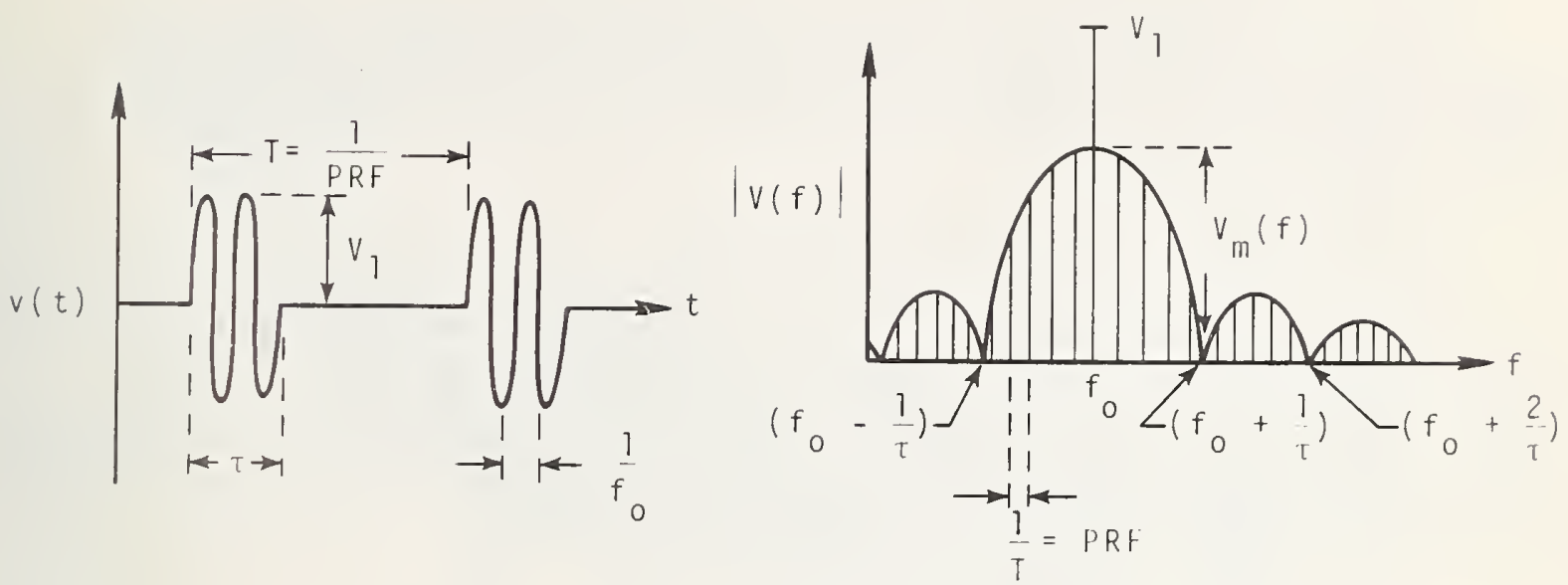

The Fourier components of the pulsed RF signal shown consist of discrete frequencies. These spectrum lines occur at the carrier frequency $f_{0}, f_{0}+P R F, f_{0}-P R F, f_{0}+2$ PRF, etc. The pulse width, $\tau$, determines the distance between the zeroes of the frequency spectrum.

Since the bandwidth of an FIM receiver is normally much greater than the PRF, it cannot resolve the individual Fourier frequency-domain components, because several lines are within its bandwidth. However, the envelope can be resolved, and it is the peak value of this envelope which is assumed proportional to impulse strength. This is the peak envelope value measured by an FIM when switched to "peak" mode. The requirements for accurate measurement of (BW) imp by this
technique are listed as follows:

(a) Receiver $(\mathrm{BW})_{3} \mathrm{~dB}>(1.7)(\mathrm{PRF})$.

This insures that a spectrum analyzer or FIM receiver can respond to each impulse independently. In other words, the receiver peak indication will be independent of PRF. According to page 11 of [15], the value of 1.7 allows the RCVR response transient to decay to $1 \%$ of the peak value between pulses.

(b) Receiver $(B W)_{3} d_{B}<(0.1) /(\tau)_{\text {eff. }}$.

This insures that the receiver bandwidth is small $(<5 \%)$ compared with the main lobe width from $\left(f_{0}-1 / \tau\right)$ to $\left(f_{0}+1 / \tau\right)$ of the sinc-function frequency spectrum, thus indicating a true peak value. 
(c) Impulse duty cycle $\equiv \mathrm{\tau} / \mathrm{T}<0.05$.

This insures that the main lobe width of the frequency spectrum is broad enough to represent a true broadband signal, whose amplitude is essentially flat across the passband of the receiver, [15].

(d) Number of cycles in RF burst $>10$.

This insures that the receiver indication (for a peak detector) is essentially the same for incoherent pulses as for coherent pulses, assuming that the two types of pulses have equal amplitude and time duration. A coherent burst is defined as one having an integral number of RF cycles, and gated on at a zero crossing of the RF sine wave, [11].

\section{EXPERIMENTAL PROCEDURE AND DATA}

Measurements of receiver input impedance and complex reflection coefficient were made for a typical interference meter, to get an indication of the receiver bandwidth and phase linearity. A comparison was made of various methods used for the initial calibration of a receiver as a CW frequency-selective voltmeter. Measurements of receiver bandwidth according to several different definitions were then performed for several values of input signal level and receiver attenuator step. Data for calculating various voltage-response bandwidths and random-noise bandwidth were taken by a stepped-frequency approach using an automatic network analyzer. Measurements of impulse bandwidth were made of two commercial receivers, designated here as FIM-1 and FIM-2, by two different techniques (pulsed DC and pulsed RF). A comparison was made of several approaches to measuring impulse bandwidth of a receiver, to determine if a constant ratio exists between the various bandwidths. The technique using a calculable pulsed-RF generator as the calibrating source appears to be the most accurate and repeatable of those we tested. The experimental results are summarized here.

4.1 Measurement of receiver input impedance and phase 1inearity.

An indication of receiver bandwidth characteristics and input VSWR variation across the passband of a typical field strength meter is given in figures 1 and 2. Typically, the receiver bandwidth is much narrower than the measured antenna bandwidths; this will be discussed in a later report. Steppedfrequency measurements were then made to determine the variation of receiver input impedance across the passband. A summary of 




Fig. 1. Measured Input VSWR of FIM-1 Receiver Tuned to $400 \mathrm{MHz}$, Signal Frequency $=100$ to $1200 \mathrm{MHz}$. 


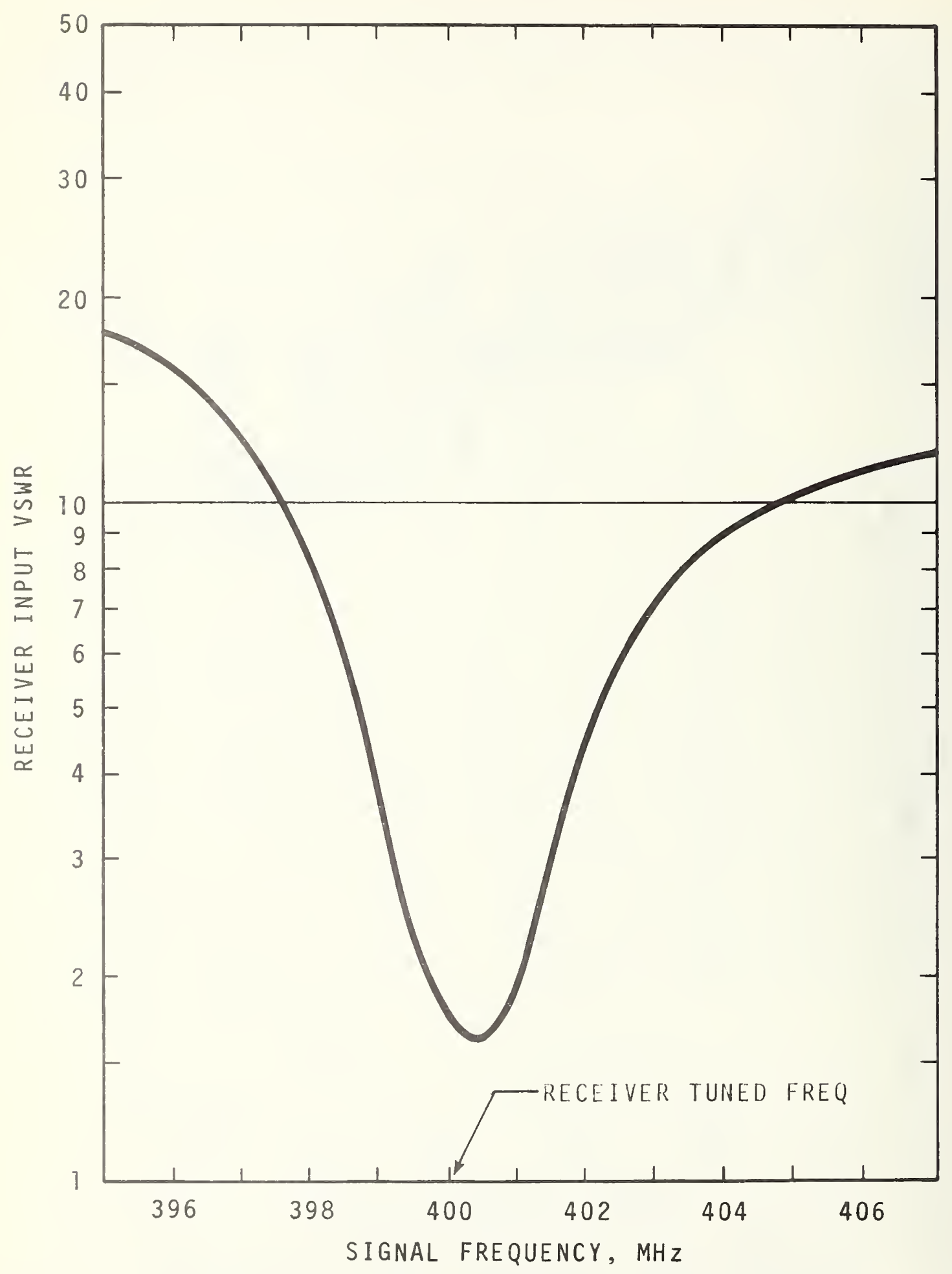

Fig. 2. Measured Input VSWR of FIM-1 Receiver Tuned to $400 \mathrm{MHz}$, Signal Frequency $=395$ to $407 \mathrm{MHz}$. 


\begin{tabular}{|c|c|c|c|c|c|c|c|c|c|}
\hline $\begin{array}{c}\text { SIGNAL } \\
\text { FREQ } \\
\text { MHz }\end{array}$ & $\begin{array}{l}R \text { in } \\
\text { OHMS }\end{array}$ & $\begin{array}{l}x \text { in } \\
\text { OHMS }\end{array}$ & $\begin{array}{r}\text { INPUT } \\
\text { VSWR } \\
\end{array}$ & $\begin{array}{c}\text { PHASE } \\
\text { ANGLE, } \\
\text { DEG. }\end{array}$ & $\begin{array}{c}\text { SIGNAL } \\
\text { FREQ. } \\
\text { MHz }\end{array}$ & $\begin{array}{l}\mathrm{R} \text { in } \\
\mathrm{OHMS}\end{array}$ & $\begin{array}{l}x \text { in } \\
\text { OHMS }\end{array}$ & $\begin{array}{r}\text { INPUT } \\
\text { YSWR } \\
\end{array}$ & $\begin{array}{c}\text { PHASE } \\
\text { ANGLE, } \\
\text { DEG }\end{array}$ \\
\hline $\begin{array}{r}399.0 \\
.1 \\
.2 \\
.3 \\
.4 \\
.5 \\
.6 \\
.7 \\
.8 \\
.9 \\
00.0 \\
.1 \\
.2 \\
.3 \\
.4 \\
.5 \\
.6 \\
.7 \\
.8 \\
.9 \\
401.0\end{array}$ & $\begin{array}{l}59.4 \\
59.9 \\
60.8 \\
61.8 \\
63.3 \\
65.1 \\
66.9 \\
69.0 \\
70.5 \\
71.5 \\
72.6 \\
73.2 \\
74.6 \\
75.8 \\
77.3 \\
78.6 \\
80.2 \\
82.0 \\
84.2 \\
86.7 \\
90.6\end{array}$ & $\begin{array}{l}-75.4 \\
-68.8 \\
-63.0 \\
-57.0 \\
-51.8 \\
-46.5 \\
-42.0 \\
-38.1 \\
-34.4 \\
-30.7 \\
-27.0 \\
-22.7 \\
-18.5 \\
-14.3 \\
-9.7 \\
-5.2 \\
-0.3 \\
+\quad 4.9 \\
+10.4 \\
+16.7 \\
+23.2\end{array}$ & $\begin{array}{l}3.67 \\
3.19 \\
3.01 \\
2.73 \\
2.50 \\
2.30 \\
2.15 \\
2.03 \\
1.94 \\
1.85 \\
1.78 \\
1.70 \\
1.65 \\
1.61 \\
1.51 \\
1.58 \\
1.60 \\
1.65 \\
1.72 \\
1.83 \\
1.98\end{array}$ & $\begin{array}{l}-51.8 \\
-49.0 \\
-46.0 \\
-42.7 \\
-39.3 \\
-35.5 \\
-32.1 \\
-28.9 \\
-26.0 \\
-23.3 \\
-20.4 \\
-17.2 \\
-13.9 \\
-10.7 \\
-7.1 \\
-3.8 \\
-0.2 \\
3.4 \\
7.1 \\
10.9 \\
14.4\end{array}$ & $\begin{array}{r}599.0 \\
.1 \\
.2 \\
.3 \\
.4 \\
.5 \\
.6 \\
.7 \\
.8 \\
.9 \\
600.0 \\
.1 \\
.2 \\
.3 \\
.4 \\
.5 \\
.6 \\
.7 \\
.8 \\
.9 \\
601.0\end{array}$ & $\begin{array}{r}119.1 \\
123.2 \\
125.0 \\
123.4 \\
119.7 \\
113.9 \\
106.6 \\
98.6 \\
89.9 \\
81.0 \\
72.5 \\
64.2 \\
57.0 \\
50.4 \\
44.9 \\
40.2 \\
36.0 \\
32.6 \\
29.4 \\
26.9 \\
24.4\end{array}$ & $\begin{array}{l}+57.9 \\
+46.1 \\
+33.5 \\
+19.5 \\
+\quad 7.8 \\
-2.8 \\
-11.9 \\
-18.7 \\
-24.4 \\
-28.7 \\
-31.0 \\
-31.7 \\
-31.0 \\
-29.3 \\
-27.4 \\
-25.3 \\
-23.1 \\
-20.9 \\
-18.6 \\
-16.4 \\
-14.4\end{array}$ & $\begin{array}{l}3.04 \\
2.87 \\
2.71 \\
2.54 \\
2.41 \\
2.28 \\
2.17 \\
2.07 \\
1.99 \\
1.92 \\
1.87 \\
1.83 \\
1.80 . \\
1.78 \\
1.79 \\
1.82 \\
1.87 \\
1.94 \\
2.03 \\
2.13 \\
2.26\end{array}$ & $\begin{array}{r}25.9 \\
20.5 \\
15.0 \\
9.0 \\
3.7 \\
-1.4 \\
-6.3 \\
-10.7 \\
-15.2 \\
-19.5 \\
-23.1 \\
-26.3 \\
-28.5 \\
-30.2 \\
-31.4 \\
-32.2 \\
-32.7 \\
-32.6 \\
-32.3 \\
-31.5 \\
-30.5\end{array}$ \\
\hline $\begin{array}{r}799.0 \\
.1 \\
.2 \\
.3 \\
.4 \\
.5 \\
.6 \\
.7 \\
.8 \\
.9 \\
00.0 \\
.1 \\
.2 \\
.3 \\
.4 \\
.5 \\
.6 \\
.7 \\
.8 \\
.9 \\
801.0\end{array}$ & $\begin{array}{l}30.5 \\
31.9 \\
33.3 \\
34.4 \\
35.5 \\
36.3 \\
37.0 \\
37.7 \\
38.2 \\
38.7 \\
39.3 \\
39.7 \\
40.0 \\
40.1 \\
40.0 \\
39.5 \\
39.0 \\
38.4 \\
37.6 \\
36.8 \\
36.1\end{array}$ & $\begin{array}{l}+11.8 \\
+11.0 \\
+10.2 \\
+9.2 \\
+8.1 \\
+7.0 \\
+\quad 5.8 \\
+4.5 \\
+3.3 \\
+2.1 \\
+\quad 0.8 \\
-0.6 \\
-2.1 \\
-3.8 \\
-5.3 \\
-6.9 \\
-8.2 \\
-9.5 \\
-10.6 \\
-11.7 \\
-12.6\end{array}$ & $\begin{array}{l}1.78 \\
1.69 \\
1.61 \\
1.54 \\
1.48 \\
1.43 \\
1.39 \\
1.35 \\
1.32 \\
1.30 \\
1.27 \\
1.26 \\
1.26 \\
1.27 \\
1.29 \\
1.33 \\
1.36 \\
1.41 \\
1.45 \\
1.50 \\
1.55\end{array}$ & $\begin{array}{r}21.1 \\
19.1 \\
17.1 \\
15.0 \\
12.9 \\
10.9 \\
8.9 \\
6.8 \\
4.9 \\
3.1 \\
1.2 \\
-0.9 \\
-3.0 \\
-5.4 \\
-7.6 \\
-9.8 \\
-11.9 \\
-13.9 \\
-15.7 \\
-17.6 \\
-19.2\end{array}$ & $\begin{array}{r}999.0 \\
.1 \\
.2 \\
.3 \\
.4 \\
.5 \\
.6 \\
.7 \\
.8 \\
.9 \\
1000.0 \\
.1 \\
.2 \\
.3 \\
.4 \\
.5 \\
.6 \\
.7 \\
.8 \\
.9 \\
1001.0\end{array}$ & $\begin{array}{l}28.3 \\
29.5 \\
31.1 \\
32.6 \\
34.1 \\
35.6 \\
37.5 \\
39.0 \\
40.7 \\
42.3 \\
44.0 \\
45.6 \\
47.1 \\
48.4 \\
49.8 \\
51.1 \\
51.9 \\
52.4 \\
52.6 \\
52.8 \\
52.7\end{array}$ & $\begin{array}{l}-18.8 \\
-18.4 \\
-17.8 \\
-17.6 \\
-17.4 \\
-17.2 \\
-17.2 \\
-17.5 \\
-17.9 \\
-18.6 \\
-19.2 \\
-20.2 \\
-21.2 \\
-22.6 \\
-24.2 \\
-26.0 \\
-27.8 \\
-29.8 \\
-31.5 \\
-34.0 \\
-36.1\end{array}$ & $\begin{array}{l}2.11 \\
2.02 \\
1.91 \\
1.83 \\
1.75 \\
1.69 \\
1.63 \\
1.59 \\
1.56 \\
1.54 \\
1.53 \\
1.54 \\
1.55 \\
1.58 \\
1.62 \\
1.66 \\
1.72 \\
1.78 \\
1.85 \\
1.92 \\
2.00\end{array}$ & $\begin{array}{l}-33.6 \\
-31.9 \\
-29.8 \\
-28.3 \\
-27.0 \\
-25.7 \\
-24.7 \\
-24.2 \\
-23.8 \\
-23.7 \\
-23.6 \\
-23.9 \\
-24.3 \\
-25.0 \\
-25.9 \\
-27.0 \\
-28.2 \\
-29.6 \\
-31.2 \\
-32.8 \\
-34.4\end{array}$ \\
\hline
\end{tabular}

Fig. 3. Variation of Receiver Input Impedance and Phase Angle Across the Receiver Passband

(Note: Circled values = receiver tuned frequencies) 
this data is given in the table of figure 3. The signal level used for these measurements was kept low so that the receiver would not have an attenuator pad inserted internally in the RF signal path.

It can be seen from figures 1 to 3 that the receiver presents a badly mismatched load to a $50 \Omega$ source, such as an antenna or a calibrating impulse generator, for all frequencies except those very close to the receiver tuned frequency. Even the tuned-frequency impedance values are considerably different from the nominal value of $50+j 0$ ohms. For example, for maximum receiver indication at $400 \mathrm{MHz}$ the input impedance is 73-j27 ohms, while zero phase angle occurs at $400.6 \mathrm{MHz}$, and a minimum VSWR of 1.5 occurs at $400.4 \mathrm{MHz}$.

\subsection{Calibration of receiver as a tuned RF voltmeter.}

A block diagram of the instrumentation used for all the stepped-frequency measurements of receiver bandwidth is given in figure 4. This setup was also used for the required initial calibration of the receiver as an RF voltmeter. Note that this is a new technique which does not require prior calibration of the receiver with an RF Micropot. Instead, it employs a special L-pad with approximately $50 \Omega$ input resistance and a low output resistance. This pad consists of a $48 \Omega$ series resistor and a $2.35 \Omega$ annular-ring resistor in shunt with the output. The L-pad is housed in a metal box 1 inch long with a type $\mathrm{N}$ coax connector at each end.

The low-impedance source for the receiver $(2.35 \Omega$ resistor in figure 4) supplies a known RF voltage to the receiver input terminal which is essentially independent of variations in receiver input impedance. For example, assume a receiver with a nominal $50 \Omega$ input but with an actual input VSWR of $2: 1$. The maximum possible variation of receiver input voltage under these conditions is $0.37 \mathrm{~dB}$ or $4 \%$. As a comparison, the receiver input voltage varies up to $3.52 \mathrm{~dB}$ or $50 \%$ when using a $50 \Omega$ generator as the receiver source. When using the $27 \mathrm{~dB}$ L-pad, the signal level is adjusted to obtain a power meter reading (accuracy $= \pm 1 \%$ ) of $1 \mathrm{~mW}$ to produce a $10 \mathrm{mV}$ signal at the receiver. The $47 \mathrm{~dB}$ L-pad has an output of $1 \mathrm{mV}$ for a power input of $1 \mathrm{~mW}$, as indicated in figure 4 .

A graph showing the measured insertion loss of the special L-pads over the frequency range of 100 to $1000 \mathrm{MHz}$ is given in figure 5. These readings are average values obtained from a multiple-scan approach. As can be seen, the attenuation of the $27 \mathrm{~dB}$ pad varies from $26.6 \mathrm{~dB}$ at a frequency of $890 \mathrm{MHz}$, to $27.4 \mathrm{~dB}$ at $190 \mathrm{MHz}$, or $\pm 0.4 \mathrm{~dB}$ over the entire decade frequency range. 


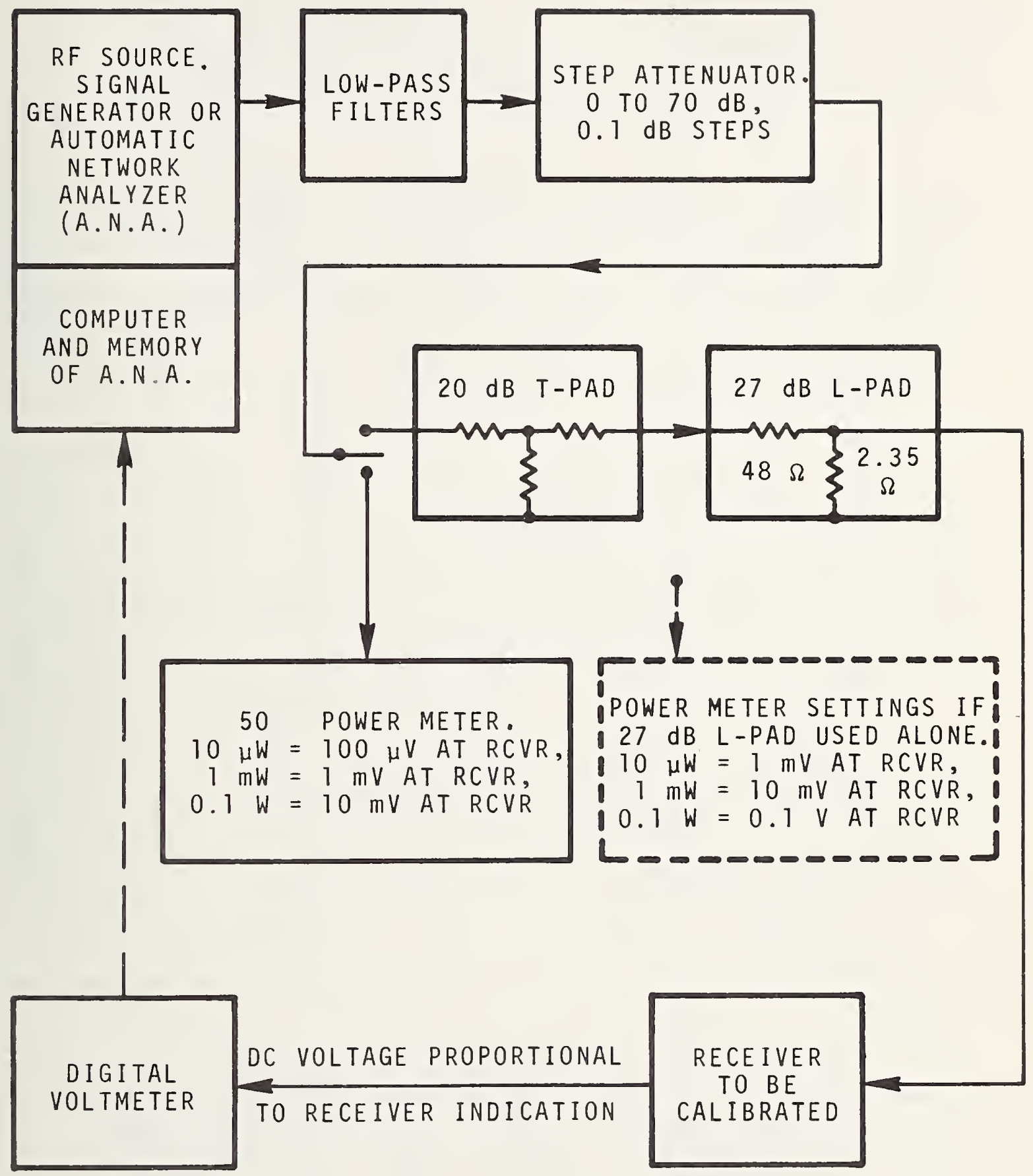

Fig. 4. Instrumentation for Calibrating a Receiver to Measure CW Voltage and Stepped-Frequency Bandwidth. 


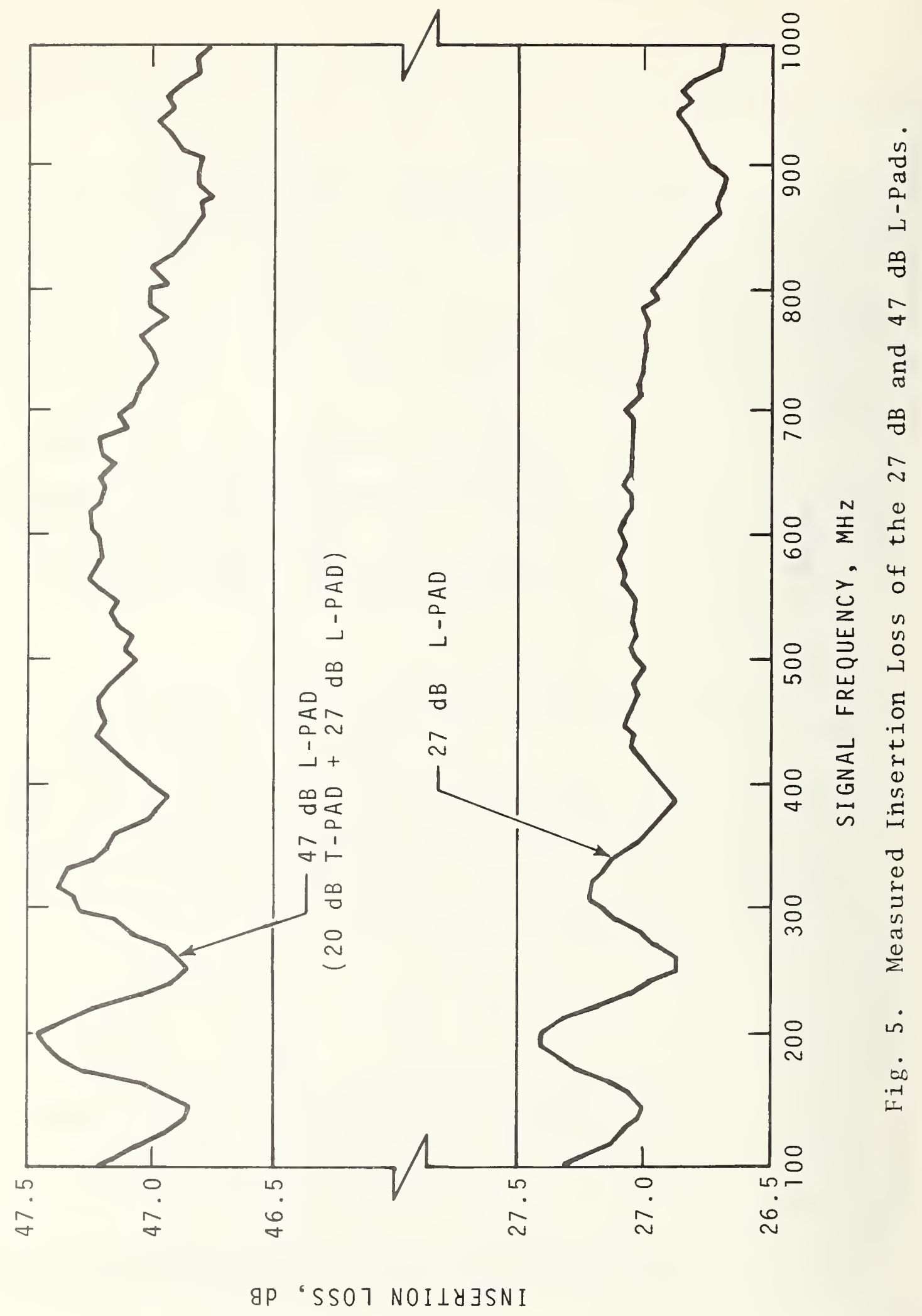


It should be mentioned that improvements could be made in the construction and attenuation-vs-frequency characteristics for this type of attenuator pad. The value of $27 \mathrm{~dB}$ for insertion loss was chosen for two reasons: (a) the output impedance is low compared with a $50 \Omega$ receiver, and (b) the conversion from power meter indication to receiver voltage is simple and convenient.

If a power meter is used for leveling the power vs. frequency at the input to the L-pad in figure 4 , then the output voltage across the $2.35 \Omega$ resistor is also leveled to within the limits of figure 5. That is, this pad can be used as a lowimpedance voltage source, giving nearly constant amplitude vs. signal frequency, for swept-frequency calibration of FIM's.

4.3 Stepped-frequency measurements of receiver bandwidth.

Graphs of some of the data taken for measurement of receiver bandwidth are given in figures 6 to 16. Al1 of these graphs are for the FIM-2 "Interference Analyzer." This interference meter covers $14 \mathrm{kHz}$ to $1 \mathrm{GHz}$ in 15 tuning bands. The receiver has a 2-position selectivity switch on the front panel. The "Wide" bandwidth position has a nominal $3-\mathrm{dB}$ bandwidth of $500 \mathrm{kHz}$ and the "Narrow" position a nominal bandwidth of $50 \mathrm{kHz}$, for frequencies above $25 \mathrm{MHz}$, according to the manufacturer's specifications. Figures 6 to 11 give our data for the "Wide" bandwidth position and figures 12 to 16 are for "Narrow" bandwidth.

The receiver attenuator was switched to the $40 \mathrm{~dB}$ step in all cases, which is the next-to-most sensitive step. The signal input level to the receiver was chosen to be $1 \mathrm{mV}$. Using the instrumentation of figure 4, with $27 \mathrm{~dB}$ L-pad used alone, the 0-to-70 dB step attenuator was adjusted to obtain a power meter indication of $10 \mu \mathrm{W}$. Then the signal was switched to the input of the $27 \mathrm{~dB}$ L-pad and the receiver gain control adjusted to obtain the correct indication of $1 \mathrm{mV}$ on the receiver meter.

Figures 6 and 12 show the measured receiver response vs. signal frequency, in $\mathrm{dB}$ above $1 \mu \mathrm{V}$. The receiver selectivity was switched to "Wide" bandwidth for figure 6 and to "Narrow" bandwidth for figure 12. Two reduced-voltage bandwidths are indicated on each of these figures, the $3 \mathrm{~dB}$ and $20 \mathrm{~dB}$ bandwidths. These represent the frequency width between points on the curves which have 0.707 or 0.1 , respectively, of the maximum voltage response. For frequencies well removed from the receiver tuned frequency, the "true" signal level was obtained by the equation: 
$($ Signal level, $\mathrm{mV})=\sqrt{\left(\begin{array}{c}\text { Receiver } \\ \text { indication, } \mathrm{mV}\end{array}\right)^{2}-\left(\begin{array}{c}\text { Receiver noise } \\ \text { level, } \mathrm{mV}\end{array}\right)^{2}}$.

Figures 6 and 12 show two curves, one the actual receiver indication and another which has been corrected for receiver internal noise. A list of the measured values of receiver internal noise level is given in the following table:

Receiver

Band

Number

14

14

14

15

15

15

15

15
Signal

Frequency,

$\mathrm{MHz}$

300

400

500

500

600

700

800

900
Noise Leve1 of EMC-25 Receiver

Wide

Bandwidth

$0.033 \mathrm{mV}$

$0.028 \mathrm{mV}$

$0.039 \mathrm{mV}$

$0.059 \mathrm{mV}$

$0.071 \mathrm{mV}$

$0.067 \mathrm{mV}$

$0.062 \mathrm{mV}$

$0.068 \mathrm{mV}$
Narrow

Bandwidth

$0.018 \mathrm{mV}$

$0.015 \mathrm{mV}$

$0.018 \mathrm{mV}$

(data not taken)

$0.030 \mathrm{mV}$

$0.036 \mathrm{mV}$

(data lost)

$0.036 \mathrm{mV}$

Figure 7 presents experimental data for receiver voltage response vs. signal frequency, over the range of 299 to 301 $\mathrm{MHz}$. Several types of commonly used bandwidths relating to field strength and interference meters are indicated on the curve in this figure. The equivalent-rectangular voltage passband is shown by the rectangle enclosed in heavy lines. This bandwidth of $645 \mathrm{kHz}$ was obtained by a numerical integration of the area under the curve of receiver indication vs. frequency. That is, the area of the rectangle (bandwidth $x$ maximum indication) has the same value as the area under the actual plotted bandpass curve. The equation used for this numerical integration is:

$$
(B W)_{\text {voltage }}=\frac{\sum V(f)}{V_{m}(f)} \times \Delta f,
$$

where $\Delta \mathrm{f}$ is the frequency increment of the stepped-frequency signal source. For example, the step size programmed into the automitic network analyzer was $0.01 \mathrm{MHz}$ in figure 7 . The analyzer was programmed to pause 1 second after phaselock at each frequency point, before digitizing and recording the indicated receiver response. Also shown in figure 7 are several reduced-voltage bandwidths (e.g., $3 \mathrm{~dB}, 6 \mathrm{~dB}$, etc.) for a receiver tuned frequency of $300 \mathrm{MHz}$, as derived from the voltage-response measurements. These will be referred to later in this report. 
Figure 8 is derived from the same data given in figure 7 , except that the ordinates are squared values of receiver indication. As mentioned on page 4, there are two basic types of broadband signal, one called "impulse interference" and the other "random noise." The effective random-noise bandwidth, sometimes called "power" bandwidth, is the frequency interval for which a power gain equal to the gain at mid-band would transmit the same noise energy as does the actual power-gain frequency curve. This effective bandwidth can be measured by dividing the area under the power response curve by the center frequency value. This is also the random noise bandwidth, (BW) ran, obtained from the equivalent rectangular bandwidth of the voltage-squared passband curve shown in figure 8. The equation used for our numerical integration is:

$$
(B W)_{\operatorname{ran}}=\frac{\left[[V(f)]^{2}\right.}{\left[V_{m}(f)\right]^{2}} \times \Delta f \text {. }
$$

It can be seen in figure 8 that the random noise bandwidth is $431 \mathrm{kHz}$ for a receiver frequency of $300 \mathrm{MHz}$, which is equal to the $3.33 \mathrm{~dB}$ bandwidth of figure 7. The difference between the $3 \mathrm{~dB}$ and random noise bandwidths, in this case, is only about $5 \%$, having the following ratio:

$$
\text { (BW) }{ }_{\text {ran }} \div(B W)_{3 \mathrm{~dB}}=431 \mathrm{kHz} \div 409 \mathrm{kHz}=1.054 \text {. }
$$

Figures 7 and 8 also indicate an "impulse" bandwidth which is defined later in section 4.5 , and has a measured value (figure 24) of $556 \mathrm{kHz}$ for this receiver frequency. The difference between the $6 \mathrm{~dB}$ bandwidth and impulse bandwidth was only about $2 \%$ in this case. The calculated ratio is

$$
(B W)_{\text {imp }} \div(B W)_{6 \mathrm{~dB}}=556 \mathrm{kHz} \div 556 \mathrm{kHz}=0.98 \text {. }
$$

Figures 9 to 11 and 13 to 16 are additional graphs of representative stepped-frequency bandwidth data taken with the automatic network analyzer. The receiver tuned frequency, bandwidth setting, band number, etc., are given in the legend of each figure. Two curves are shown on each figure, using a solid line for voltage-response data and a dashed line for squared-voltage-response data. The two equivalent-rectangular bandwidths are shown by rectangular lines, that is, voltage $\mathrm{b}$ andwidth and random-noise bandwidth. Also indicated on the figures are the $3 \mathrm{~dB}, 6 \mathrm{~dB}$ and $20 \mathrm{~dB}$ bandwidths. 


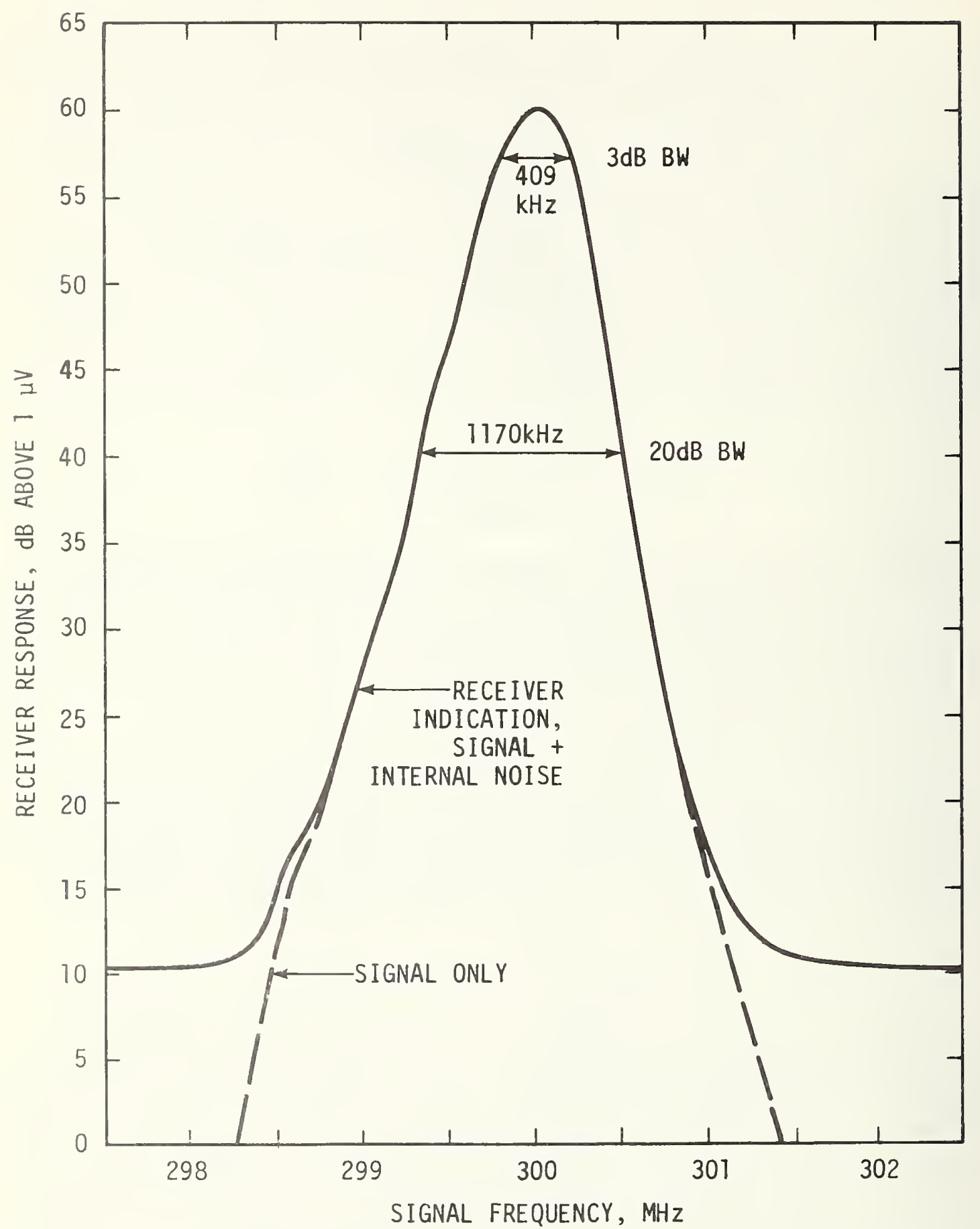

Fig. 6. Stepped-Frequency Measurement of Receiver Bandwidth Tuned frequency $=300 \mathrm{MHz}$ (Band 14) Receiver selectivity = "Wide Bandwidth" Signal level $=1 \mathrm{mV}$, Step size $=0.01 \mathrm{MHz}$. 


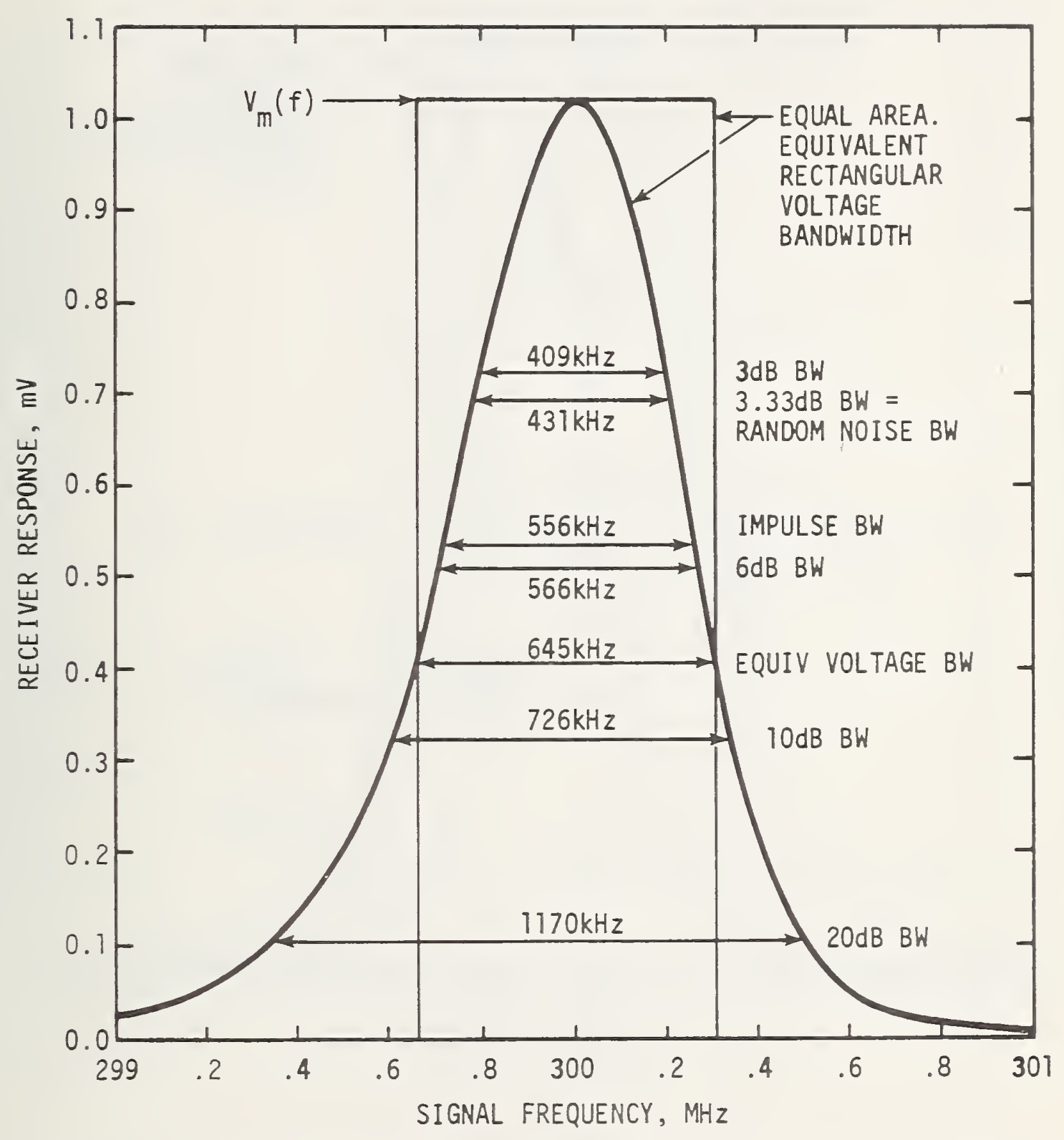

Fig. 7. Stepped-Frequency Measurement of Receiver Bandwidth Indicated Voltage vs. Frequency

Tuned frequency $=300 \mathrm{MHz}$ (Band 14)

Receiver selectivity = "Wide Bandwidth"

Signal level $=1 \mathrm{mV}$, Step size $=0.01 \mathrm{MHz}$. 


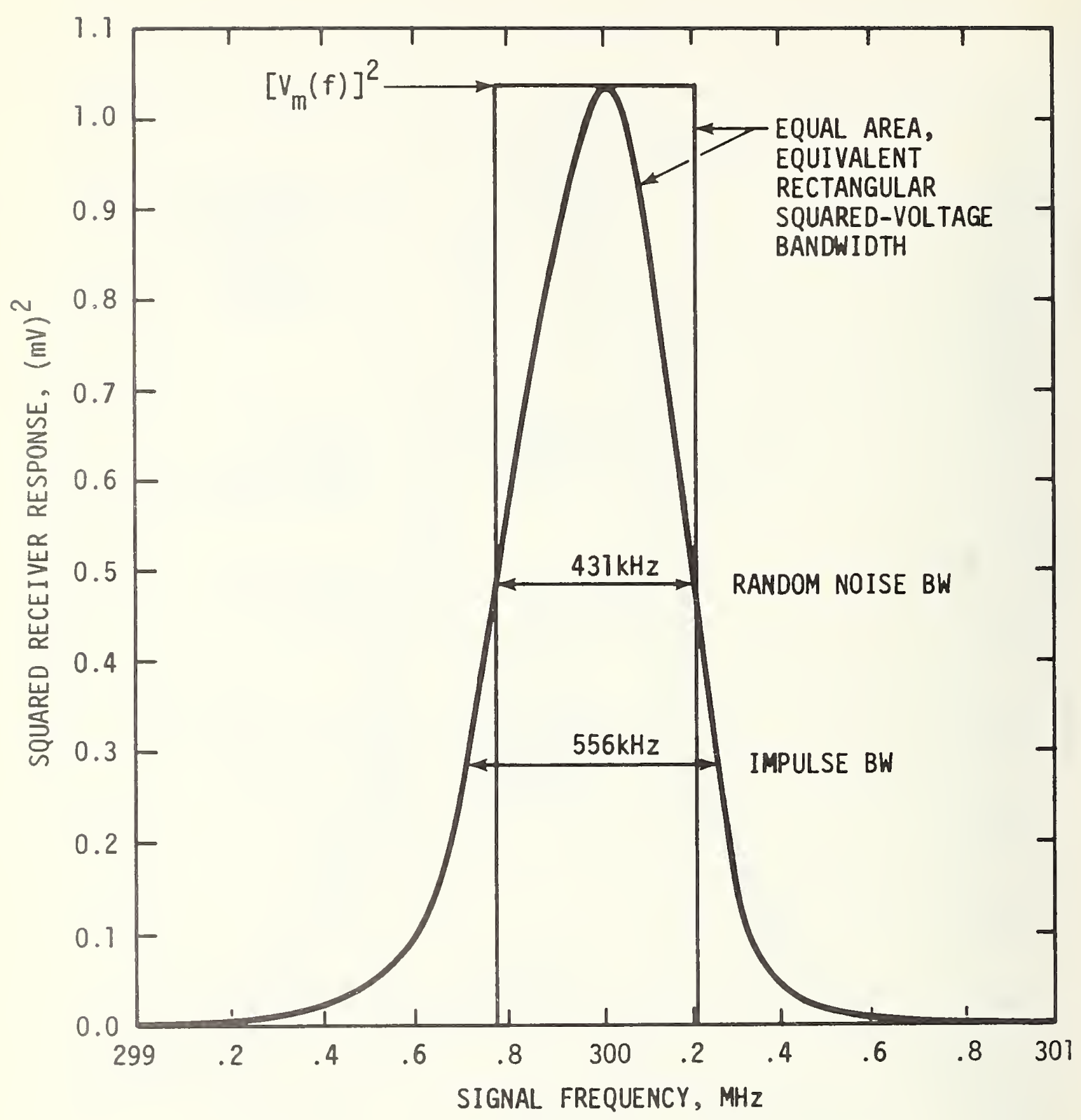

Fig. 8. Stepped-Frequency Measurement of Receiver Bandwidth Squared Voltage vs. Frequency

Tuned frequency $=300 \mathrm{MHz}$ (Band 14)

Receiver selectivity = "Wide Bandwidth"

Signal level $=1 \mathrm{mV}$, Step size $=0.01 \mathrm{MHz}$. 


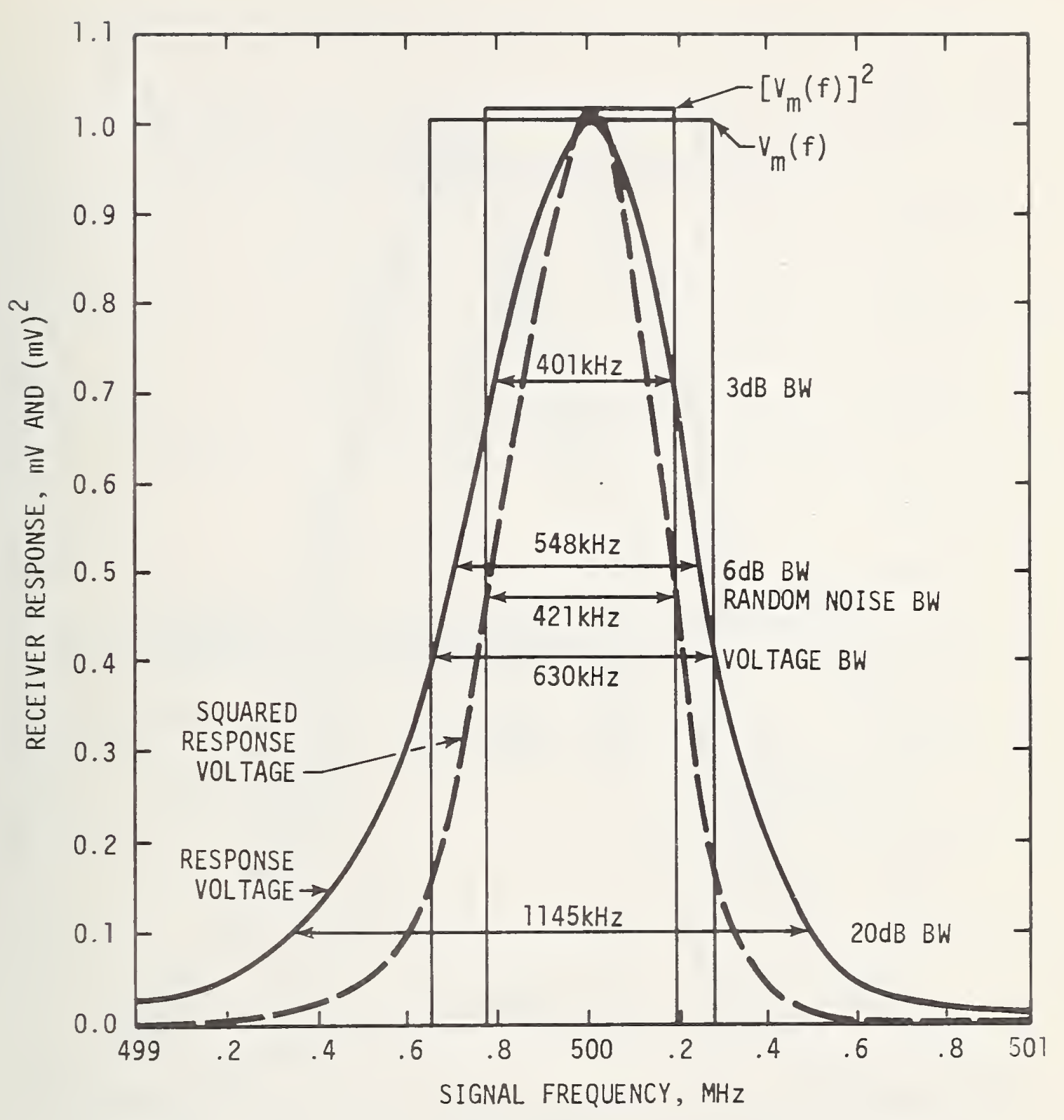

Fig. 9. Stepped-Frequency Measurement of Receiver Bandwidth Tuned frequency $=500 \mathrm{MHz}$ (Band 14)

Receiver selectivity = "Wide Bandwidth"

Signal Level $=1 \mathrm{mV}$, Step size $=0.01 \mathrm{MHz}$. 


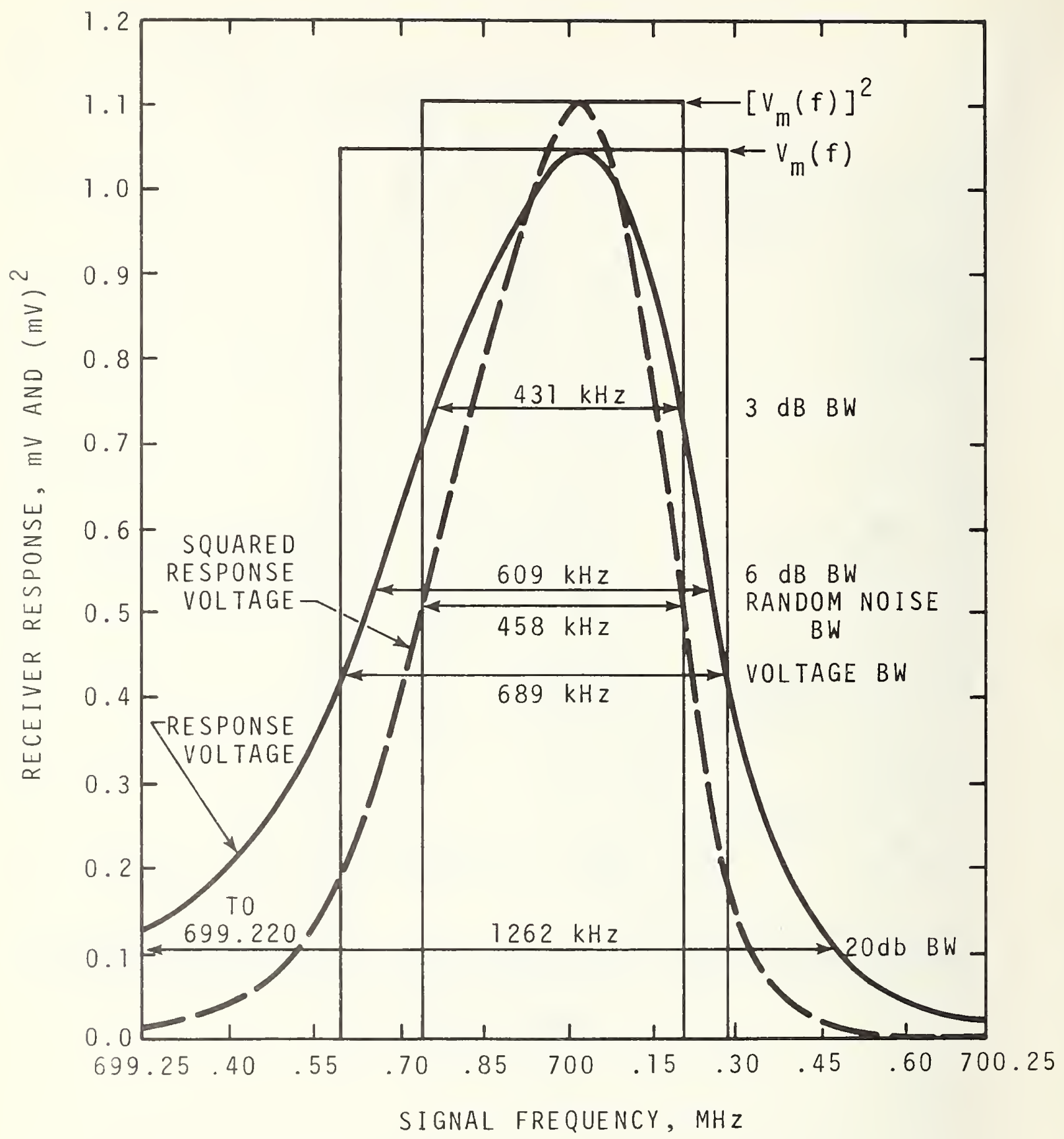

Fig. 10. Stepped-Frequency Measurement of Receiver Bandwidth Tuned frequency $=700 \mathrm{MHz}$ (Band 15)

Receiver selectivity = "Wide Bandwidth"

Signal level $=1 \mathrm{mV}$, Step size $=0.015 \mathrm{MHz}$. 




Fig. 11. Stepped-Frequency Measurement of Receiver Bandwidth Tuned frequency $=900 \mathrm{MHz}$ (Band 15)

Receiver selectivity = "Wide Bandwidth"

Signal level $=1 \mathrm{mV}$, Step size $=0.015 \mathrm{MHz}$. 


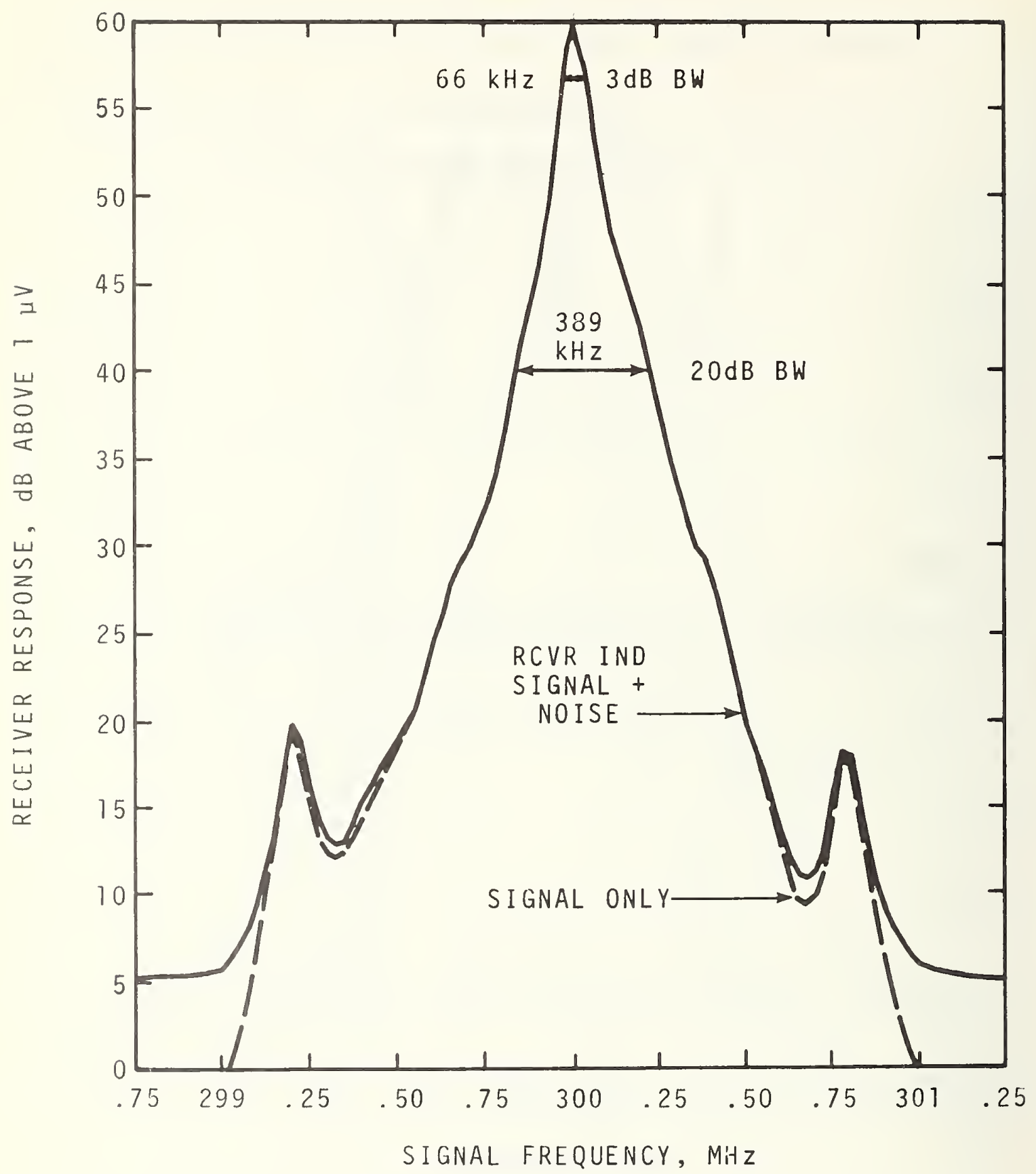

Fig. 12. Stepped-Frequency Measurement of Receiver Bandwidth Tuned frequency $=300 \mathrm{MHz}$ (Band 14) Receiver selectivity = "Narrow Bandwidth" Signal level $=1 \mathrm{mV}$, Step size $=0.0025 \mathrm{MHz}$. 


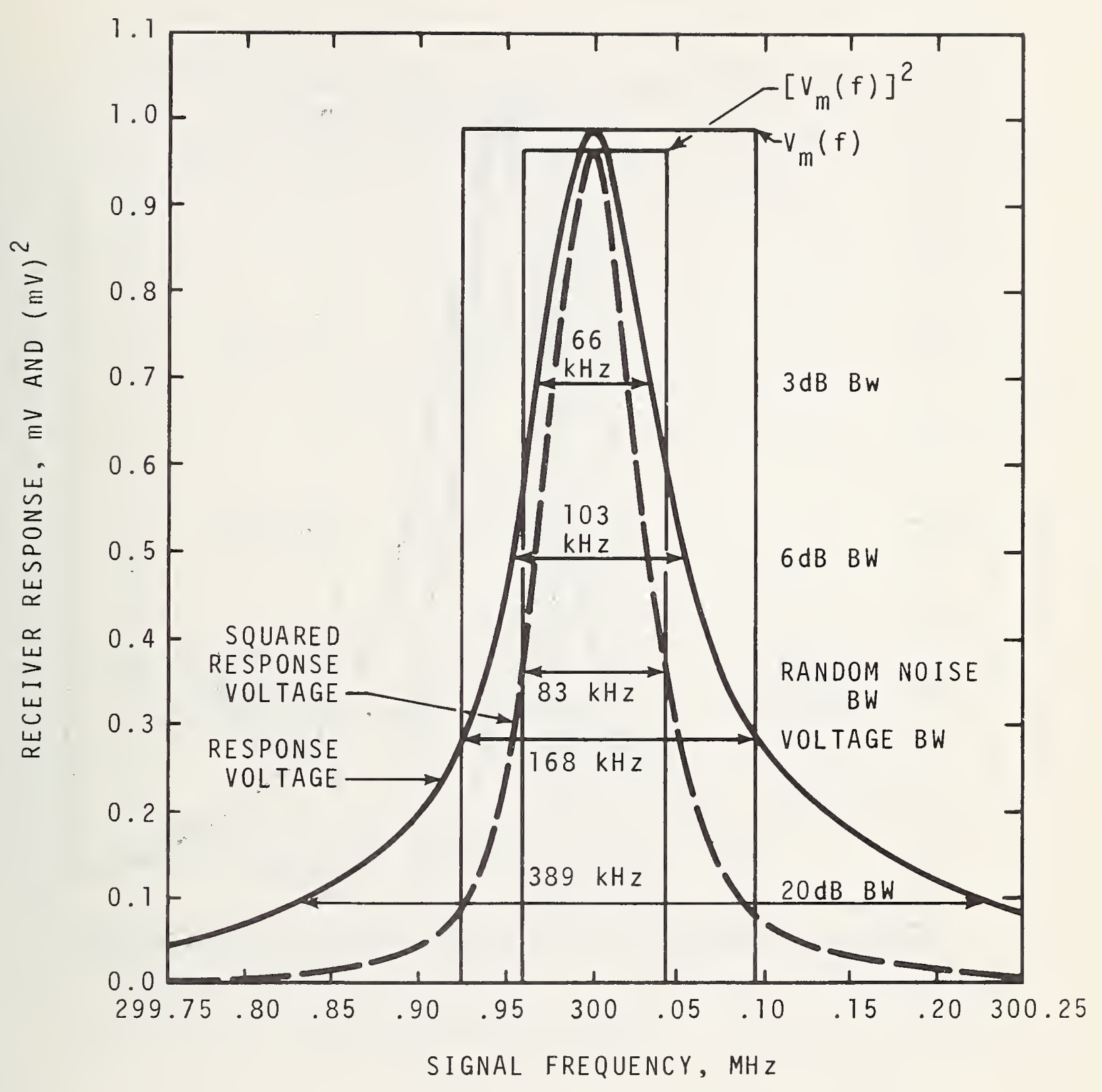

Fig. 13. Stepped-Frequency Measurement of Receiver Bandwidth Tuned frequency $=300 \mathrm{MHz}$ (Band 14)

Receiver selectivity = "Narrow Bandwidth"

Signal level $=1 \mathrm{mV}$, Step size $=0.0025 \mathrm{MHz}$. 


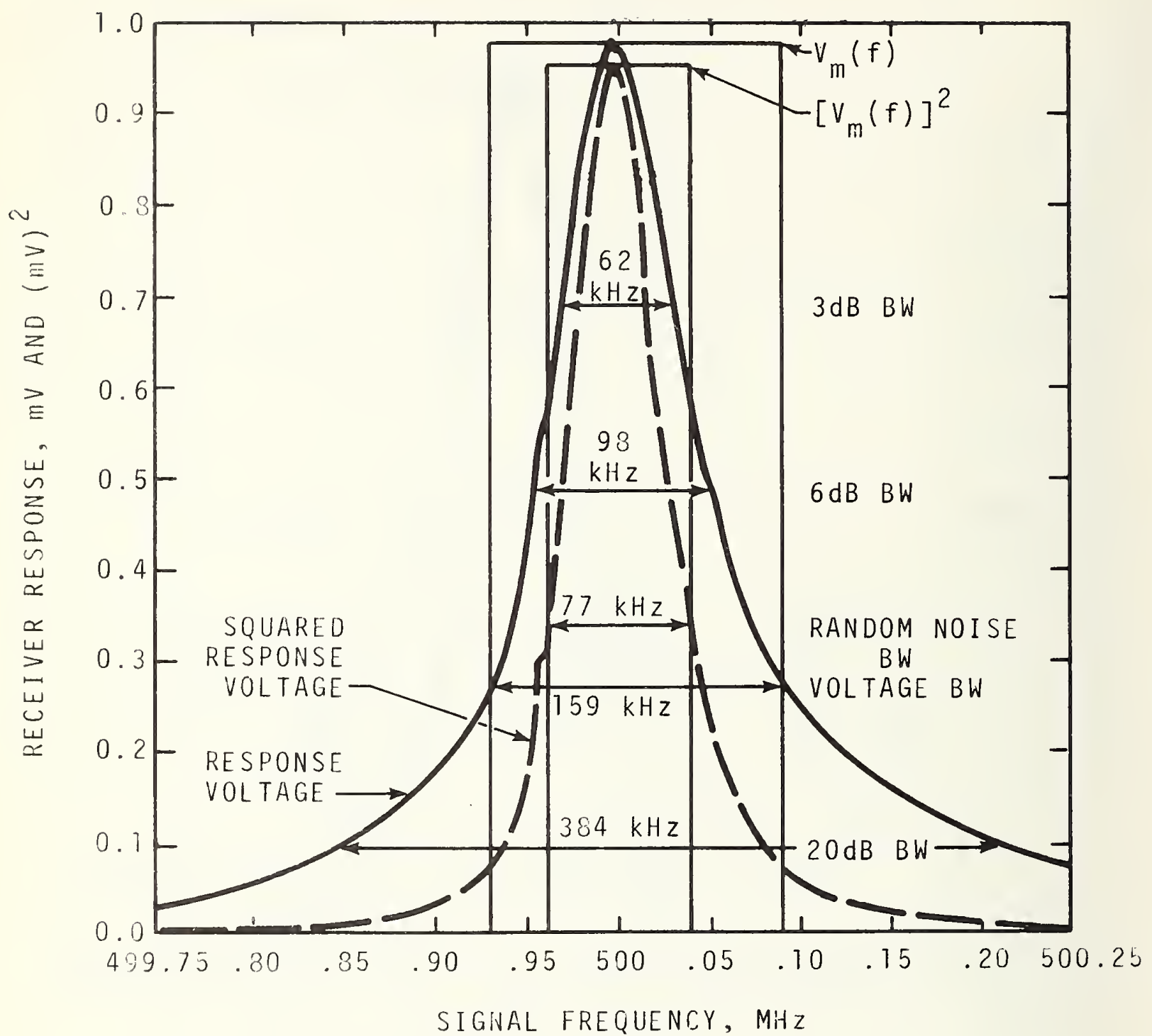

Fig. 14 Stepped-Frequency Measurement of Receiver Bandwidth Tuned frequency $=500 \mathrm{MHz}$ (Band 14) Receiver selectivity = "Narrow Bandwidth" Signal level $=1 \mathrm{mV}$, Step size $=0.0025 \mathrm{MHz}$. 


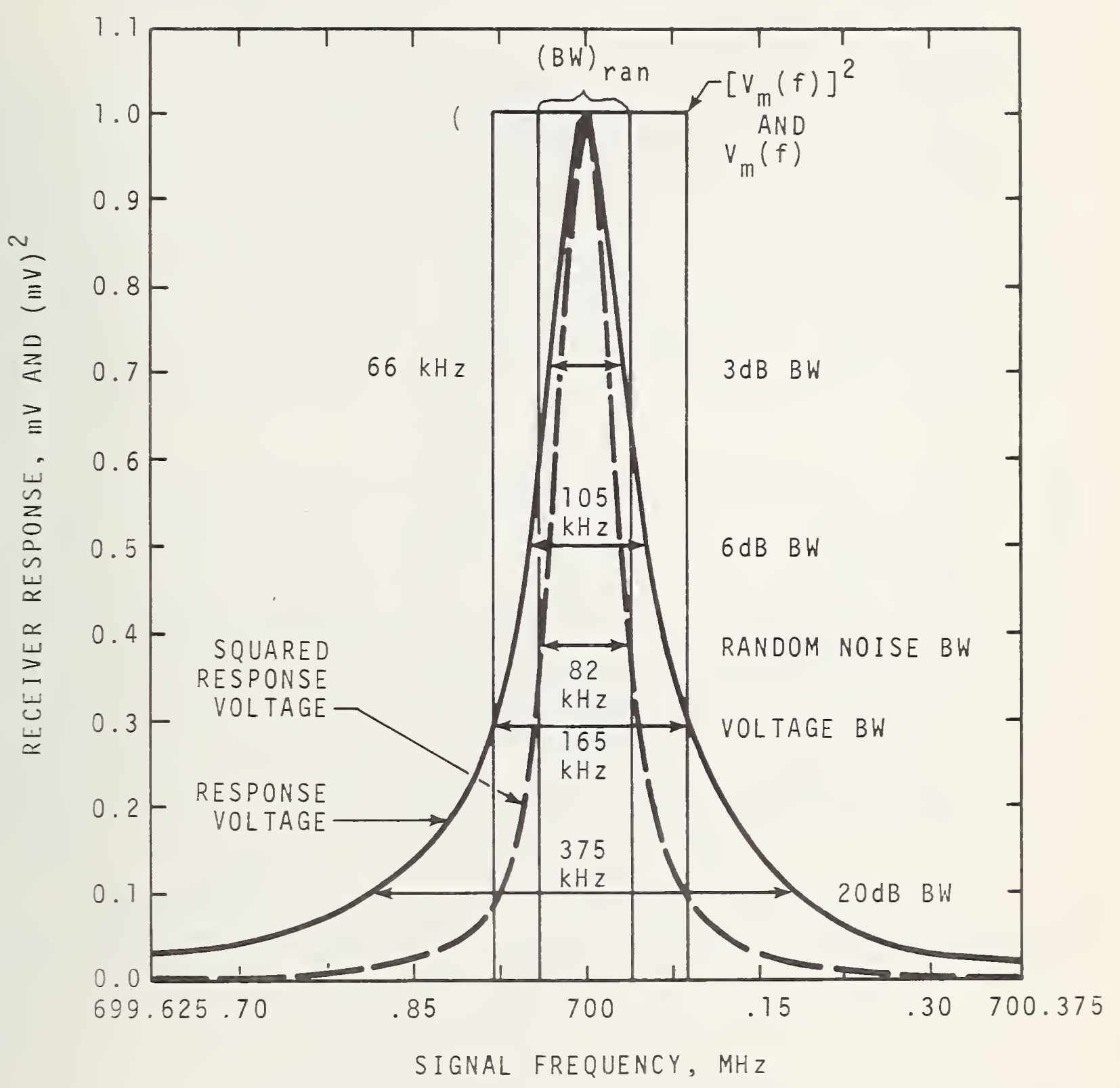

Fig. 15. Stepped-Frequency Measurement of Receiver Bandwidth Tuned frequency $=700 \mathrm{MHz}$ (B and 15) Receiver selectivity = "Narrow Bandwidth" Signal level $=1 \mathrm{mV}$, Step size $=0.0075 \mathrm{MHz}$. 


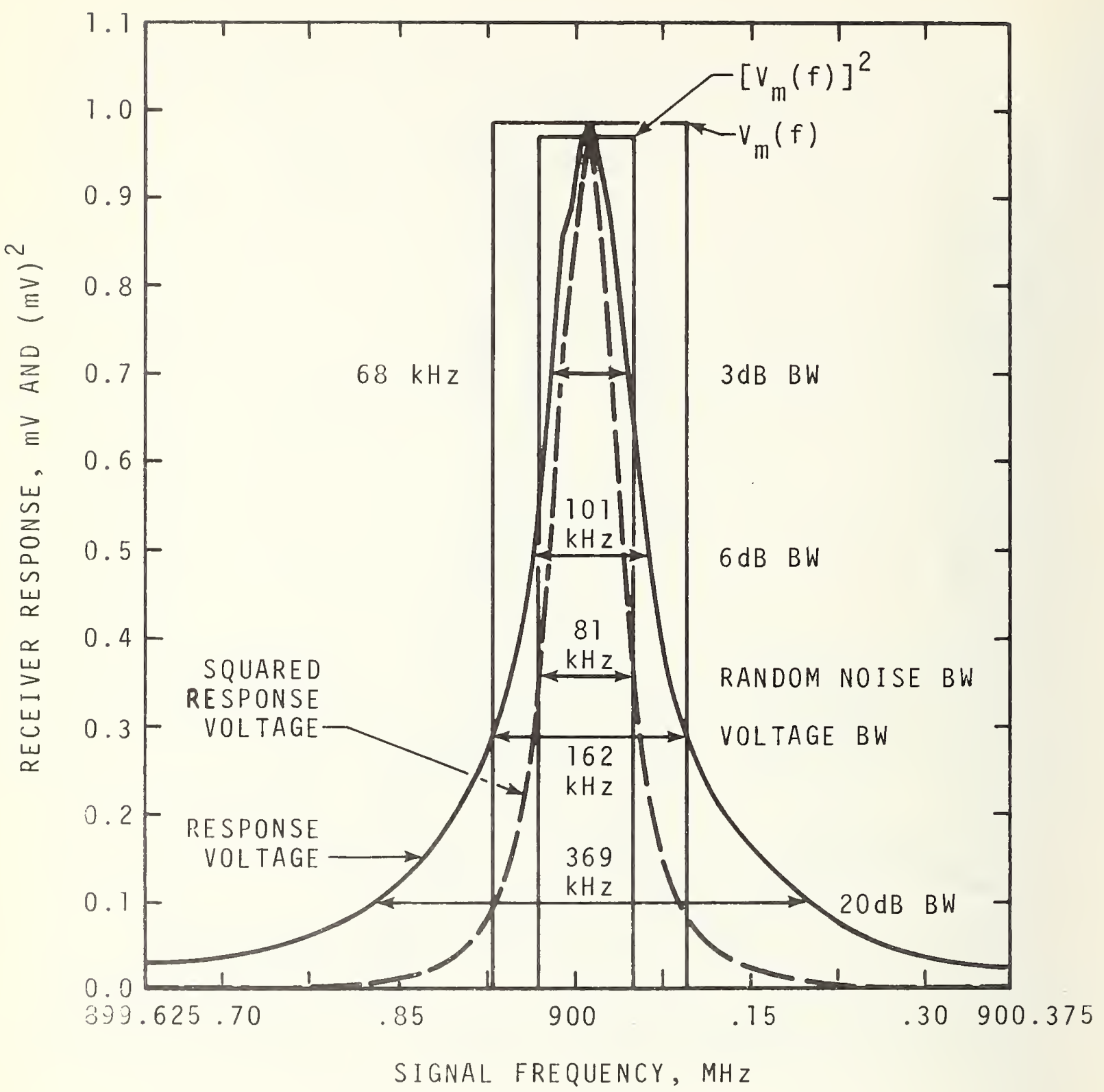

Fig. 16. Stepped-Frequency Measurement of Receiver Bandwidth Tuned frequency $=900 \mathrm{MHz}$ (Band 15)

Receiver selectivity = "Narrow Bandwidth"

Signal level $=1 \mathrm{mV}$, Step size $=0.0075 \mathrm{MHz}$. 
4.4 Calibration of receiver impulse bandwidth with a baseband pulse generator.

A "standard" impulse generator producing known DC (baseband) pulses was developed at NBS on a previous project [12] and was available for calibrating impulse bandwidth of the FIM-2 receiver. This solid-state impulse generator uses a step-recovery diode to generate pulses with a risetime of about 0.1 ns, amplitude of about 8 volts, and equivalent rectangular time duration of about $0.2 \mathrm{~ns}$. The output spectrum for this generator is reported as known to $\pm 1 \mathrm{~dB}$ for frequencies up to $1 \mathrm{GHz}$, and has a nominal amplitude of 2.8 $\mathrm{mV} / \mathrm{MHz}$ [12]. A plot of the maximum delivered impulse strength (spectral intensity) vs. frequency is given in figure 17. The generator is equipped with a built-in 50 -ohm step attenuator to obtain any desired output below this maximum value, assuming that the load is 50 ohms.

A block diagram of the instrumentation used to calibrate impulse bandwidth of the receiver is given in figure 18. In a manner similar to the stepped-frequency measurements of receiver bandwidth described in section 4.3 , the receiver was initially calibrated for $\mathrm{CW}$ voltage at each tuned-frequency tested. This "voltmeter" calibration was made using a $27 \mathrm{~dB}$ L-pad and power meter, similar to the method shown in figure 4. This initial calibration merely adjusts the receiver gain control to the proper setting to read correct voltage, as explained in section 4.2 . For the data reported here the signal level used for CW calibration was $1 \mathrm{mV}$ RMS, or $60 \mathrm{~dB}>1 \mu \mathrm{V}$. The curve of figure 5 was used to set the power meter to the required value for obtaining a signal of $1 \mathrm{mV}$.

The principle used to calibrate impulse bandwidth of a receiver is simply to apply a known impulse, expressed in $\mu \mathrm{V} / \mathrm{MHz}$, and note the receiver indication in $\mu \mathrm{V}$. The calibrated bandwidth is then determined from the relation:

Receiver impulse bandwidth, MHz

$$
=\frac{\text { Receiver indication, } \mu \mathrm{V}}{\text { Strength of impulse generator, } \mu \mathrm{V} / \mathrm{MHz}} \text {, or },
$$

RCVR (BW) ${ }_{\text {imp }}, \mathrm{MHz}=(\mathrm{RCVR}$ Ind, $\mu \mathrm{V}) /(\mathrm{I} . \mathrm{G}$. output, $\mu \mathrm{V} / \mathrm{MHz})$. Another way of expressing this same relation, using logarithmic units, is as follows:

RCVR (BW) imp, $d B>1 \mathrm{MHz}=($ RCVR Ind, $d B>1 \mu V)-(I . G$. Output, $d B>1 \mu V / M H z)$. 
To illustrate the above equation and to check receiver linearity, the measured values of receiver indication were plotted vs. applied impulse strength. The data for one case (receiver tuned to $400 \mathrm{MHz}$ ) are tabulated in figure 19 and plotted as a graph in figure 20. This type of plot is also used to check for the possibility of receiver saturation (overloading) during the high-voltage, low-duty-cycle pulses. The plotted data should be linear, with a slope of unity. That is, each $5 \mathrm{~dB}$ increase in impulse strength should cause a $5 \mathrm{~dB}$ increase in receiver indication. The average value of receiver impulse bandwidth, at a given frequency, can be obtained from the best-fit line with $45^{\circ}$ slope, as indicated in figure 20 . For example, choosing a signal level of $50 \mathrm{~dB}$ above $1 \mu \mathrm{V} / \mathrm{MHz}$, the receiver indication is $43 \mathrm{~dB}$ above $1 \mu \mathrm{V}$. Therefore the "average" receiver impulse bandwidth is (43-50) $\mathrm{dB}$ or $-7 \mathrm{~dB}$ with respect to $1 \mathrm{MHz}$, which is $447 \mathrm{kHz}$. The non-linearity of data is noticeable at both ends of the curves. The departure at the lower end is due to the receiver internal noise, but the error at the upper end is due to signal compression in the receiver. The data for the major portions of the curves indicate that the concept of impulse bandwidth is sound and usable.

A summary of all the data for receiver impulse bandwidth, using the technique of figure 18 , is given in figure 21 . The pulse repetition rate of the impulse generator was $300 \mathrm{~Hz}$. As can be seen, the measured values of impulse bandwidth were in the range 398 to $544 \mathrm{kHz}$ for the FIM-2 receiver switched to the wideband position, with average $=467 \mathrm{kHz}$ and standard deviation $=53 \mathrm{kHz}$. This represents a total variation of $2.7 \mathrm{~dB}$ for the wideband measurements. The narrowband values ranged from 68 to $89 \mathrm{kHz}$, with average $=78 \mathrm{kHz}$ and standard deviation $=7 \mathrm{kHz}$. The measured values for specific cases are compared with other types of bandwidth measurements in section 6 .

4.5 Calibration of receiver impulse bandwidth with a pulsed-RF source.

A block diagram of another type of instrumentation used to calibrate impulse bandwidth of the FIM-2 receiver is given in figure 22. The basis of this standard impulse generator is the "known" voltage and time duration of the RF burst applied to the receiver. As shown in the figure, a baseband pulse generator is used to establish the pulse duration and repetition rate. Each DC pulse overcomes the cutoff bias normally applied to the solid-state switch by the 10 volt power supply. In other words, the switch presents a very high impedance to the RF signal except during the "on" time of the DC pulses. 
gp '

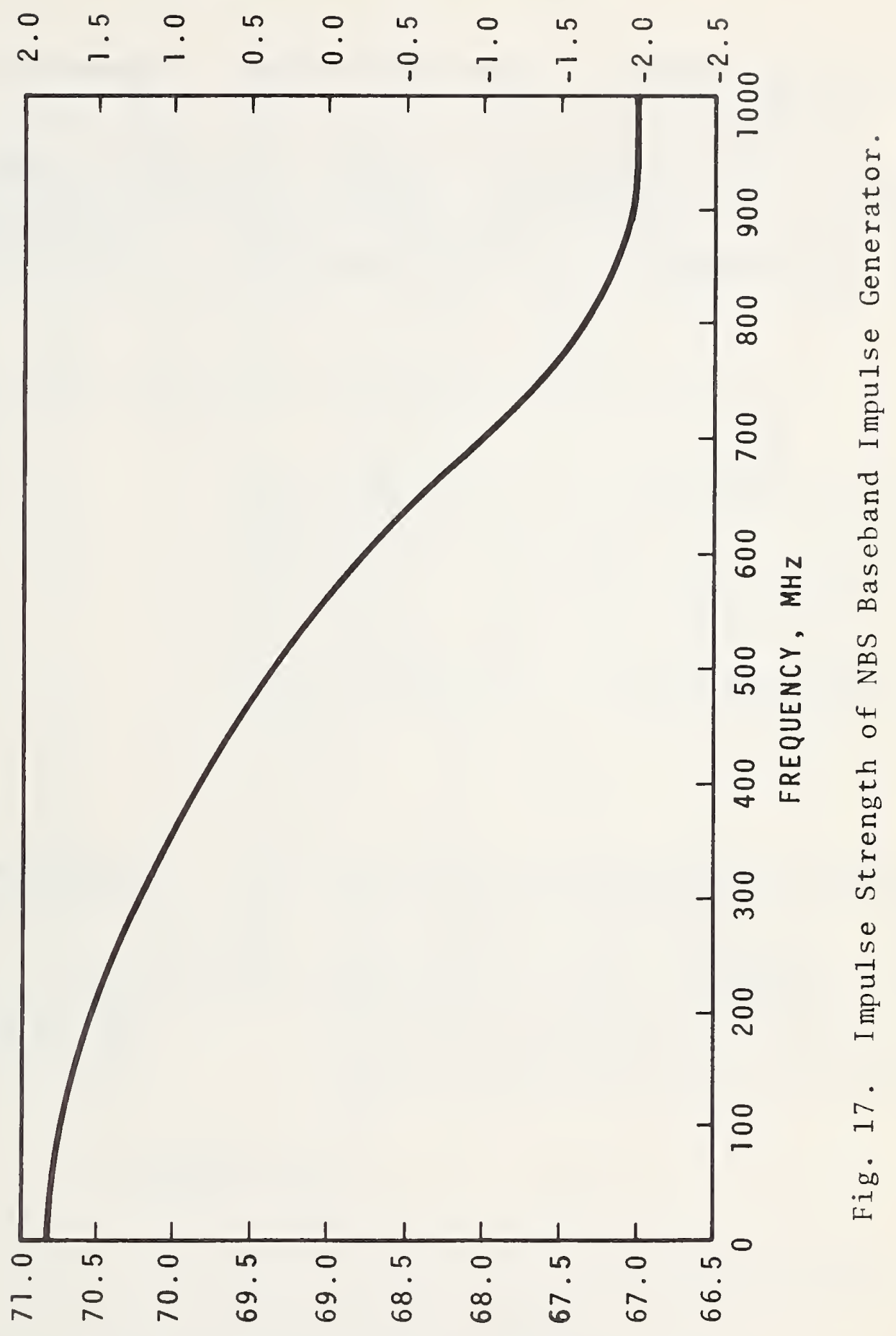

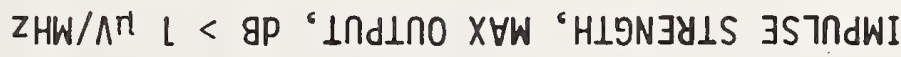



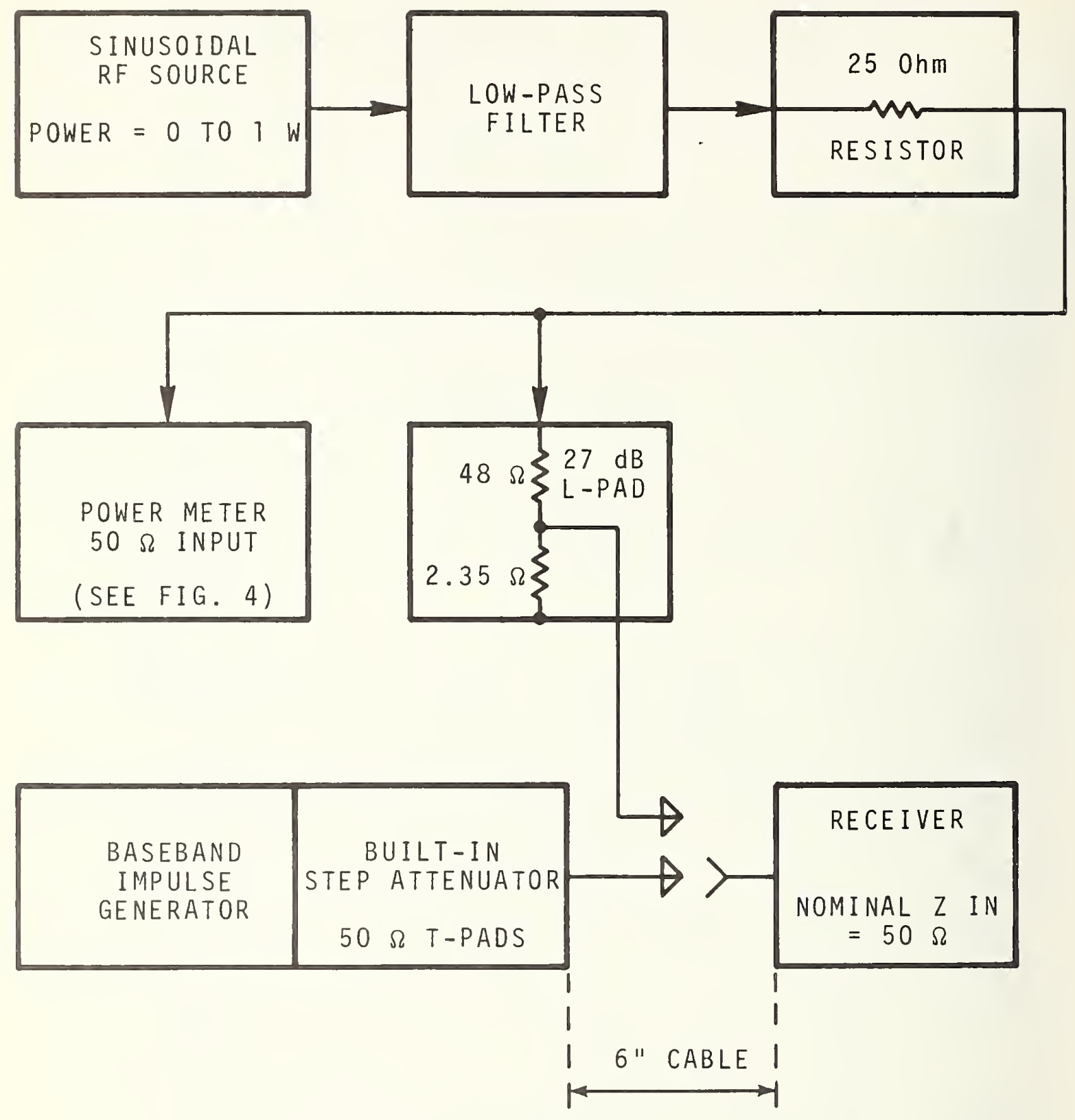

Fig. 18. Instrumentation for Calibrating Receiver Impulse Bandwidth with a Standard Baseband Pulser. 


\begin{tabular}{|c|c|c|c|c|c|c|}
\hline \multirow{2}{*}{$\begin{array}{c}\text { RCVR } \\
\text { Bandwidth } \\
\text { Switch }\end{array}$} & \multirow{2}{*}{$\begin{array}{c}\text { Impulse } \\
\text { Generator } \\
\text { Setting } \\
\mathrm{dB}>1 \mu \mathrm{V} / \mathrm{MHz} \\
\end{array}$} & \multirow{2}{*}{$\begin{array}{c}\text { Corrected } \\
\text { Imp. Gen. } \\
\text { Output } \\
\mathrm{dB}>1, \mu \mathrm{V} / \mathrm{MHz} \\
\end{array}$} & \multicolumn{4}{|c|}{ Receiver dial reading, $\mathrm{dB}>1 \mu \mathrm{V}$} \\
\hline & & & $\begin{array}{l}+20 \mathrm{~dB} \\
\text { Step } \\
\end{array}$ & $\begin{array}{l}+40 \mathrm{~dB} \\
\text { Step } \\
\end{array}$ & $\begin{array}{l}+60 \mathrm{~dB} \\
\text { Step } \\
\end{array}$ & $\begin{array}{l}+80 \mathrm{~dB} \\
\text { Step } \\
\end{array}$ \\
\hline "Wide" & 20 & 20.8 & -6.0 & -21.0 & -23.0 & -23.0 \\
\hline 11 & 25 & 25.8 & -0.8 & -20.0 & $"$ & $"$ \\
\hline$"$ & 30 & 30.8 & 3.9 & -14.8 & $"$ & " \\
\hline$"$ & 35 & 35.8 & 8.5 & -10.4 & " & " \\
\hline " & 40 & 40.8 & 14.2 & -6.5 & " & " \\
\hline " & 45 & 45.8 & 19.2 & $-2 \cdot 0$ & -21.0 & " \\
\hline$"$ & 50 & 50.8 & X & 3.0 & -16.1 & $"$ \\
\hline " & 55 & 55.8 & X & 7.9 & -10.6 & " \\
\hline$"$ & 60 & 60.8 & X & 13.2 & -6.8 & " \\
\hline$"$ & 63 & 63.8 & $x$ & 16.2 & -4.5 & -22.0 \\
\hline$"$ & 65 & 65.8 & X & 17.7 & -2.2 & -21.0 \\
\hline$"$ & 67 & 67.8 & $\mathrm{X}$ & 18.5 & -0.2 & -19.0 \\
\hline$"$ & 69 & 69.8 & X & 19.4 & 1.4 & -17.3 \\
\hline "Narrow" & 20 & 20.8 & -16.5 & -23.5 & -23.5 & -23.5 \\
\hline " & 25 & 25.8 & -13.9 & $"$ & "1 & $" 1$ \\
\hline " & 30 & 30.8 & -11.5 & " & " & $"$ \\
\hline$" 1$ & 35 & 35.8 & -7.5 & " & $" 1$ & $"$ \\
\hline$"$ & 40 & 40.8 & -1.8 & -20.5 & $"$ & $"$ \\
\hline$"$ & 45 & 45.8 & 3.1 & -15.4 & $"$ & " \\
\hline$" 1$ & 50 & 50.8 & 7.6 & -11.8 & $" 1$ & $"$ \\
\hline$" 1$ & 55 & 55.8 & 12.8 & -7.2 & $"$ & $"$ \\
\hline$"$ & 60 & 60.8 & 15.9 & -2.5 & -21.0 & " \\
\hline$"$ & 63 & 63.8 & 17.1 & 0.2 & -17.8 & $"$ \\
\hline$"$ & 65 & 65.8 & 18.1 & 1.7 & -15.7 & $"$ \\
\hline$"$ & 67 & 67.8 & 19.2 & 2.5 & -14.0 & $"$ \\
\hline$"$ & 69 & 69.8 & 20.6 & 3.1 & -13.0 & \\
\hline
\end{tabular}

Fig. 19. Check of Receiver Linearity for Impulse Interference Receiver tuned frequency $=400 \mathrm{MHz}$ Signal source $=$ Baseband impulse generator Pulse repetition frequency $\cong 300 \mathrm{~Hz}$ 


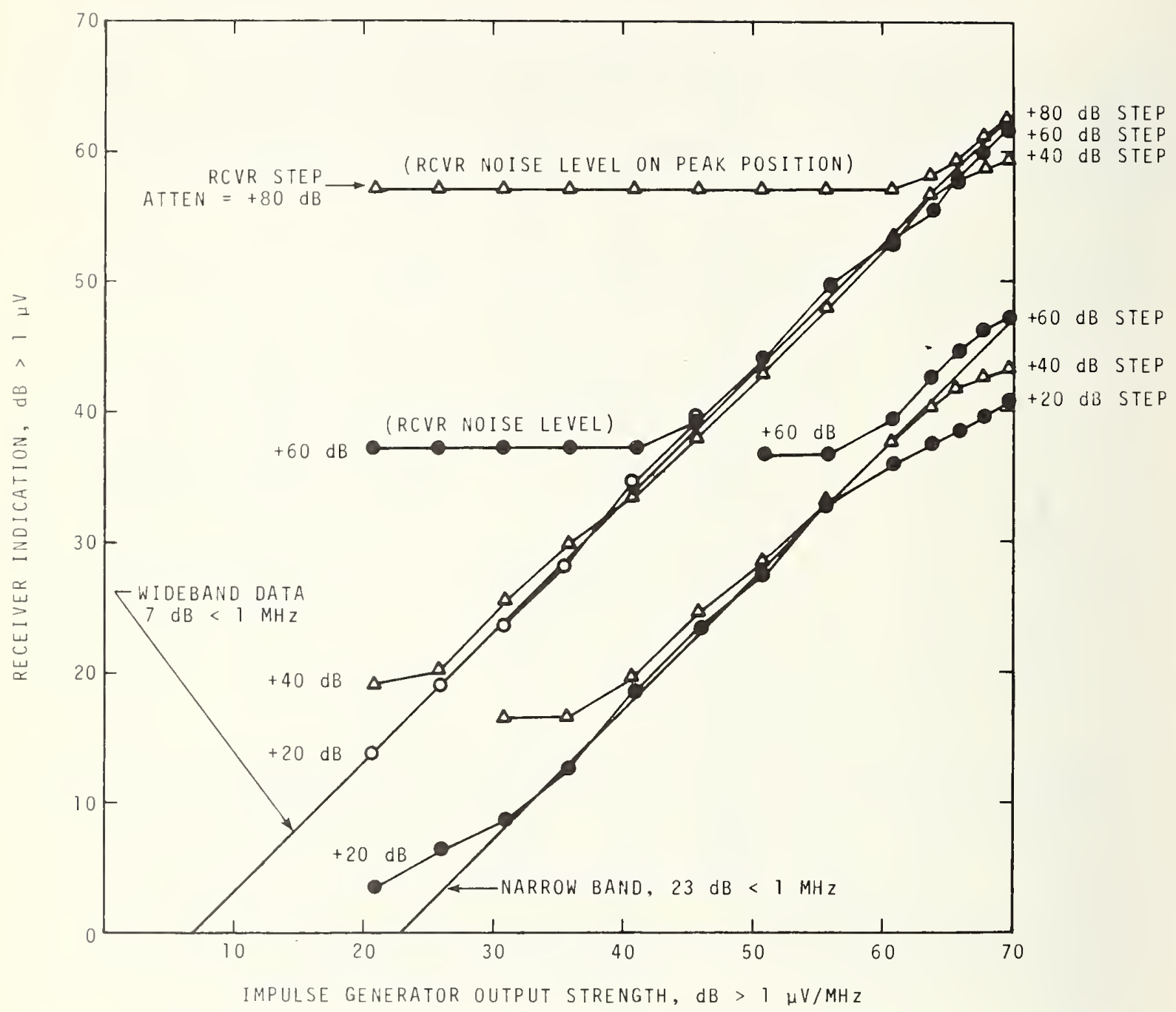

Fig. 20 Receiver Linearity for Impulse Interference (See legend and data in Figure 19) 


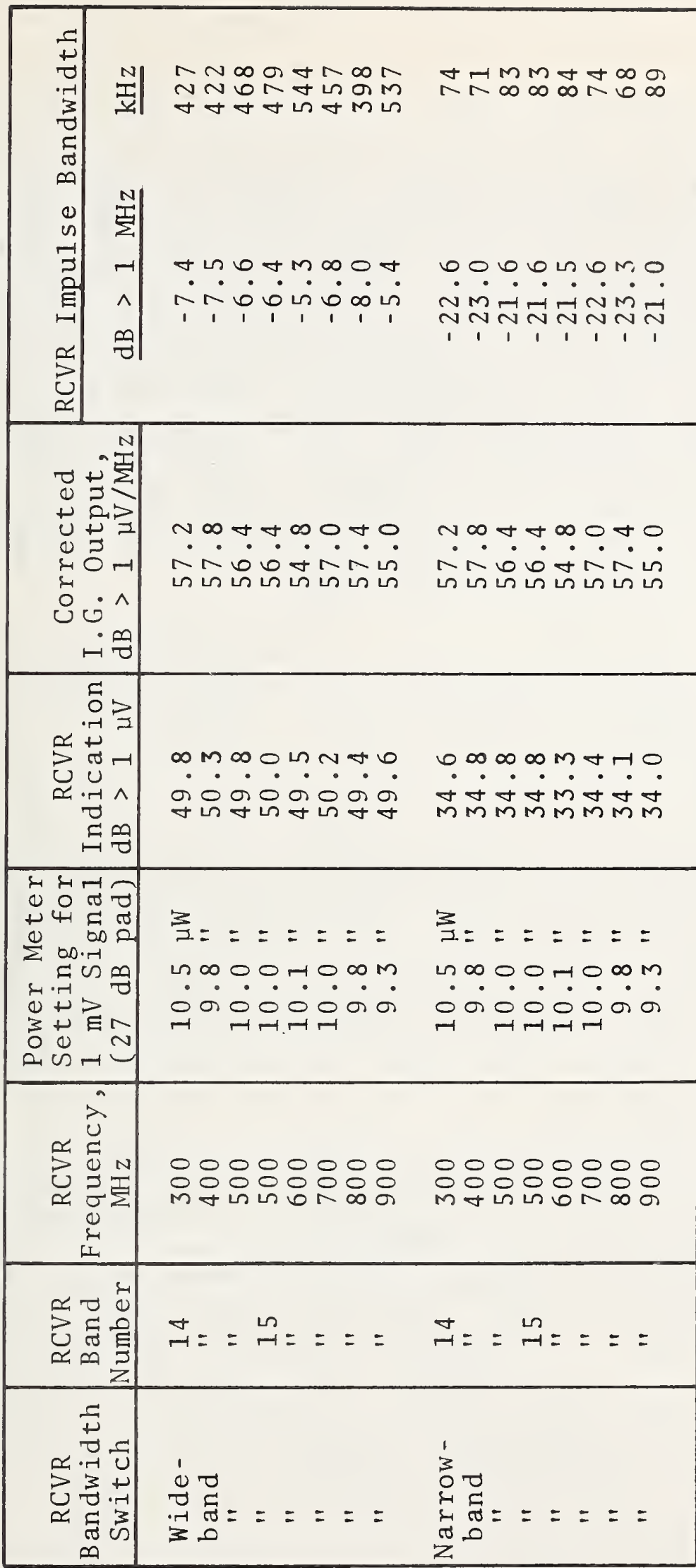

.

2

N

$\stackrel{+}{*}$

$\sum_{-1}$

巧 0

4

प

us 0

도

$+=$

.

3 E

ت

त

a

(1) 0

도

a

$\Xi$

당

(1)

约

क

तथ

$\sum \pi$

$\dot{\sim}$

bo

垊 
Measurements of pulse duration were made with a sampling oscilloscope. The switch was found to have a $12 \mathrm{~ns}$ rise time, 8 ns fall time, and a 90 ns flat-top time, when the baseband pulser was set to $100 \mathrm{~ns}$. This produces an effective pulse time, $\tau_{\text {eff, }}$ of $100 \mathrm{~ns}$ or $0.1 \mathrm{\mu s}$. Figure 23 shows a tracing of the RF burst made with a sampling-oscilloscope head and $x-y$ plotter, for the case where the baseband pulser was set to $70 \mathrm{~ns}$. In this case the measured rise time was $11 \mathrm{~ns}$ (about 5 cycles of a $450 \mathrm{MHz}$ signal), the flat-top time was $52 \mathrm{~ns}$, and the fall time was $7 \mathrm{~ns}$. The calculated effective time duration for this pulse, as seen in figure 23, is thus $11 / 2+52+7 / 2=61 \mathrm{~ns}$. It can be shown that the Fourier spectrum value, at the pulse carrier frequency, is the same for the actual pulse and for a rectangular pulse $61 \mathrm{~ns}$ long having zero rise time and zero fall time.

Examination of the oscilloscope trace of the RF pulse was done both in the coherent mode and in the incoherent mode, to study the effect of circulators, filters etc. We were able to produce a "clean" RF pulse with little overshoot, jitter, or ripple. The term "coherent pulse" is used for one which is triggered on at a zero crossing of the sine wave and which contains an integral number of RF cycles. A "circulator" is a ferromagnetic device which permits energy to flow in one direction (toward the load) with little loss, but introduces a large loss to energy flowing in the opposite direction (toward the source). Any energy reflected by the switch during the pulse off-time is dissipated in a $50 \Omega$ resistor. The oscilloscope was also used to measure a possible difference in amplitude between the steady CW voltage and the RF voltage during the pulse "on" time. No discernible amplitude difference was found.

It can be shown mathematically that if an RF pulse contains at least 15 cycles, the calculated worst-case variation in impulse strength due to non-coherence is approximately $1 \%$. For an incoherent burst with approximately 10 cycles of RF, the maximum range is $2 \%$, with an average error of $1 \%$. Thus, for carrier frequencies above $100 \mathrm{MHz}$, using an RF pulse of 0.1 us duration leads to an average amplitude jitter of only $1 \%$. For lower carrier frequencies it would be possible to use longer pulses. Also, it would be advantageous to use coherent pulses. In this case there would be no uncertainty added to the calculated value of impulse strength, even for pulses consisting of only one sine-wave cycle. 
Similar to the bandwidth measurements described previous $1 y$, the receiver was initially calibrated for CW voltage with a $27 \mathrm{~dB}$ (or $47 \mathrm{~dB}$ ) L-pad and power meter. It should be noted that the measured values of receiver impulse bandwidth, for the technique shown in figure 22 , are not changed by small differences in receiver gain, because the receiver is used only as a reference indicator. The actual measurement of bandwidth is obtained from the difference of two readings on a step attenuator, which should therefore be accurately calibrated.

A check was made to determine the effect of pulse repetition frequency (PRF) on the "peak" response readings of the FIM-2 receiver. The CW signal amplitude was adjusted to $1 \mathrm{mV}$ and the pulse time duration ( $\tau_{\text {eff }}$ ) was set to $0.1 \mu \mathrm{s}$. The readings obtained on the receiver for a signal frequency of $400 \mathrm{MHz}$ are given in the following table:

Pulse Repetition Frequency

$\begin{array}{rl}1 & \mathrm{kHz} \\ 10 & \mathrm{kHz} \\ 100 & \mathrm{kHz} \\ 1 & \mathrm{kHz}\end{array}$

Receiver Indication

$\begin{array}{llll}60.0 & \mathrm{~dB} \text { above } & \mu \mathrm{V} \\ 60.2 & \mathrm{~dB} \text { above } 1 & \mu \mathrm{V} \\ 60.4 & \mathrm{~dB} \text { above } 1 & \mu \mathrm{V} \\ 60.0 & \mathrm{~dB} \text { above } 1 & \mu \mathrm{V}\end{array}$

Checks were also made on the effect of pulse repetition frequency and duty cycle on the measured impulse bandwidth of the receiver. These tests were done with the receiver tuned to $300 \mathrm{MHz}$ or $800 \mathrm{MHz}$. In both cases, changing the PRF from 300 to $1000 \mathrm{~Hz}$ decreased the measured impulse bandwidth by about $10 \mathrm{kHz}$. Changing the PRF from 300 to $100 \mathrm{~Hz}$ increased the measured impulse bandwidth by about $10 \mathrm{kHz}$, which is negligible compared with other system errors.

The experimental procedure for measuring impulse bandwidth of a receiver, using the setup of figure 22, is quite simple. It consists of noting the receiver indication for a CW signal, turning on the solid-state switch to obtain pulsed $\mathrm{CW}$, and measuring the ratio between the two values (steady $\mathrm{CW}$ vs. pulsed RF). The measurement is made by adjusting the 3 drum step attenuator until the receiver returns to its original CW indication. The equation used is as follows (see section 3.9 for definition of terms):

$$
\operatorname{RCVR}(B W)_{i m p}=\frac{1}{\tau} \times \frac{V_{m}(t)}{V_{c}} .
$$

But $1 / \tau=10 \mathrm{MHz}$ when the applied pulses have $(\tau)_{\text {eff }}=0.1 \mu \mathrm{s}$. In other words, as shown in the following sketch, the main lobe 
of the pulse spectrum has a width of $20 \mathrm{MHz}$ (carrier frequency $\pm 10 \mathrm{MHz}$ ) for the chosen RF pulses which have a time duration of 0.1 us per pulse. This spectrum is sufficiently broad for typical receivers having bandwidths less than $0.5 \mathrm{MHz}$. Therefore the equation used for calibrating the impulse bandwidth of a receiver, which can then be used for measuring impulse interference, is as follows:

$$
\operatorname{RCVR}(B W)_{i m p}, M H z=\left(\begin{array}{ll}
10 & M H z
\end{array}\right)\left(\frac{V_{p k} \text { for pulsed RF }}{V_{C}}\right) \text {. }
$$

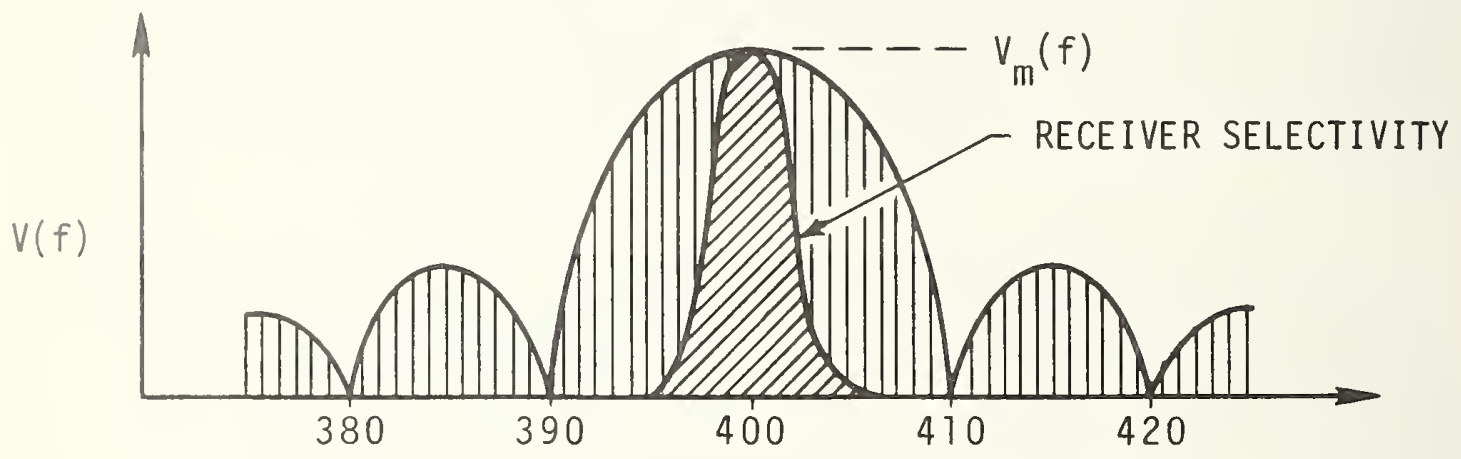

FREQUENCY, MHZ

A table of experimental data for measurements of receiver impulse bandwidth at tuned frequencies between 300 and $900 \mathrm{MHz}$ is given in figure 24. The $\mathrm{CW}$ signal level at the receiver input terminal (figure 22) was set to $1 \mathrm{mV}$ in all cases. The FIM-2 receiver was switched to the "Carr" position for $\mathrm{CW}$ signals and to the "Peak" position for pulsed-RF signals. It can be seen from figure 24 that the measured values of impulse bandwidth were in the range 537 to $589 \mathrm{kHz}$ for the wideband measurements, with average $=563 \mathrm{kHz}$ and standard deviation $=$ $16 \mathrm{kHz}$. This represents a total variation of on $1 \mathrm{y} 0.8 \mathrm{~dB}$ for all the wideband measurements. The variation when calibrating the same receiver with a baseband impulse generator (figure 21) was $2.7 \mathrm{~dB}$. The narrowband measurements (figure 24) range from 104 to $115 \mathrm{kHz}$, with average $=112 \mathrm{kHz}$ and standard deviation $=4 \mathrm{kHz}$.

An estimate of the maximum possible error in calibrating the impulse bandwidth of a receiver, using a pulsed-RF generator, can be obtained by adding the known uncertainties. (a) The RMS voltage of the CW signal before being pulsed is measured with a $50 \Omega$ power meter, which has a calibration error bound of $\pm 1 \%$ in voltage when used in a $50 \Omega$ system (e.g., figure 22). 


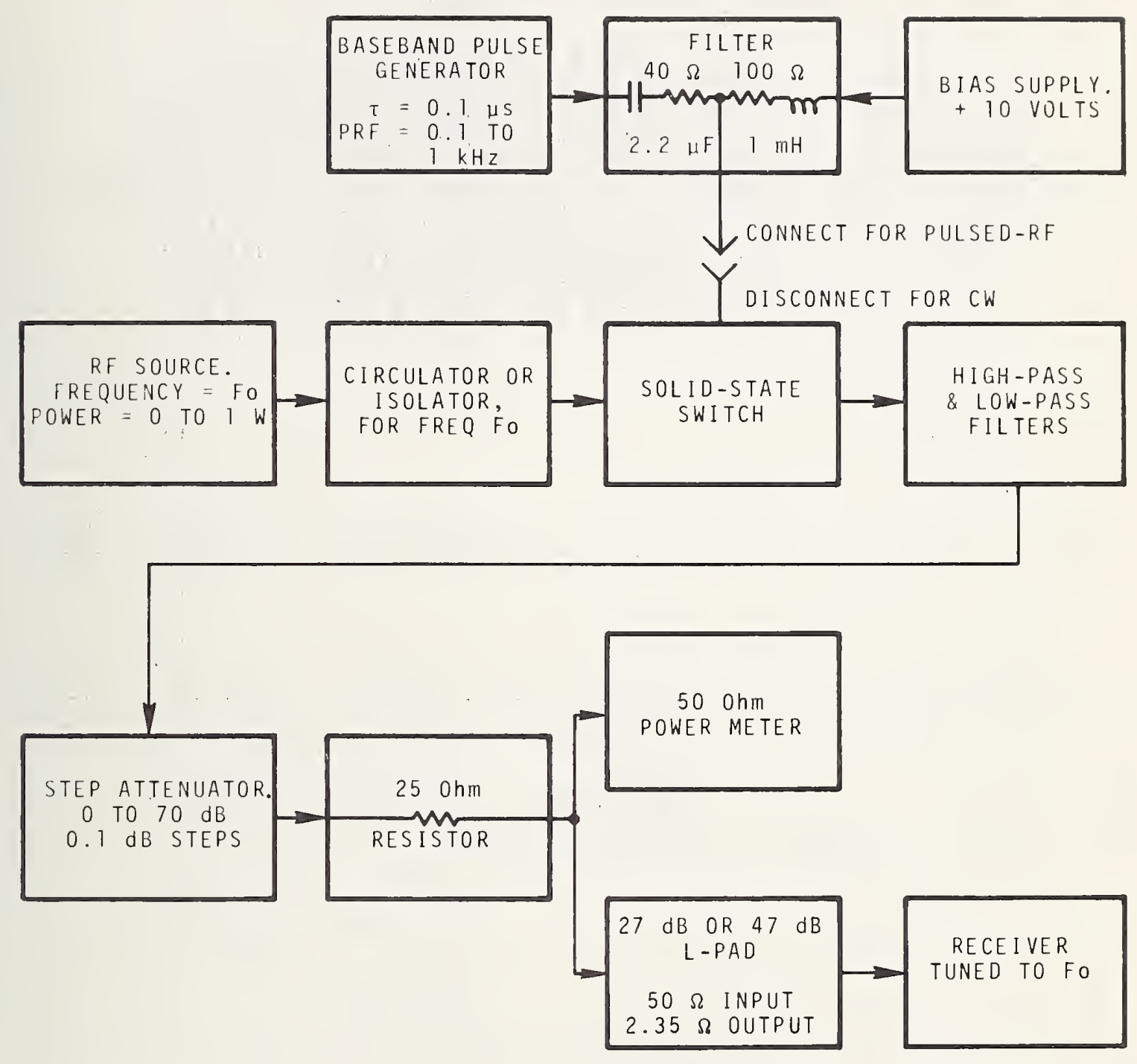

Fig. 22. Instrumentation for Calibrating Receiver Impulse Bandwidth with a Pulsed-RF Source. 


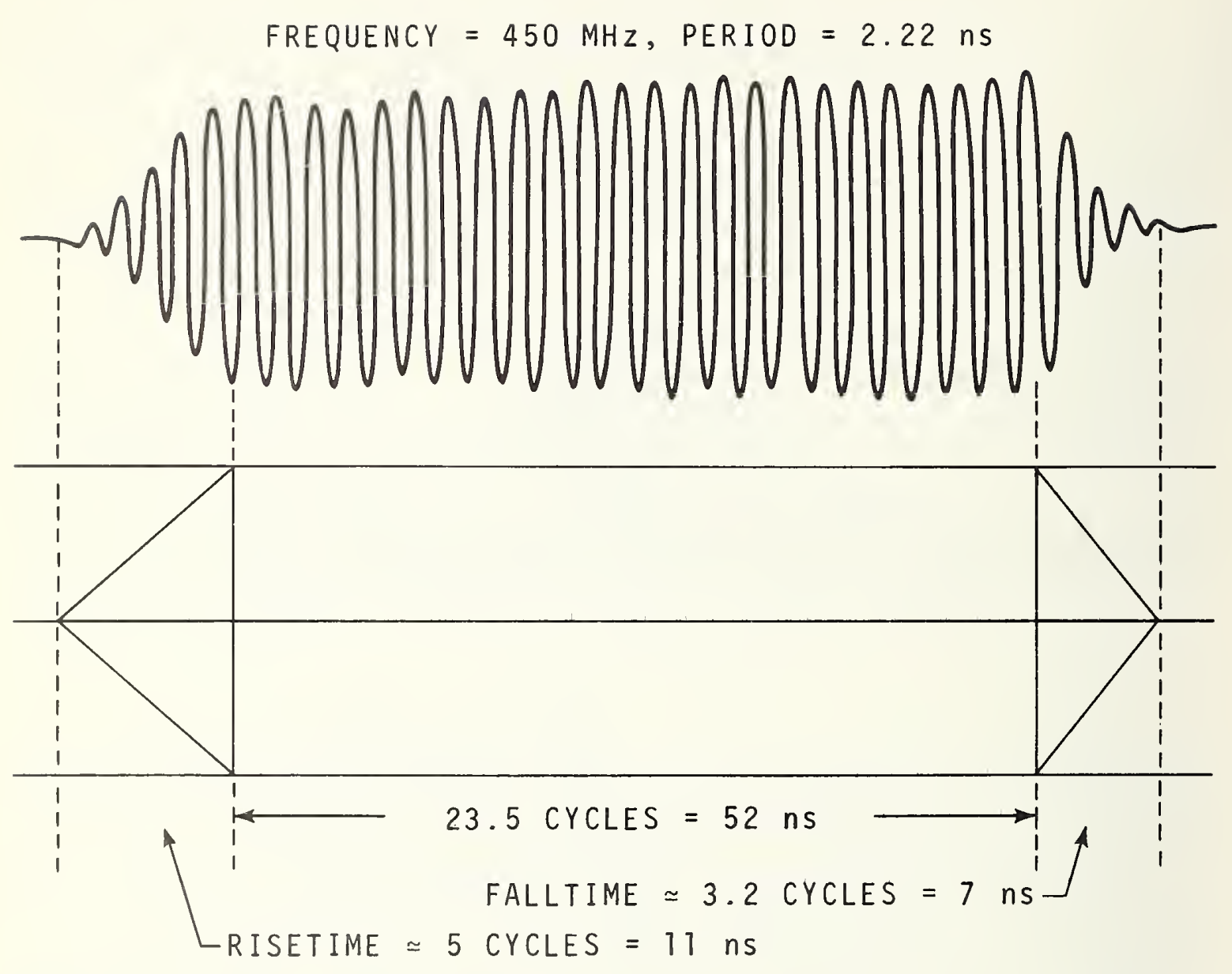

Fig. 23. Waveform of the Pulsed-RF Burst Measured With a Sampling Oscilloscope. 


\begin{tabular}{|c|c|c|c|c|c|}
\hline 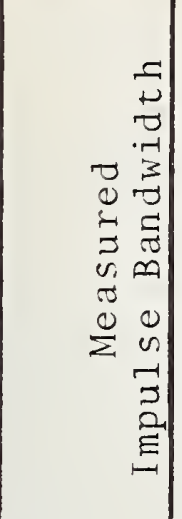 & 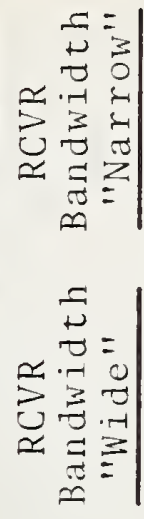 & $\stackrel{N}{I}$ & 픔ન ન્ન & & 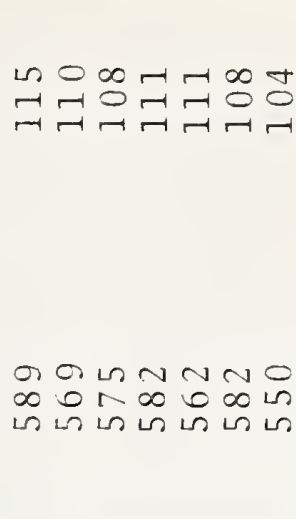 \\
\hline 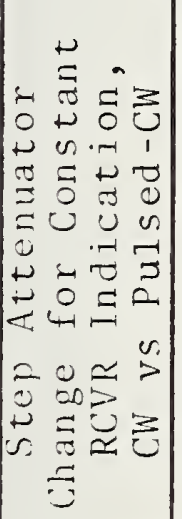 & 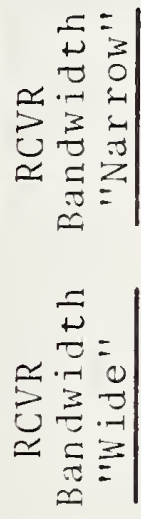 & 更 & 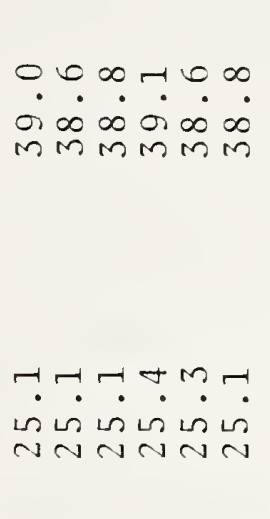 & & 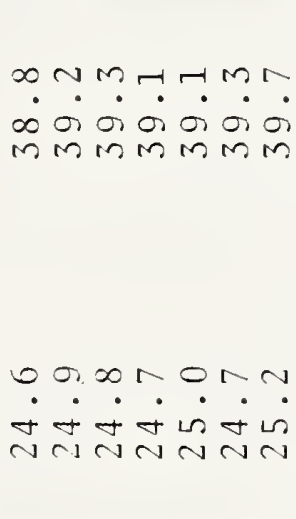 \\
\hline & 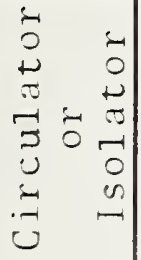 & $\stackrel{N}{E}$ & $\begin{array}{c}0 \\
n \\
m \\
1 \\
0 \\
m \\
N\end{array}=\begin{array}{l}0 \\
1 \\
0 \\
m\end{array}==$ & & 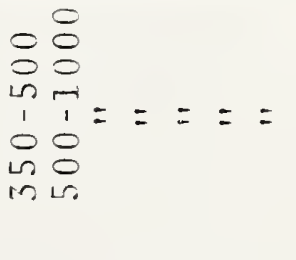 \\
\hline $\begin{array}{l}\omega \\
\text { en } \\
\text { on } \\
0 \\
1 \\
=1 \\
=\end{array}$ & 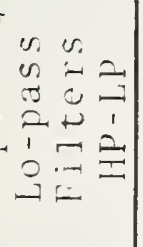 & $\stackrel{N}{E}$ & 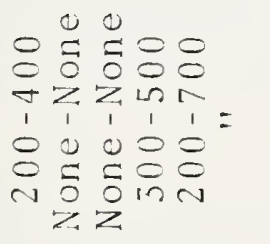 & & 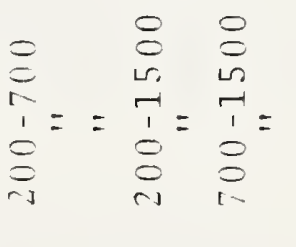 \\
\hline & 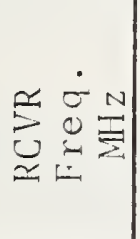 & 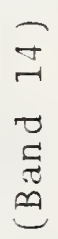 & $\underset{0}{0}=\underset{0}{0}==\underbrace{0}_{10}$ &  &  \\
\hline
\end{tabular}


(b) The effective rectangular pulse duration of the source can be measured to about $\pm 3 \%$. The error is due mainly to pulse jitter or non-uniformity in the shape and width of the RF burst. (c) The spectrum amplitude of the RF pulse decreases at the edges of the receiver passband, compared with the maximum value $V_{m}(f)$ at the $C W$ frequency. This rolloff in amplitude of the spectrum lines, due to the $(\sin \pi f \tau) /(\pi f \tau)$ envelope, is about $1 / 2 \%$ for a pulse width of 0.1 Hs and receiver bandwidth of $1 / 2 \mathrm{MHz}$. (d) The error in calibration of the step attenuator used in figure 22 is about $1 \%$. (e) Other possible variations in establishing the impulse strength of the pulsed-CW calibrator (see figure 24) are estimated to be $\pm 2 \%$. The overall uncertainty is summarized in the following table:

(a) Measurement of $\mathrm{CW}$ voltage at receiver input ter$\operatorname{minal}= \pm 1 \%$

(b) Measurement of pulse duration $= \pm 3 \%$

(c) Rolloff in amplitude of spectral lines from $V_{m}(f)=$ $-1 / 2 \%$

(d) Error in calibration of step attenuator $= \pm 1 \%$

(e) Other uncertainties in impulse strength of the calibrating source $= \pm 3 \%$.

Maximum total uncertainty $= \pm 8.5 \%= \pm 0.7 \mathrm{~dB}$.

Root-mean-square uncertainty $= \pm 2 \%= \pm 0.2 \mathrm{~dB}$.

There is also another error when measuring impulse interference with a calibrated "typical" receiver having a VSWR $\leq 1.5$, which is connected to a "typical" antenna (or unknown impulse generator to be calibrated) having a VSWR as high as 2 to 1 . This additional possible error due to system impedance mismatches for the above "typical" case is $\pm 6 \mathrm{~dB}$ or \pm a factor of two for measurement of impulse interference. It is for this reason that NBS is now developing a new "system" approach to measuring radiated interference, as mentioned on page 2 of this report.

\section{DISCUSSION OF IMPULSE INTERFERENCE AND} FOURIER TRANSFORMS

There are two possible approaches to devising a standard of impulse strength (spectral intensity): (a) design a standard receiver with calculable impulse bandwidth and use it to calibrate an unknown impulse generator, which in turn is used to calibrate an unknown receiver, or (b) design a standard (calculable) impulse generator (source) and use it to calibrate the impulse bandwidth of an unknown receiver. The first 
approach requires that the bandpass characteristics of the standard receiver (narrowband filter) be known mathematically and that it can be maintained as a stable accurate standard. The second approach was chosen in our project as being more direct, fundamental and definable.

Impulse interference, by its nature, has a spectrum content which covers a wide range of frequencies. It is assumed that a valid measurand for this type of signal is impulse strength "S", the voltage amplitude per unit of bandwidth. To simplify measurement of broadband noise, two concepts are commonly introduced: (a) equivalent rectangular bandwidth of the receiving system, and (b) impulse strength of the broadband signal. Unfortunately, several definitions of both are in use. Some of the differences in definition are trivial but nevertheless inconvenient, for example differing by a factor of 2 or $\sqrt{2}$. Some of the definitions are poorly chosen in that they are not well grounded in Fourier transform theory. More seriously, most interference literature defines impulse band-

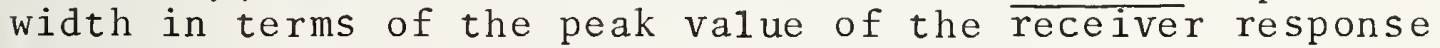
transient, $V_{m}(t)$. Such a definition lacks precision because it defines the quantity being measured, (BW) imp, in terms of the measured response by an instrument (receiver) which does not have any specified characteristics.

During the past 15 years peak measurements have become common for measuring impulse interference, particularly by military agencies and the automobile industry. One reason for its wide acceptance is the availability of inexpensive impulse generators which furnish a simple and convenient procedure for calibrating impulse bandwidth of the measuring receiver. The impulse generator most commonly found is a baseband (DC) pulser. Mathematically, the "ideal" impulse is perhaps a delta function, which assumes a DC pulse of infinite voltage, zero time duration, but known area in volts.seconds. The Fourier spectrum of this fictitious pulse has a constant amplitude and phase for all frequency components from 0 to $\infty$. It can be shown mathematically that the impulse strength of this "instantaneous" impulse in volts per hertz is numerically equal to double the area of the applied pulse in volt. seconds.

One good method of describing the response of a receiver (1inear filter network) to a short impulse is in terms of a Fourier transform pair, which then permits description in the frequency domain. This transform pair is defined mathematically as 


$$
\begin{aligned}
& V(t)=\int_{-\infty}^{\infty} V(f) e^{j 2 \pi f t} d f \\
& V(f)=\int_{-\infty}^{\infty} V(t) e^{-j 2 \pi f t} d t
\end{aligned}
$$

where: $v(t)=$ Instantaneous voltage as a function of time $V(f)=$ Transformed voltage, in volt.seconds, as a function of frequency.

In order to deal with quantities which can be handled on a digital computer it is necessary to use a finite discrete form of Fourier transform. The coefficients for the complex exponential form, for uniform time spacing of the voltage samples, are given by the equations

$$
\begin{aligned}
& v_{n}(t)=\sum_{k=0}^{N-1} v_{k}(f) e^{j \frac{2 \pi k n}{N}} \\
& V_{k}(f)=\frac{1}{N} \sum_{n=0}^{N-1} v_{n}(t) e^{-j \frac{2 \pi k n}{N}}
\end{aligned}
$$

where: $v_{n}(t)=n t h$ sample of the time wave which consists of a total of $N$ samples

$V_{k}(f)=k$ fh coefficient of the discrete Fourier trans$\begin{aligned} \mathrm{n} & =0,1,2,3, \cdots, \mathrm{N}-1 \\ \mathrm{j} & =\sqrt{-1} .\end{aligned}$

To simplify our mathematical treatment it is instructive to consider the case of a short rectangular pulse applied to an "ideal" rectangular filter. This filter (receiver) is defined as shown in the following sketch, where $H(f)$ is the receiver amplitude-vs.-frequency transfer characteristic. That is, the filter is assumed to have unity gain in the passband and zero gain elsewhere. Also, it is assumed that the phase change across the bandwidth is linear, following the relation $\phi(f)=(2 \pi)\left(f_{0}-f\right)\left(t_{0}\right)$, where $f_{0}$ is the center frequency of the passband and $t_{0}$ is the transmission time of the filter. In this case the transfer function is given by $H(f)=|H(f)| e^{j \phi(f)}$. 


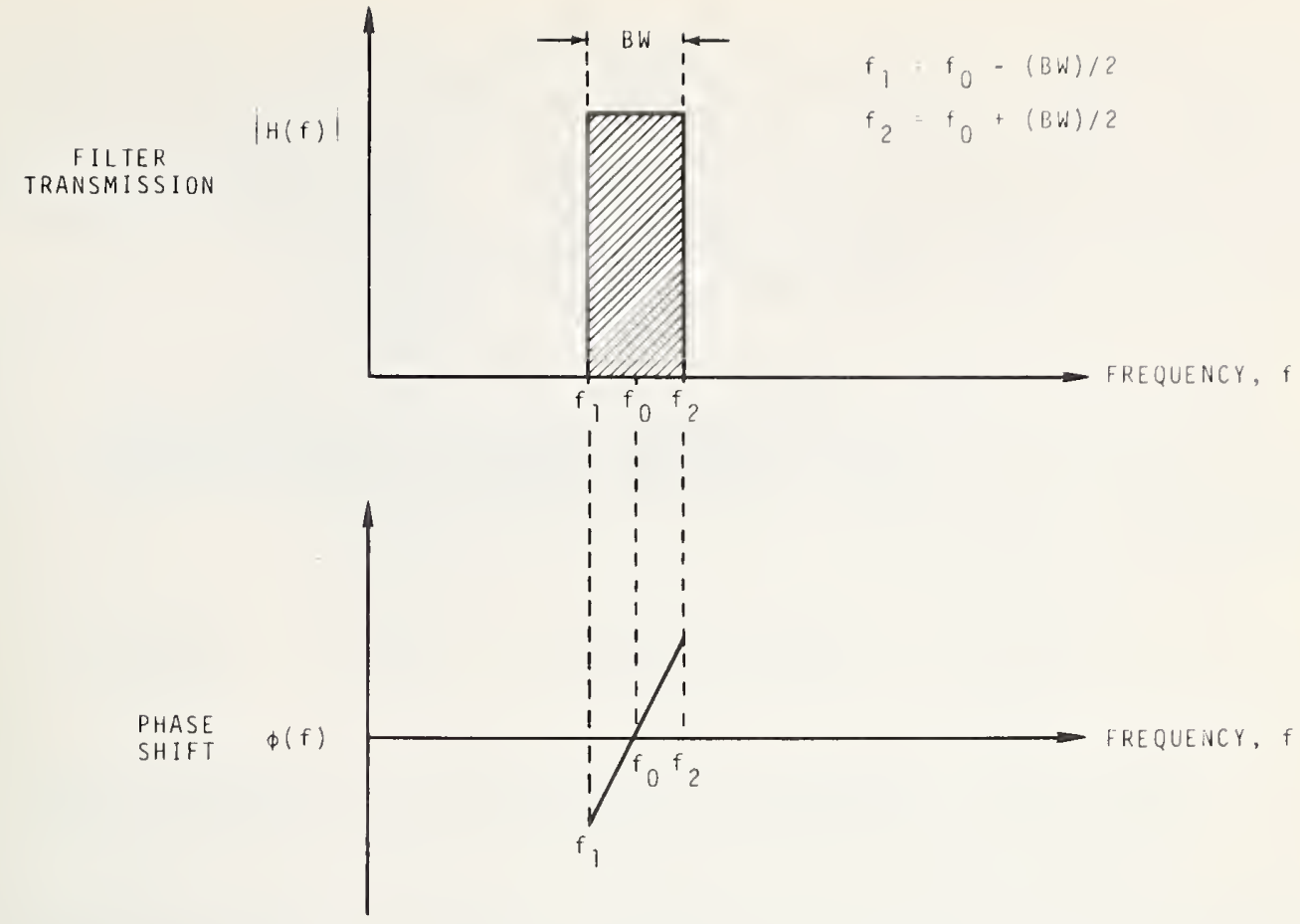

The time-domain response of this ideal filter to rectangular DC pulses can be found by using Fourier methods. First, by taking the Fourier transform of a rectangular pulse, one obtains the frequency spectrum as shown in the following sketch. The mathematical expression is

$$
V(f)=V_{0} \tau\left(\frac{\sin \pi f \tau}{\pi f \tau}\right),
$$

where: $V_{0}=$ Voltage amplitude of DC pulse $\tau=$ Time duration of rectangular pulse, seconds.
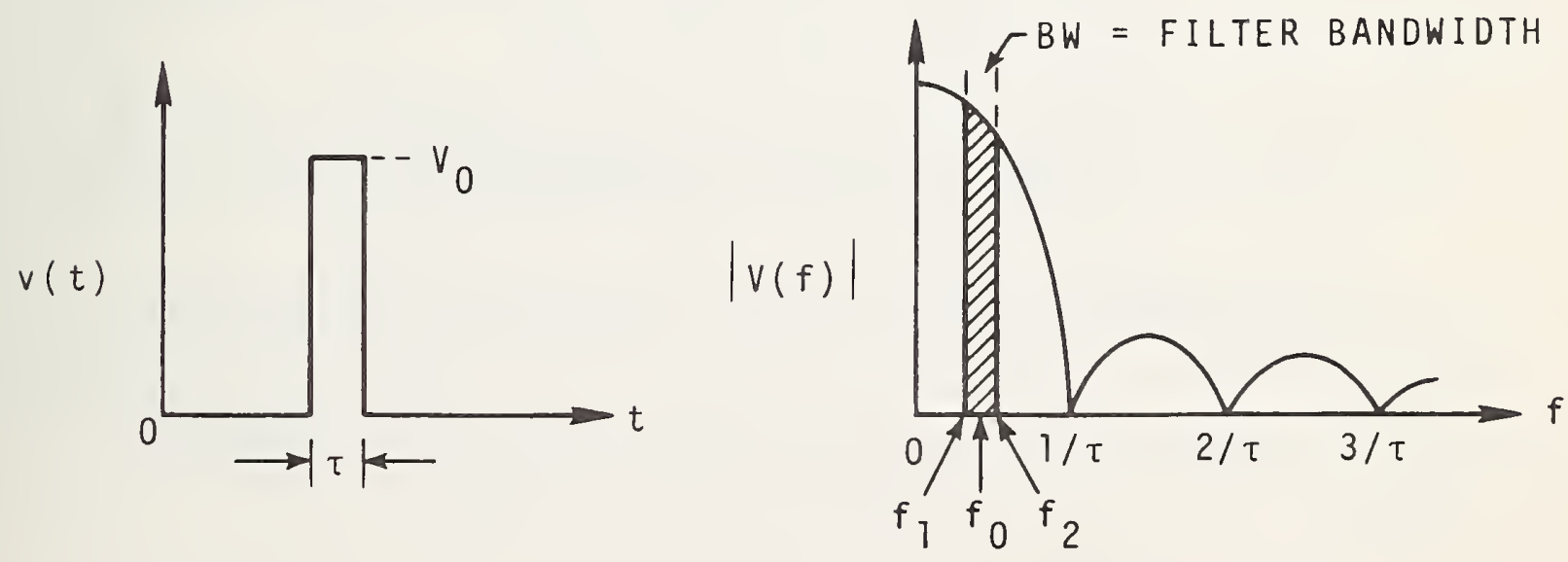
Multiplying the above expression $V(f)$ for the frequency spectrum, by the filter frequency response function $H(f)$ shown previously, one obtains the frequency spectrum of the filter output. That is, $G(f)=V(f) x H(f)$. The time-domain response of the ideal filter output to DC pulses can then be found by applying the inverse Fourier transform to $G(f)$.

$$
v(t)=\int_{-\infty}^{\infty} V(f) \times|H(f)| e^{j[2 \pi f t+\phi(f)]} d f .
$$

Because $H(f)$ is an even function of frequency and $\phi(f)$ is an odd function of frequency, this reduces to

$$
\begin{aligned}
v(t) & =2 \int_{0}^{\infty} V(f) \times|H(f)| \cos \left[2 \pi f\left(t-t_{0}\right)+2 \pi f_{0} t_{0}\right] d f \\
& =2 V_{0} \tau \int_{f_{1}}^{f_{1}}\left(\frac{\sin \pi f \tau}{\pi f \tau}\right) \cos \left[2 \pi f\left(t-t_{0}\right)+2 \pi f_{0} t_{0}\right] d f .
\end{aligned}
$$

The limits of the above integral are from $f_{1}$ to $f_{2}$ because $|H(f)|$ is unity between these limits and zero elsewhere.

The above integral can be evaluated approximately if it is assumed that the value of $(\sin \pi f \tau) /(\pi f \tau)$ changes so little in the range $f_{1}$ to $f_{2}$ that it may be considered a constant. This corresponds to the requirement that the filter bandwidth (BW) is small compared with $(1 / \tau)$. In other words, for a broadband signal and narrowband receiver, the value of $V(f)$ is essentialiy constant over the receiver passband. In this case the (sin $\pi f \tau) /(\pi f \tau)$ part of the expression may be moved outside the integral. Using the trigonometric identity $\sin A-\sin B=2 \sin \left(\frac{A-B}{2}\right) \cos \left(\frac{A+B}{2}\right)$, and the approximation $\left(f_{1}+f_{2}\right) \simeq 2 f_{0}$, leads to the final solution:

$$
\begin{aligned}
v(t) & \simeq\left(2 V_{0} \tau\right)\left\{\frac{\sin \pi f_{0} \tau}{\pi f_{0} \tau}\right\}(B W)\left\{\frac{\sin (\pi)(B W)\left(t-t_{0}\right)}{(\pi)(B W)\left(t-t_{0}\right)}\right\} \cos \left(2 \pi f_{0} t\right) \\
& \equiv\left(2 V_{0} \tau\right)(B W)\left(\operatorname{sinc} \pi f_{0} \tau\right)\left[\operatorname{sinc}(\pi)(B W)\left(t-t_{0}\right)\right] \cos \left(2 \pi f_{0} t\right) .
\end{aligned}
$$

Eq. (30) assumes that the receiver gain has been normalized to unity. 




A picture of the expression for $v(t)$ is shown in the sketch above. As indicated on this sketch, the envelope of the response voltage given by eq. (30) comes from the function sinc $(\pi)(B W)\left(t-t_{0}\right)$. As can be seen from this expression, the time duration of the receiver response ringing is inversely proportional to the bandwidth (BW), because smaller values of (BW) lead to a slower decay in the envelope-amplitude function.

An oscilloscope trace of the time-domain response given by eq. (30) can be obtained from the IF output jack of the usual FIM receiver. This approach to defining impulse bandwidth is described in section 3.2. The maximum value of the detected envelope of this transient response is the receiver peak-mode indication. The mathematical value of the peak reading can be obtained by differentiating the envelope of $v(t)$ with respect to time, setting this equal to zero, and then solving the equation for the peak voltage $V_{m}$. This gives

$$
V_{m}(t)=\left(2 V_{0} \tau\right)\left(\operatorname{sinc} \pi f_{o} \tau\right)(B W)_{i m p} \cdot
$$

The peak response for this ideal case is seen to be proportional to the strength of the applied impulse $\left(2 \mathrm{~V}_{0} \tau\right)$ and to the receiver impulse bandwidth (BW) $i m p$. If the receiver is tuned to a frequency $f_{0}$ which is close to zero, or at least a frequency which is low compared with the first spectral zero at $f=1 / \tau$, then the function (sinc $\pi f_{0} \tau$ ) is approximately equal to unity, and

$$
\mathrm{V}_{\mathrm{m}}(t) \simeq\left(2 \mathrm{~V}_{\mathrm{o}} \tau\right)(B W)_{\mathrm{imp}} \cdot
$$


We were able to obtain greater measurement precision and repeatibility when using a pulsed-RF generator as a standard impulse source, compared with a baseband pulser, as mentioned on page 46, If the impulses applied to a receiver consist of pulsed RF, the mathematical solution for $V_{m}(t)$ is very similar to eq. (32). However, the frequency-domain sketch for $|V(f)|$ is now symmetrical about the filter tuned frequency $f_{0}$, rather than being one-sided with maximum amplitude at zero frequency. This is illustrated by the sketches on pages 12 and 15. Theory indicates that if the receiver bandwidth is small compared with $(1 / \tau)$, where $\tau$ is the time duration of the RF pulse, the peak response of a receiver tuned to $f_{0}$ is equal to the product of receiver bandwidth and the Fourier spectrum value at the receiver tuned frequency. That is,

$$
V_{m}(t) \simeq\left(V_{1} \tau\right)(B W)_{i m p} \cdot
$$

When a pulse is impressed on a linear filter network, Fourier methods can be used to analyze the filter response. For simplicity of analysis it was assumed above (incorrectly) that the receiver of an interference meter is a linear device. Also, it should be noted that a single pulse cannot actually be resolved into a Fourier series. However, the frequency spectrum of a pulse can be approximated and interpreted by considering a train of identical repetitive pulses, letting the period $T$ approach infinity while the time duration per pulse $\tau$ remains constant. The amplitudes of the spectral components of the pulses are indicated qualitatively in the following sketches, for progressively smaller values of duty cycle $\tau / T$, where $V_{0}$ is the voltage of each pulse. It is seen that for a single rectangular pulse the lines become infinitesimally close together, forming a continuous spectrum rather than a line spectrum. 


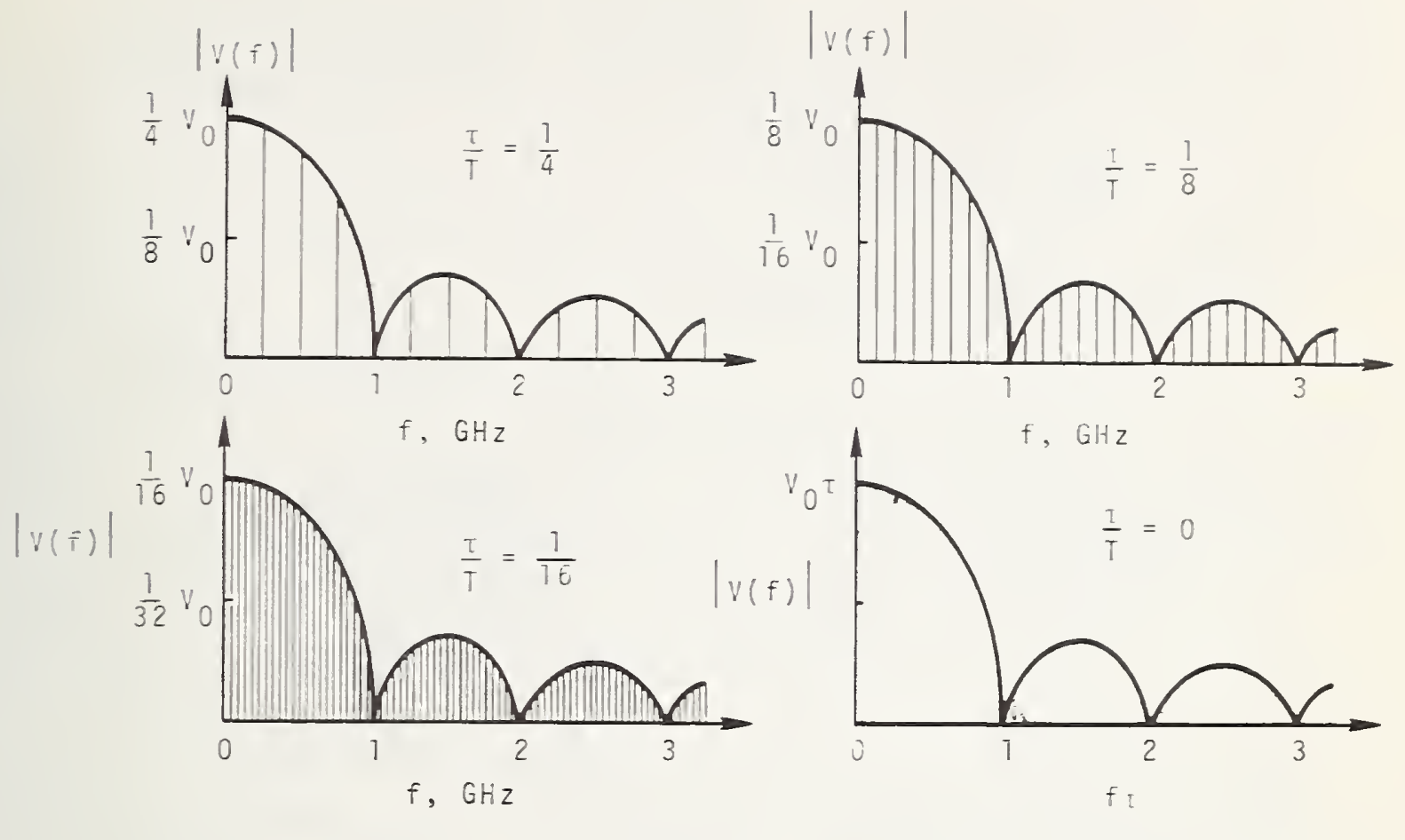

It is interesting to examine the relations between the "strength" of an impulse, the energy content, and the "power" of an impulse source. This can be derived easily for baseband pulses, as follows:

Impulse strength $=2 \mathrm{~V}_{0} \tau$, dimensions of volt.seconds,

Energy delivered per pulse $=\frac{V_{0}^{2} \tau}{R}=\frac{V_{0}^{2} \tau}{50}$, joules

$$
\begin{aligned}
& \text { Average power delivered }=\text { (Energy per pulse) } \text {. } \\
& \text { (pulses per second) } \\
& =\text { Energy/sec } \\
& =\frac{\left(V_{0}^{2} \tau\right)(P R F)}{50} \text {, watts. }
\end{aligned}
$$

It is also interesting to examine how a narrowband filter network "stretches" a pulse in the time domain. The narrower the receiver bandwidth (higher circuit Q), the longer is the time required for the receiver pulse to decay. That is, the 
narrowe $r$ the bandwidth, the longer the receiver remains "inoperative" after each input pulse, due to the so-called IF ringing. The effect of an interference impulse on a typical FIM receiver is shown qualitatively in the following sketches.


$v(t)$

IF AMPLIFIER OUTPUT
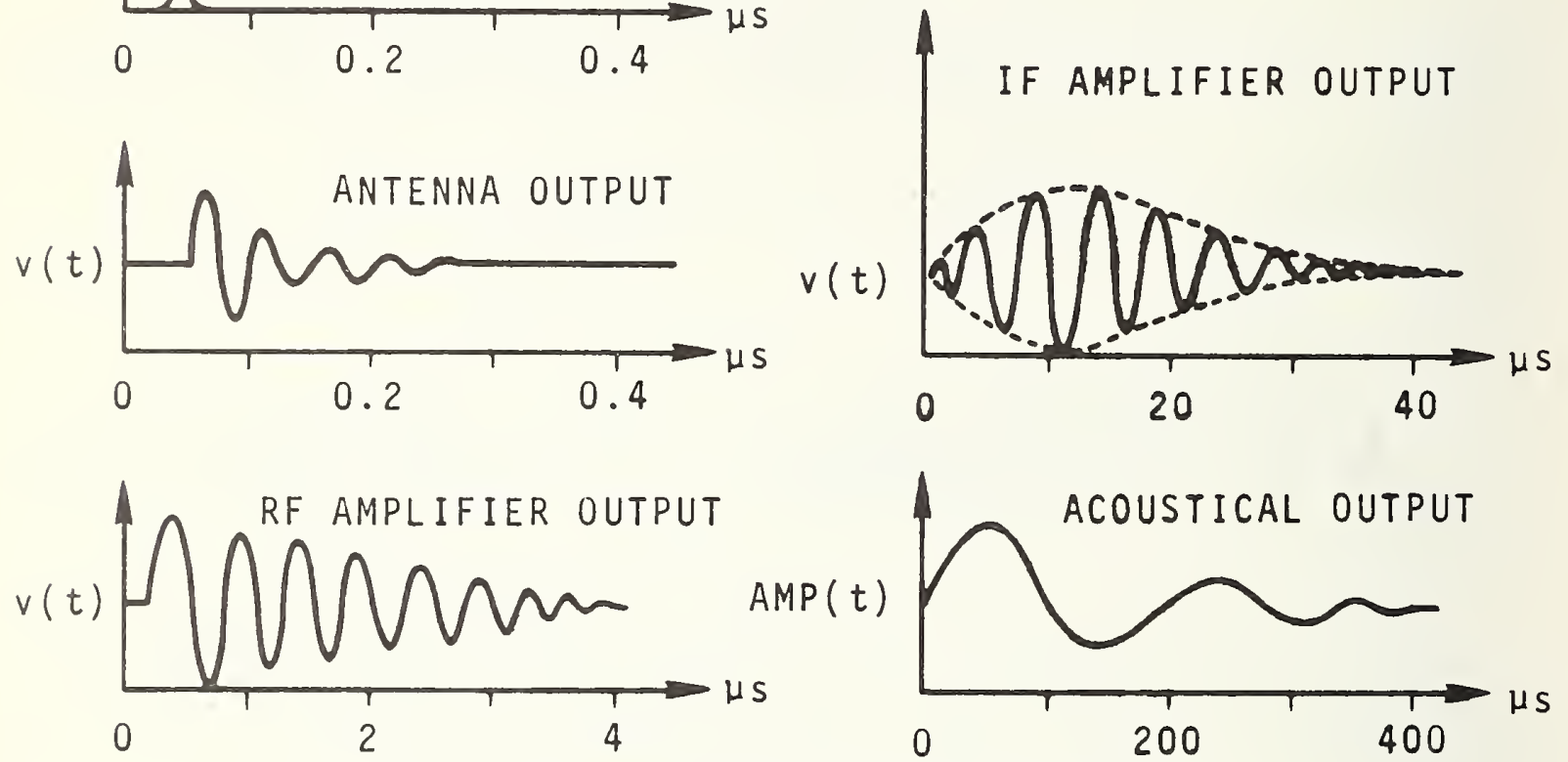

6. SUMMARY AND CONCLUSIONS

The term "bandwidth" is used both for the frequency spectrum of a signal and for the size of "window" in the viewing receiver. The term "narrowband" or "broadband" interference is used according to whether the frequency spectrum of the signal is small or large relative to the bandwidth of the measuring receiver. In order to quantize a broadband signal it is necessary to use a unit of measurement involving the receiver bandwidth, such as volts/hertz. Even though two filter circuits may have the same frequency selectivity according to the customary CW voltage-response-vs.-frequency bandwidth, they may nevertheless show different responses to the same broadband interference. It is thus necessary to define socalled effective bandwidths for a receiver.

Broadband interference is generally divided into two categories, random noise and impulse interference, as discussed on page 4. Mixtures of the two types can also occur in practice, but we have considered only the ideal cases in this report. Random noise (nonperiodic broadband signal) is best 
characterized by its power spectral density, that is by the mean square value of signal passed through the receiver bandwidth. This quantity is defined on page 6. The square root of random noise is often used as a measurand and is sometimes labeled as RMS noise level, with the units of volts/ $\sqrt{\text { hertz }}$ or volts per root hertz. Impulse interference (uniform periodic pulses) is best characterized by its impulse strength, a voltage-time unit (volt•seconds), or by its spectral intensity, a voltage per unit bandwidth quantity (volts/hertz). This quantity may be defined in terms of Fourier transforms as discussed in section 5 .

Several methods for calibrating the so-called impulse bandwidth of a measuring receiver have been analyzed and checked at NBS. The approach described in sections 3.9 and 4.5 , that of pulse-modulating a $\mathrm{CW}$ carrier, was the best of those we considered. It is theoretically sound, and experimentally it is simple and direct. The measured data are not as precise as those obtained from a stepped-CW approach, but are more meaningful for measuring impulse quantities, besides avoiding the complicated and tedious task of numerical integration.

The type of "known" impulse source chosen in our project involves measuring the voltage and effective time duration of a rectangular RF burst, and calculating the impulse strength from this information. The maximum total uncertainty of this "standard" source for calibrating receiver impulse bandwidth was found to be $\pm 0.7 \mathrm{~dB}$, with a root mean square error of $0.2 \mathrm{~dB}$. We were able to produce a clean RF pulse with 11 ns risetime, 7 ns falltime, and low ripple. The gating time is adjustable but we chose an effective pulse length of $0.1 \mu \mathrm{s}$ in our experiments, which covered a frequency range of 100 to $1000 \mathrm{MHz}$.

A table summarizing our measured values of receiver bandwidth, for various definitions, is given in figure 25 . Most of these data are shown graphically in figure 26 . It can be seen that all the stepped-CW bandwidth curves have a similar shape. That is, if one type of bandwidth is measured as a function of receiver frequency, for example the $6 \mathrm{~dB}$ bandwidth, then the other bandwidths can be found approximately by multiplying this value by some factor. The same observation could be made for the $10 \mathrm{~dB}$ and $20 \mathrm{~dB}$ bandwidths, which are not shown in the graph. It can also be seen in figure 26 that the equivalent-rectangular, voltage-response bandwidth was always greater than the $6 \mathrm{~dB}$ bandwidth, and that the random-noise bandwidth was always greater than the $3 \mathrm{~dB}$ bandwidth. These statements hold true for both the wideband and narrowband data. 


\begin{tabular}{|c|c|c|c|c|}
\hline 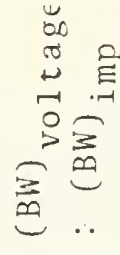 & 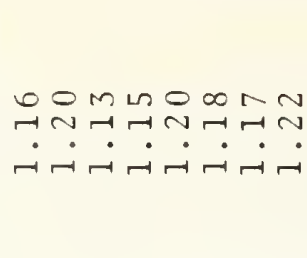 & $\begin{array}{l}0 \\
\sim 00 \\
\dot{1} 0\end{array}$ & 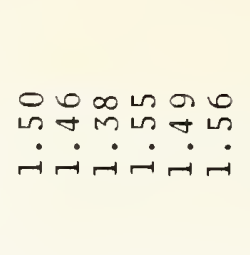 & $\begin{array}{l}0 \\
\text { or } 010 \\
\forall \dot{r} \\
\dot{r}\end{array}$ \\
\hline 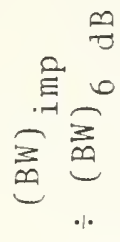 & 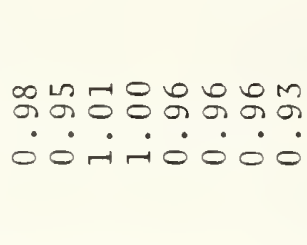 & $\begin{array}{l}\text { a } \\
\text { a } 010 \\
0 \text { i }\end{array}$ & 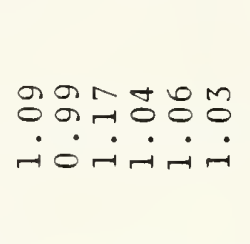 & $\begin{array}{l}m \\
0 \\
0 \\
\dot{r}\end{array}$ \\
\hline 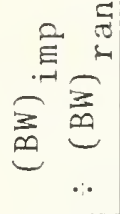 & 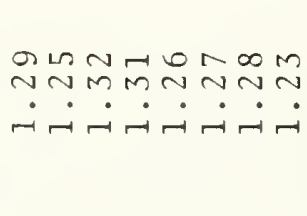 & 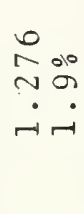 & 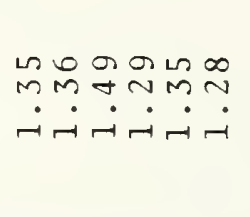 & $\begin{array}{l}m \\
\text { in olo } \\
m \text { in } \\
\dot{m} \dot{m}\end{array}$ \\
\hline 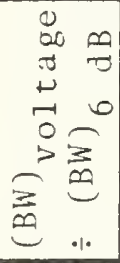 & 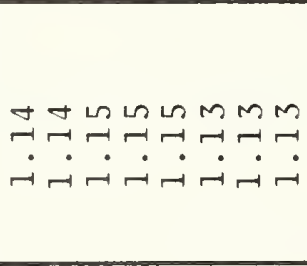 & 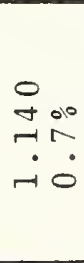 & 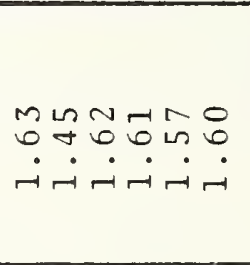 & 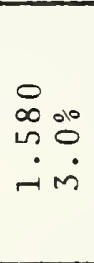 \\
\hline$\sum_{\infty}^{\infty} \underbrace{\infty}_{\cdots}$ & 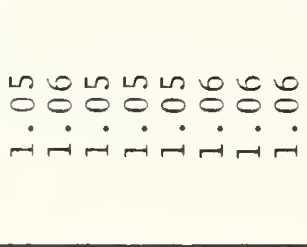 & 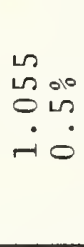 & 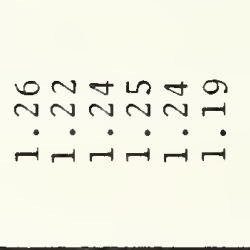 & $\begin{array}{l}m \text { olo } \\
\text { Min } \\
\dot{r} \text {. }\end{array}$ \\
\hline 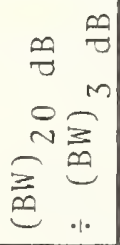 &  & $\begin{array}{l}m \\
\infty \\
\infty \\
\dot{N} 0\end{array}$ & 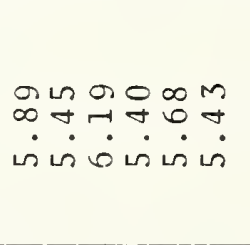 & $\begin{array}{l}m \\
\dot{b}\end{array}$ \\
\hline 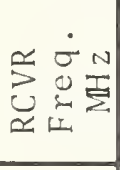 & 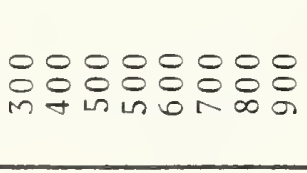 & $\begin{array}{l}3 \\
0 \\
0 \\
\geq \\
\geq \\
\geq \\
\geq\end{array}$ & 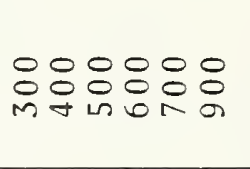 & $\begin{array}{c}3 \\
0 \\
0 \\
3 \\
3 \\
3 \\
3 \\
3\end{array}$ \\
\hline 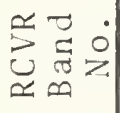 & $\vec{\Delta}==\frac{n}{\sim}===$ & & $\vec{\oplus}==\frac{\omega}{n}=$ & \\
\hline 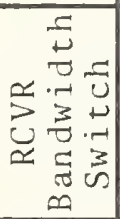 & $\begin{array}{l}\frac{0}{\partial}======= \\
\frac{1}{3}\end{array}==$ & & $\begin{array}{l}3 \\
0 \\
\sum_{n=1}^{3} \\
z \\
z\end{array}====$ & \\
\hline
\end{tabular}




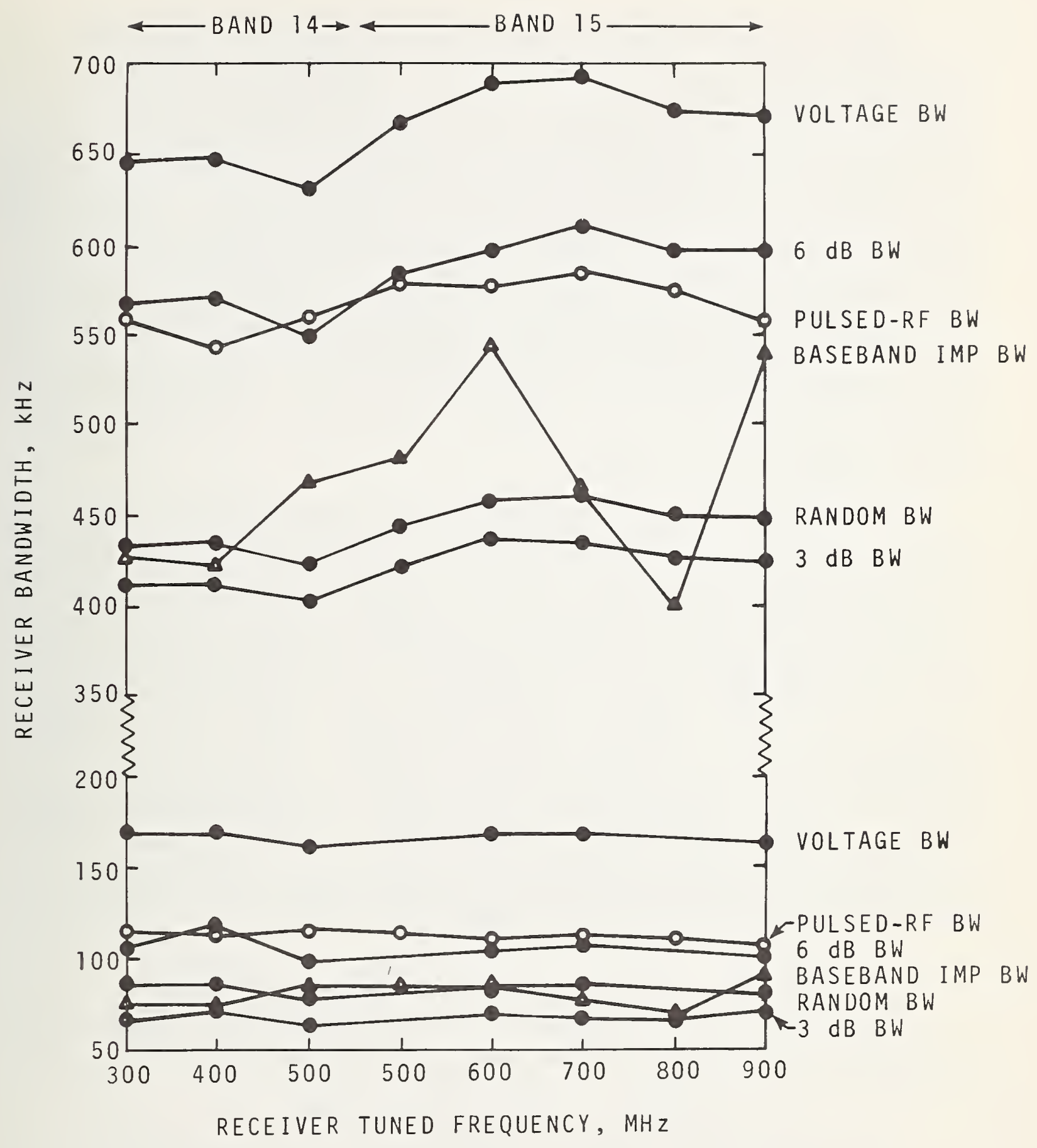

Fig. 26. Measured Bandwidths of the FIM-2 Receiver. 
The two sets of data for impulse bandwidth have more variation than any of the stepped-CW bandwidths. The variability is especially high when using the baseband pulser as a standard impulse calibrator. In fact, the data for the baseband pulser appear to be low and somewhat inconsistent. In some cases the measured impulse bandwidths, using the baseband pulser, were less than the random-noise bandwidth. Considering, therefore, only the data for the pulsed-RF impulse calibrator, the measured receiver impulse bandwidths were approximately equal to the $6 \mathrm{~dB}$ bandwidth. This is an approximation which has often been used in practice. For the measurements given in figures 25 and 26, covering frequencies from 300 to 900 $\mathrm{MHz}$, the average difference between the $6 \mathrm{~dB}$ bandwidth and this impulse bandwidth is approximately $5 \%$. The maximum difference between these two types of bandwidth was $7 \%$ for the wideband measurements (at $900 \mathrm{MHz}$ ) and $17 \%$ for the narrowband measurements (at $500 \mathrm{MHz}$ ).

It is instructive to examine the ratios between the various types of receiver bandwidth measured here, and compare these with the corresponding values reported elsewhere in the EMC literature for typical FIM's. The ratios between the effective bandwidths defined in section 3 depend mainly on the shape of the receiver selectivity curve. This, in turn, is determined primarily by the IF amplifier characteristics. Thus, in general, the ratio $(B W)_{\text {imp }} \div\left({ }^{(B W}\right)_{\text {ran }}$ is somewhat independent of the receiver tuned frequency. For example, the calibration charts supplied with our FIM-1 receiver give graphs for random-noise bandwidth only. A multiplying factor of 1.35 is then specified to convert this bandwidth to impulse bandwidth, for any receiver-tuned frequency of interest. According to the FIM-1 calibration charts, the impulse bandwidth of this receiver can also be obtained by multiplying the $6 \mathrm{~dB}$ bandwidth by 1.055. That is,

$$
(B W)_{i m p}=(B W)_{\operatorname{ran}} \times 1.35=(B W)_{6 \mathrm{~dB}} \times 1.055 \text {. }
$$

According to an example given in "ITEM 1972," page 73 of reference $[8],(B W)_{\text {ran }}=(B W)_{3} \mathrm{~dB} \times 1.07$, and

$$
(B W)_{i m p}=(B W)_{6} \mathrm{~dB} \times 1.093 \text {. }
$$

The multiplying factors suggested by the HewlettPackard Company for use with their spectrum analyzers [15] are given as follows:

$$
(B W)_{\text {imp }} \simeq(B W)_{3} \mathrm{~dB} \times 1.5 \simeq(B W)_{6} \mathrm{~dB}^{\cdot}
$$


The peak response to repetitive pulses, according to "HP Application Note 150-2," has been established and is essentially independent of pulse shape and repetition frequency. For the synchronously-tuned stages used in their IF amplifier, the claimed effective impulse bandwidth is 1.5 times the $3 \mathrm{~dB}$ bandwidth. However, several conditions must be satisfied before this factor can be used, as specified in [15]. They are: (a) The $3 \mathrm{~dB}$ bandwidth must be > (1.7)(PRF), (b) The product of $3 \mathrm{~dB}$ bandwidth and pulse width must be $<0.1$, (c) The peak-pulse amplitude at the mixer input must be less than that which begins to produce compression, (d) The receiver must respond to each pulse independently; that is, the ringing caused by one pulse must decay before the next pulse occurs, (e) The ratio $\tau / T \equiv$ duty cycle must be $<0.05$, and (f) The product of PRF and spectrum-analyzer scan time must be > 10 .

A report for the U.S. Navy [2] describes a slightly more complicated procedure for estimating a receiver's impulse bandwidth from measurements of voltage-response bandwidth. In this approach, use is made of a "shape factor" defined as the ratio of $20 \mathrm{~dB}$ bandwidth to $3 \mathrm{~dB}$ bandwidth. It is then necessary to use this "shape factor" to look up a so-called "correction factor." Finally the receiver impulse bandwidth and random-noise bandwidth are calculated from the measured $6 \mathrm{~dB}$ and $3 \mathrm{~dB}$ bandwidths. This approach is demonstrated by the following example, for the FIM-2 receiver tuned to a frequency of $300 \mathrm{MHz}$. From the data of figure 25,

$$
\text { "Shape factor" }=\frac{(B W)_{20 \mathrm{~dB}}}{(\mathrm{BW})_{3 \mathrm{~dB}}}=\frac{1170 \mathrm{kHz}}{409 \mathrm{kHz}}=2.86 \text {. }
$$

The "correction factors" for this situation are found from a graph in [2] to be 1.075 for impulse bandwidth and 1.091 for random-noise bandwidth. Therefore

$$
\begin{aligned}
& (B W)_{\text {imp }}=\left(\begin{array}{c}
\text { correction } \\
\text { factor } 1
\end{array}\right)(B W)_{6 \mathrm{~dB}}=(1.075)(566 \mathrm{kHz})=608 \mathrm{kHz} \text {, } \\
& (B W)_{\text {ran }}=\left(\begin{array}{c}
\text { correction } \\
\text { factor } 2
\end{array}\right)(B W)_{3} \mathrm{~dB}=(1.091)(409 \mathrm{kHz})=446 \mathrm{kHz} \text {. }
\end{aligned}
$$

This compares with our measured bandwidth values given in figure 25 as

$$
\begin{aligned}
& (B W)_{\text {imp }}=556 \mathrm{kHz} \quad(9.4 \% \text { lower }) \text {, and } \\
& (B W)_{\text {ran }}=431 \mathrm{kHz} \quad(3.5 \% \text { lower }) .
\end{aligned}
$$


Theoretically-derived bandwidth ratios have also been reported in the literature [2]. The conclusions for several types of filter networks are summarized here as follows:

(a) Rectangular passband, linear phase, $(B W)_{\text {imp }}=(B W)_{\text {ran }}$

(b) Gaussian passband, linear phase, $(B W)_{i m p}=(\sqrt{2})(B W)_{\text {ran }}$

(c) Triangular passband, linear phase, $(B W)_{\text {imp }}=(3 / 2)(B W)_{\mathrm{ran}}$

(d) Single resonant tank, actual phase, $(B W)_{i m p}=(2)(B W)_{\text {ran }}$

(e) Single resonant tank, linear phase, $(B W)_{\text {imp }}=(\infty)(B W)_{\mathrm{ran}}$

(f) Cascaded double-tuned IF transformers



From the above table it can be concluded that for most amplifiers used in interference meters, impulse bandwidth is 5 to 10 percent above the $6 \mathrm{~dB}$ bandwidth, and random-noise bandwidth is 10 to 15 percent above the $3 \mathrm{~dB}$ bandwidth.

Based on data taken at NBS with a pulsed-RF source, it is concluded that impulse bandwidth of a receiver is not related in any simple way to the $6 \mathrm{~dB}$ bandwidth or to the random-noise bandwidth. In all cases, however, the bandwidth is determined primarily by the IF amplifier characteristics. The usually-assumed approximation, that of a rectangular bandpass with linear phase function, is not physically realizable. In fact, this shape of passband is not even desirable for measurement of impulses. A synchronously-tuned IF amplifier produces a more optimum response. Our experiments showed that stagger tuning or use of mechanical filters to produce a rectangular passband, will cause severe pulse jitter and multiple-response envelopes. A receiver intended for measuring impulse interference should therefore be designed specifically for this use. It is not necessarily true that impulse bandwidth is approximately equal to the $6 \mathrm{~dB}$ bandwidth.

A summary of several bandwidth ratios measured at NBS for the FIM-2 receiver, using the data of figure 25 , is given in figure 27. It can be seen from the values in the first column that the "shape factor" (20 dB bandwidth $\div 3 \mathrm{~dB}$ bandwidth) is much higher for the "narrow" bandwidth (5.67) than 
it is for the "wide" bandwidth position (2.89). This can also be observed by comparing the two graphs of figures 6 and 12. The passband "shape factor" and general shape for the narrowband position do not appear to be a typical or preferred design for measuring impulses. Considering only the more normal (Gaussian-shaped) curves for the "wide" bandwidth positions, it can be seen that (on the average) the random-noise bandwidth for this receiver is equal to 1.055 times the $3 \mathrm{~dB}$ bandwidth. The average deviation from the mean value is only $0.5 \%$. This average ratio of 1.055 is within a few percent of the typical design value. The average ratio of (BW) imp to (BW) $6 \mathrm{~dB}$ was 0.97 for the wideband data and 1.06 for the narrowband data. These values are 5 to 10 percent lower than typically-reported values. It can also be seen in figure 27 that the bandwidth values based on stepped-frequency CW data are less variable than those involving measurement of impulse bandwidth.

Several possible approaches were given in section 3 for defining and measuring the various bandwidths of an FIM receiver. If the impulse bandwidth has been calibrated, the peak value of a receiver response transient can be used to measure the impulse strength. Impulse bandwidth is a calibrating factor which can be used to convert the receiver indication ( $\mu \mathrm{V}$, peak mode) to the impulse strength $(\mu \mathrm{V} / \mathrm{MHz})$ of repetitive pulses. It is approximately true that the receiver indication is proportional to the product of receiver bandwidth and impulse strength. In this case, and for this reason, it is legitimate and desirable to calibrate the impulse bandwidth of a receiver.

Of the two types of calculable impulse sources evaluated at NBS (pulsed DC and pulsed RF), the latter was chosen in our project, for frequencies between 100 and $1000 \mathrm{MHz}$. A pulsedRF generator produces a signal which is sufficiently broadband (much broader than the receiver bandwidth), but has greater intensity near the receiver-tuned frequency than a baseband pulse of the same voltage. This is because the spectral energy is concentrated at the frequency to which the receiver is tuned. The maximum value of spectral output for a baseband pulse is at zero frequency (DC). It is concluded that the pulsed-RF approach is the most accurate, repeatable and easy to operate of those we have tested. 


\begin{tabular}{|c|c|c|c|c|}
\hline 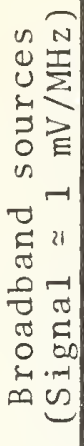 & 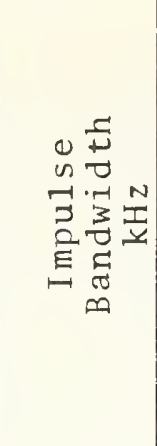 & 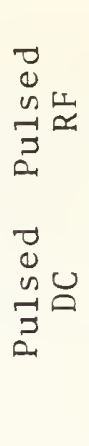 & 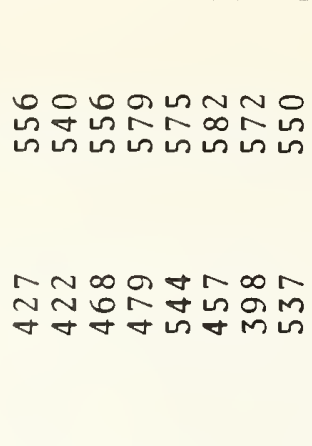 &  \\
\hline 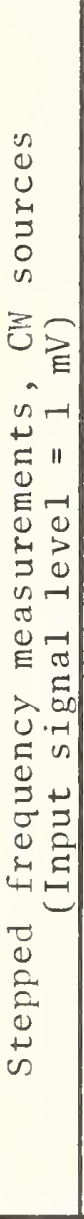 & 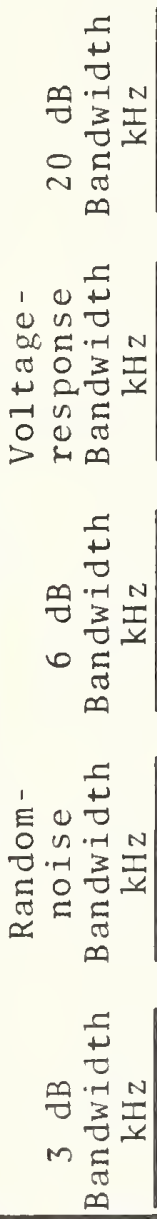 & & 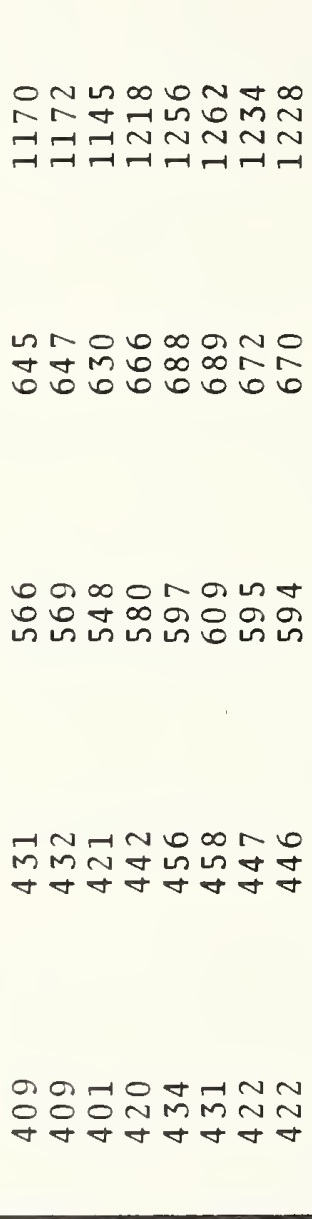 & 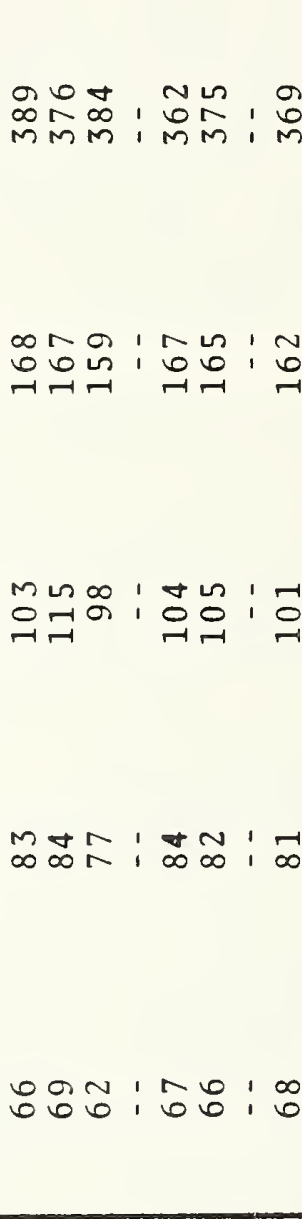 \\
\hline & 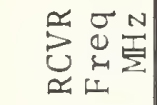 & & 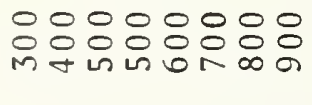 & 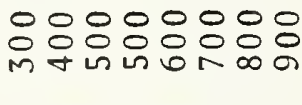 \\
\hline & 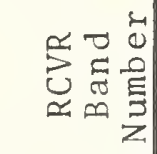 & & $\stackrel{\nabla}{r}=\stackrel{\sim}{r}===$ & $\stackrel{\nabla}{\sigma}=\frac{\operatorname{Ln}}{\sigma}===$ \\
\hline &  & & $\begin{array}{ll}1 & 0 \\
0 & 0 \\
0 & 0 \\
\Sigma & 0 \\
3 & 0\end{array}$ & $\begin{array}{ll}1 & \\
3 & 0 \\
0 & 0 \\
2 & 5 \\
2 & 0 \\
z & 0\end{array}$ \\
\hline
\end{tabular}

$\dot{4}$
0
3
0
0
0
0
0

I

4

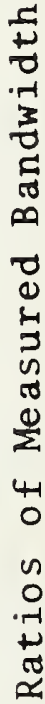

Ni 


\section{ACKNOWLEDGMENTS}

Appreciation is expressed to all those who have contributed time, interest and suggestions for the success of this project, especially the following members of the tri-service CCG committee:
J.L. Hayes
S. Feldman
F. Flynn
J.H. McAdams
$\mathrm{J}$. Pyo.

Many of my fellow employees in the Electromagnetics Division of the National Bureau of Standards have encouraged and helped me in various aspects of this project. Thanks are due especially to the following persons:

M.G. Arthur - - For technical advice, historical background and being technical reader for this report,

Dr. R.C. Baird -- For his helpful and patient attitude toward this project,

Dr. P.F. Wacker -- For discussions on Fourier theory and definitions of terms,

Dr. R.A. Lawton -- For design and testing of the pulsed-RF impulse standard,

P.A. Simpson -- For measurements and calibrations in the early stage of this work,

G.R. Reeve - - For us eful suggestions and discussions relating to noise standards,

S.C. Foote and J.R. Becker - - For efficient and accurate typing and proofreading of this manuscript. 


\section{REFERENCES}

[1] D.B. Geselowitz, "Response of ideal radio noise meter to continuous sine wave, recurrent impulses, and random noise," IRE Trans. Radio Freq. Interference, Vol. RFI-3, pp. 2-11, May 1961 .

[2] "The radio frequency interference meter," NAVSHIPS 94180 , U.S. Navy, 201 pages, July 1962.

[3] F. Haber and R.M. Showers, "Instrumentation for radiointerference measurements," Electronic Industries, pp. 110-118, March 1961.

[4] "An investigation into existing calibration methods of field intensity meters," RADC-TR-64-527, D.R. Clark, Project Leader, 228 pages, January 1965.

[5] "Proposed standard for the measurement of impulse strength and impulse bandwidth," IEEE Subcommittee 27.1, 13 pages, Draft of April 1971.

[6] M.G. Arthur, "Standards and measurement of impulse spectral intensity," Unpublished NBS Report, Final Report on U.S. Army Contract, 56 pages, October 1969.

[7] J.R. Palladino, "A new method for the spectral density calibration of impulse generators," IEEE Trans., Vol. EMC-13, pp. 2-7, February 1971.

[8] "Item 1972, a publication of R \& B Enterprises," An interference directory and design guide, 118 pages.

[9] R.B. Andrews, Jr., "An impulse spectral intensity measurement system," IEEE Trans., Vol. IM-15, pp. 299-303, December 1966.

[10] M.G. Arthur, "Impulse spectral intensity calibration at the National Bureau of Standards," Proc. 1969 Dept. Defense Electromag. Compat. Symp., pp. 133-138.

[11] G.R. Reeve, "Calibration of impulse noise generators," Unpublished NBSIR.

[12] A.R. Ondrejka, "Development and evaluation of a solid state impulse generator," Unpublished NBS Report, Final Report on Proj. CCG 69-26, 56 pages, December 1970.

[13] "Spectrum Analysis," Hewlett-Packard Application Note 63, 41 pages, August 1968. 
[14] "Calibration of impulse spectral intensity using pulsed CW Signals," Andy Hish Associates, Tech. Report 0-057010-1, 5 pages, 1971.

[15] "Spectrum analysis ... Pulsed RF," Hewlett-Packard Application Note 150-2, 33 pages, November 1971.

[16] "EMI measurement procedure," Hewlett-Packard Application Note 142, 111 pages, July 1972. 


\begin{tabular}{|c|c|c|c|}
\hline $\begin{array}{l}\text { U.S. DEPT. OF COMM. } \\
\text { BIBLIOGRAPHIC DATA } \\
\text { SHEET }\end{array}$ & $\begin{array}{l}\text { 1. PUIBLICATION OR REPORT NO. } \\
\text { NBSIR } 73-335\end{array}$ & $\begin{array}{l}\text { 2. Gov't Accession } \\
\text { No. }\end{array}$ & 3. Recipient's Accession No. \\
\hline \multirow{2}{*}{\multicolumn{3}{|c|}{$\begin{array}{l}\text { 4. TITLE AND SUBTITLE } \\
\text { Calibration of Radio Receivers to Measure Broadband } \\
\text { Interference }\end{array}$}} & $\begin{array}{l}\text { 5. Publication Date } \\
\text { September } 1973\end{array}$ \\
\hline & & & 6. Performing Organization Code \\
\hline $\begin{array}{l}\text { 7. AUTHOR(S) } \\
\text { Ezra B. Larsen }\end{array}$ & & & 8. Performing Organ. Report No. \\
\hline \multirow{2}{*}{\multicolumn{3}{|c|}{$\begin{array}{l}\text { 9. PERFORMING ORGANIZATION NAME AND ADDRESS } \\
\qquad \begin{array}{l}\text { NATIONAL BUREAU OF STANDARDS } \\
\text { DEPARTMENT OF COMMERCE } \\
\text { BOUlder, COlOrado } 80302\end{array}\end{array}$}} & $\begin{array}{l}\text { 10. Project/Task/Work Unit No. } \\
2727281\end{array}$ \\
\hline & & & 11. Contract/Grant No. \\
\hline \multirow{2}{*}{\multicolumn{3}{|c|}{$\begin{array}{l}\text { 12. Sponsoring Organization Name and Complete Address (Street, City, State, ZIP) } \\
\text { Calibration Coordination Group } \\
\text { Army/Navy/Air Force }\end{array}$}} & $\begin{array}{l}\text { 13. Type of Report \& Period } \\
\text { Covered }\end{array}$ \\
\hline & & & 14. Sponsoring Agency Code \\
\hline
\end{tabular}

\footnotetext{
15. SUPPLEMENTARY NOTES
}

\footnotetext{
16. ABSTRACT (A 200-word or less factual summary of most significant information. If document includes a significant bibliography or literature survey, mention it here.)
}

This report covers one phase of a project to improve the accuracy for calibrating fieldstrength meters to measure broadband signals, especially impulse interference. The amplitude of a narrowband signal is commonly expressed in $\mu V$, and a broadband signal is expressed in $\mu \mathrm{V} / \mathrm{MHz}$ bandwidth. A future report (2nd phase) will deal with standards and techniques for producing a known impulse field to calibrate an antenna-receiver system in $\mu \mathrm{V} /(\mathrm{m} \cdot \mathrm{MHz})$. The technique used for initial calibration of a receiver as an $R F$ voltmeter is new, employing a special L-pad with $48 \Omega$ input resistor and $2 \Omega$ output resistor across the recelver. The input power across $50 \Omega$ is leveled, producing a low-impedance, constant-voltage source at the receiver input terminal.

Broadband interference is generally divided into two types: (a) random noise is best characterized by its power spectal density, and (b) impulse interference (uniform periodic pulses) is best quantified by its impulse strength. Several possible approaches were evaluated for defining and measuring various bandwidths of a receiver. The response of a receiver to impulses, as measured with a peak-reading detector, is proportional to the product of receiver impulse bandwidth and signal impulse strength. Of the two types of impulse sources evaluated here (pulsed DC and pulsed RF), the latter appears to be the most accurate and repeatable. We were able to produce a clean $R$ pulse, choosing an effective duration of $0.1 \mathrm{\mu s}$ in our experiments, which covered a requency range of 100 to $1000 \mathrm{MHz}$. The worst-case uncertainty of this standard source for calibrating receiver impulse bandwidth is $\pm 0.7 \mathrm{~dB}$.

17. KEY WORDS (six to twelve entries; alphabetical order; capitalize only the first letter of the first key word unless a proper name; separated by semicolons) Broadband interference; field strength meter; impulse

standards; receiver bandwidth calibration; spectral intensity.
18. AVAILABILITY
Xnlimited

For Official Distribution. Do Not Release to NTIS

Order From Sup. of Doc., U.S. Government Printing Office Washington, D.C. 20402, SD Cat. No.C13

Order From National Technical Information Service (NTIS) Springfield, Virginia 22151
19. SECURITY CLASS ('THIS REPORT)

UNCL ASSIF IED

20. SECURITY CLASS (THIS PAGE)

UNCLASSIFIED
21. NO. OF PAGES

21. NO. OF PAGES

22. Price

Price 



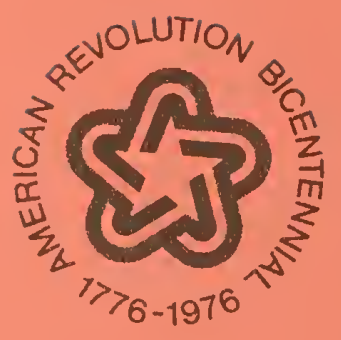

